\author{
UNITED STATES \\ DEPARTMENT OF THE INTERIOR \\ GEOLOGICAL SURVEY
}

\title{
SEISMIC-REFRACTION STUDIES OF THE IMPERIAL VALLEY REGION, CALIFORNIA-- PROFILE MODELS, A TRAVELTIME CONTOUR MAP, AND A GRAVITY MODEL
}

by

\author{
G.S. Fuis, W.D. Mooney, J.H. Healy, G.A. McMechan, \\ and W.J. Lutter
}

Open-File Report $81-270$

This report is preliminary and has not been reviewed for conformity with the U.S. Geological Survey editorial standards and stratigraphic nomenclature. Any use of trade names is for descriptive purposes only and does not imply endorsement by the USGS. 
Abstract .................. 1

Introduction ................ 3

Data Collection ............. . . 4

Data Analysis .............. 5

Profile Models:

Profile 6NW-1SE-INW

Data . . . . . . . . . . . 7

Interpretation ......... 10

Profile 1E-2W

Data . . . . . . . . . . . . 17

Interpretation ......... 18

Profile 1OSE-2NW

Data . . . . . . . . . . . . 21

Interpretation ........... 21

Profile IESE

Data and Interpretation ........ . 24

Traveltime Contour Map .. . . . . . . . . 26

A Gravity Model across the Imperial Valley Region . . 29

Sumary . . . . . . . . . . . . . 31

Acknowledgment . . . . . . . . . . . 35

References Cited . . . . . . . . . 36 
Illustrations

(Plate in pocket)

\section{Plate}

Map showing shotpoints and recorder locations

\section{Figure}

1 Index map showing shotpoints, recorder locations, and profiles analyzed ...............

2 Record sections for lines 6NW, ISE, and INW and final model

3 Traveltime pick diagram for lines $6 \mathrm{NW}, 1 \mathrm{SE}$, and $1 \mathrm{NW}$. .

Record sections for lines $2 \mathrm{~W}$ and $\mathrm{IE}$ and final model .

5 Record sections for lines 2NW and IOSE and final model

Record section for Iine IESE and final model .....

Record sections for segments of lines 135 and $5 \mathrm{~N} .$.

Velocity-depth curves at various locations along the profiles analyzed ............... 70

10 Contour map of reduced traveltime for first arrivals

from shotpoint 1.................

Gravity profile across California from La Jolla to the Chocolate Mountains and gravity model ........

Table 


\section{ABSTRACT}

The Imperial Valley region is of tectonic and geothermal importance. An extensive seismic refraction survey was conducted to determine the crustal structure in more detail, over a wider area, and to greater depth than was accomplished by earlier studies. A combination of new instrumentation and improved methods of analysis expedited this project.

This paper describes in detail a) models for 4 seismic refraction profiles, b) a traveltime contour map, and c) a gravity model. A model for a fifth refraction profile is presented in Mooney and McMechan (in press). For a discussion of the petrologic and tectonic implications of the models, the reader is referred to Fuis and others (in press).

Forty shots, ranging in yield from 1000 to 2000 pounds, were fired at 7 shotpoints. Each shot was recorded by 100 portable seismic instruments arranged in profiles and arrays with typical instrument spacing of 0.5 to $1 \mathrm{~km}$. More than 1300 recording locations were occupied and more than 3000 usable seismograms obtained.

Analysis of the data from this survey was accomplished primarily through a standard ray-tracing program newly adapted for interactive computing. This program enables rapid testing of models for traveltime consistency with the data and for qualitatively correct amplitude behavior.

All profile models have in common a sedimentary section (modeled in one to three parts), a transition zone, a basement, and subbasement.

Sediment velocity increases with depth without discontinuities but, in many cases, with changes in gradient. In the central valley, velocity increases from $1.8 \mathrm{~km} / \mathrm{s}$ at the surface to about $5 \mathrm{~km} / \mathrm{s}$ at the base of the sediments. Along the axis of the trough, sediment thickness ranges from about $4.8 \mathrm{~km}$ at the U.S.-Mexico border to $3.7 \mathrm{~km}$ along the southwest shore of the Salton Sea.

In the central Imperial Valley the sediment/basement transition zone is generally $1 \mathrm{~km}$ thick and velocity increases from $5 \mathrm{~km} / \mathrm{s}$ at the base of the sediments to $5.65 \mathrm{~km} / \mathrm{s}$, in most places, at the top of the basement. On West Mesa and in other places where the sediments are thinner than 2.5 $\mathrm{km}$, a prominent velocity discontinuity is present at the top of this zone, and the zone is less than $1 \mathrm{~km}$ thick.

Upper basement has a velocity of $5.65 \mathrm{~km} / \mathrm{s}$ in most places in the Imperial Valley, but on West Mesa, its velocity is about $6 \mathrm{~km} / \mathrm{s}$. 
Several structures are seen which affect basement, transition zone, and deeper sediments. They are a) a scarp along the Imperial fault, decreasing in height from $1 \mathrm{~km}$ southeast of El Centro to $0 \mathrm{~km}$ southwest of Brawley, b) a structure in deeper sediments along the Brawley seismic zone north of Brawley, and c) a scarp passing under shotpoint 1, ranging in height from 1 to $3.5 \mathrm{~km}$. The latter scarp probably correlates with the Superstition Mountain fault northwest of shotpoint 1 and with a roughly north-south trending basement bench south of shotpoint 1 which has no surface expression.

A subbasement, with a velocity of $7.2 \mathrm{~km} / \mathrm{s}$ near its top, is present at depths ranging from $10 \mathrm{~km}$ at the U.S.-Mexico border to $16 \mathrm{~km}$ at the south end of the Salton Sea.

A contour map of reduced traveltime constructed for our most widely recorded shotpoint is qualitatively analogous to a sediment isopach map. Steep scarps are seen on this map along some major mapped faults and along some structures not seen at the surface. Subtle patches of early arrivals among the otherwise late arrivals in the central Imperial Valley correlate uniquely with known geothermal resource areas having reservoir temperatures of more than $150^{\circ} \mathrm{C}$. The shapes of these patches are roughly linear with lengths of the order of $15 \mathrm{~km}$ and a northeast trend.

Using the new velocity structure for the Imperial Valley region to constrain a gravity model, we discover that a) gravitational compensation for the sediments is accomplished largely by the subbasement, with a model density of $3.1 \mathrm{~g} / \mathrm{cc}, \mathrm{b})$ the relatively flat gravity profile across the Salton Trough requires that the upper surface of this subbasement largely mirror the contact between sediments and basement, and $c$ ) the negative gravity anomalies over the Peninsular Ranges and Chocolate Mountains require that the subbasement deepen and pinch out in those directions. 


\section{INTRODUCTION}

The Imperial Valley region of southeastern California is of tectonic and geothermal importance. During a 3-month period in 1979, we conducted a detailed seismic refraction survey of the region primarily to determine the crustal structure in more detail, over a wider area, and to greater depth than was accomplished in previous surveys by Kovach and others (1962) and Biehler and others (1964). A combination of new instrumentation and improved methods of analysis expedited this survey.

In this paper, we describe in detail the models for three reversed refraction profiles and one unreversed profile crossing the Imperial Valley region at different azimuths. These profiles are 6NW-1SE-1NW, 1E-2W, 10SE-2NW, and 1ESE (fig. 1) 1). In a paper by Mooney and McMechan (in press) a fourth reversed profile, 6NNW-13SSE (fig. 1), is described. We present a contour map of reduced traveltime from our most widely recorded shotpoint. In addition, we present a model for an existing gravity profile across the Imperial Valley region based on our refraction models. This paper is intended to be a presentation of data and a detailed discussion of modeling. For an expanded discussion of the background for this experiment and for a discussion of the petrologic and tectonic implications of the models developed here, the reader is referred to Fuis and others (in press).

I' Seismic lines constituting a profile are given names such as $6 \mathrm{NW}$ and 1SE. These names derive from the shotpoints from which the lines originate and the azimuths of the lines, NW--northwest, SE--southeast, and so forth. 


\section{DATA COLLECTION}

The refraction survey was conducted primarily during the period January through March 1979. Following the October 1979 earthquake, one profile, 1E-2W was reshot and another profile, 1ESE, was recorded from 0 to $25 \mathrm{~km}$ at $50-100 \mathrm{~m}$ spacing.

During the primary survey, forty shots ranging in yield from 1000 to 2000 pounds of high explosives were fired at 7 shotpoints (fig. 1, table 1). The shotpoints were located for obtaining reversed profiles in key areas, but gaps in the pattern can be seen, most notably in the BrawleyEl Centro area, where culture precluded a shotpoint, and in the area east of the Salton Sea where time, money, and logistics of obtaining a shot hole penetrating the water table prevented a good location from being obtained. The explosives for each shot were in most instances loaded into a single hole $15 \mathrm{~cm}$ ( 6 inches) in diameter and about 50 meters (over 160 feet) deep. Most of the shot holes had to be cased, as the material penetrated at all shotpoints was Quaternary lake deposits consisting of sand, silt, and clay. The water table was apparently penetrated at most shotpoints, promoting relatively high efficiency in converting explosive energy into seismic energy.

The seismic recorders in this experiment are of new design (Blank and others, 1979). Each instrument consists of a single verticalcomponent seismometer, with a free period of 1 second, a programmable clock, a calibrator, an amplifier with three adjustable gain levels, a tape-speed-compensation tone generator, and a cassette tape recorder. About half the instruments also have a WWVB radio receiver backup. The instruments can be programmed to turn on for as many as 10 shots with 3 minutes of recording time per shot, of which about one minute is used for recording of the calibration sequence.

Each shot was recorded by 100 of these seismic instruments arranged in lines and arrays with typical instrument spacing of $0.5 \mathrm{~km}$ to $1 \mathrm{~km}$ (fig. 1). On a typical night, shots were fired at 3 different shotpoints and recorded by these patterns of instruments. More than 1300 recording locations were occupied (plate 1, table 2) and more than 3000 usable seismograms were recorded. At a temporary field office in Brawley, data from each instrument was dubbed onto master library tapes and digitized. Using a portable computer and plotter, digital record sections from all shots were produced; these record sections were frequently completed within 3 or 4 days of a shot, so that the survey could be monitored and changed during its course. 
DATA ANALYSIS

A ray tracing method described by Červený and others (1977) and coded by $I$. Pšenčik and V. Cervený was adapted for interactive computing by R.L. Nowack. This program made possible rapid testing of models for traveltime consistency with the data. In addition, it enabled us to use amplitudes in a qualitative (and, after modification, in a semiquantitative way--see Mooney and McMechan, in press) to further constrain the data. Traveltimes and the amplitude behavior of both first arrivals and multiple refractions were fitted. The extra time constraints provided by multiple refractions plus the sensitivity of these arrivals to lateral velocity changes made them very useful in constraining the model.

Analysis of the five profiles reported here was split up among various combinations of the authors of this paper. Except for agreeing on the starting model at mutual shotpoints the analyses were carried out more or less independently, although the models were largely patterned after that of Mooney and McMechan (in press) for profile 6NNW-13SSE

(fig. 1), where the structure is simple and where use is made of amplitude ratios. The models are largely consistent with one another in places where they cross one another or where they are near one another. For example, where reversed profiles 6NNW-13SSE and 1E-2W cross, velocity contours and structural boundaries in the models agree in depth to within a few tenths of a kilometer down to a depth of over $5 \mathrm{~km}$, but deeper contours and boundaries diverge by as much as $1 \mathrm{~km}$ (compare fig. 4c with fig. $4 a$ of Mooney and McMechan, in press). The area of this intersection represents our best control on structure anywhere in the Imperial Valley region. Note that agreement between models near mutual shotpoints is not necessarily expected due to the fact that these regions are unreversed, if sampled at all.

Some features of the model may relate to the specific capability of the computer program used to calculate ray paths through the models. A brief description of the pertinent features of this program is needed here. The program permits the construction of two-dimensional models consisting of layers separated by boundaries which can vary laterally in velocity and depth. The analyst may assign linear, vertical velocity gradients within each layer along arbitrary numbers of vertical grid lines. The reader will note that if velocity gradients are assigned to a layer with an irregular variation horizontally the boundaries between layers cannot be lines of constant velocity; rather, they are lines at which the gradient changes. In the models presented (figs. $2 c, 4 c, 5 c$, $6 \mathrm{~b})$, the heavy lines indicate the boundaries between layers and the dashed lines are contours of constant velocity. One can envision changing these models by a trade-off between velocity gradient and the position of the layer boundaries. We believe that it is not a serious ambiguity, but it certainly introduces some degree of nonuniqueness. 
Further possible uncertainties on the complex structure may result from the fact that the ray theory involved in the program used to interpret the data does not calculate the diffracted waves. This could present a problem in the determination of velocity gradients in the deeper horizons where the ray theory approach demands a velocity increase with depth to bend the ray and return it to the surface, whereas a more complete wave theory might explain some of the arrivals as diffracted energy without requiring a velocity increase with depth. With these exceptions, it is our belief that the main features of the models are approximately correct and will not be dramatically changed by further work. Traveltimes generated by all models generally agree with the data to within $0.05 \mathrm{~s}$, and in the worst case the agreement is $0.15 \mathrm{~s}$. Both the first arrivals and the secondary phases are fitted by the models presented.

In the following discussion of profile modeling, the modeling procedures and model limits are discussed at length for the first profile $6 \mathrm{NW}-1 \mathrm{SE}-1 \mathrm{NW}$, and more briefly for the remaining three. It should be noted that the major features of the model described for $6 \mathrm{NW}-1 \mathrm{SE}-1 \mathrm{NW}$, including a sedimentary section with a continuous velocity increase, a transition zone, a basement, and a subbasement, are seen in all the models. 
PROFILE MODELS

Profile 6NW-1SE-1NW

$\underline{\text { Data }}$

Explosions at shotpoints 6 and 1 were recorded along refraction lines $6 \mathrm{NW}, 1 \mathrm{SE}$, and $1 \mathrm{NW}$. These lines cross the southwest part of the Imperial Valley and also West Mesa (fig. 1). Shotpoint 6 is located on the U.S.Mexico border approximately $30 \mathrm{~km}$ southeast of El Centro. It is approximately on the geometric axis of the Salton Trough 1 , but about $30 \mathrm{~km}$ east of the topographic center of the Imperial Valley, on the edge of East Mesa. Geologically, it is on the east shoreline of ancient Lake Cahuilla and penetrates basin sediments. Shotpoint 1 is $22 \mathrm{~km}$ northwest of El Centro, on the opposite side of the Imperial Valley, on the edge of West Mesa. Geologically, it is on the west shoreline of Lake Cahuilla and also penetrates basin sediments. It is $3 \mathrm{~km}$ southwest of the Superstition Mountain fault, an branch of the San Jacinto fault zone in the Imperial Valley. Superstition Mountain, $9 \mathrm{~km}$ northwest, is a block of Mesozoic granodiorite uplifted along this fault.

The parts of the refraction lines between shotpoints 6 and 1 cross the Imperial fault obliquely and are parallel to and southwest of the Superstition Mountain fault. The parts of the lines that lie northwest of shotpoint 1 are also parallel to, and southwest of, the Superstition Mountain fault, but cross and recross the Coyote Creek fault, its apparent continuation to the northwest.

Line $6 \mathrm{NW}$ is $98 \mathrm{~km}$ long, extending $45 \mathrm{~km}$ beyond shotpoint 1 . It contains 64 seismic traces of which 51 are shown (fig. 2a). Line 1SE is $54 \mathrm{~km}$ long, extending to shotpoint 6. It contains 41 traces of which 39 are shown (fig. 2b). Line $1 \mathrm{NW}$ is $45 \mathrm{~km}$ long and contains about 40 traces of which 16 are shown (fig. 2b).

I' In this report, we define the "axis of the Salton Trough" to be line that bisects the Salton Sea and projects southeastward with the same trend, passing a few kilometers east of shotpoint 6 (fig. 1). Note that the topographic axis of the Imperial Valley diverges from the trough axis to the south; at the U.S.-Mexico border, it lies approximately $30 \mathrm{~km}$ west. In this report, we use the phrases "Imperial Valley", "central Imperial Valley", and "central valley" to denote the cultivated lowlands south of the Salton Sea within the confines of the Lake Cahuilla shorelines. The phrase "Imperial Valley region" includes Imperial Valley, Salton Sea, East and West Mesas and flanking mountains. 
Between shotpoints 6 and 1 , all arrivals define smooth traveltime curves with little scatter. Northwest of shotpoint 1, however, the first arrivals define a bumpy travel-time curve (figs. $2 a$ and $2 b$ ). This observation is seen even more dramatically where only traveltime picks are plotted (fig. 3). On this plot, arrivals between shotpoints 1 and 6 define smooth curves except in the vicinity of the Imperial fault where an offset of about $0.18 \mathrm{~s}$ is conspicuous, with earlier arrivals northwest of the fault. The irregularity beyond shotpoint 1 on $6 \mathrm{NW}$ and $1 \mathrm{NW}$ is striking in contrast but is similar on both profiles. The picks appear to "track" each other, with differing overall apparent velocities. The time difference between late and early arrivals is greater on $6 \mathrm{NW}(1.05 \mathrm{~s})$ than on INW $(0.70 \mathrm{~s})$.

Between 0 and $17 \mathrm{~km}$ on $6 \mathrm{NW}$ and between 0 and $10 \mathrm{~km}$ on 1SE, the travel-time curve has strong curvature, and apparent velocities range progressively from $1.6 \mathrm{~km} / \mathrm{s}$ to $4.85 \mathrm{~km} / \mathrm{s}$ ( $\mathrm{fig} .3$ ). These velocities correspond to sediments (see discussion in Fuis and others, in press). In contrast, the travel-time curve between 17 and $27 \mathrm{~km}$ on $6 \mathrm{NW}$ and between 10 and $40 \mathrm{~km}$ on $1 \mathrm{SE}$ is flat, with apparent velocities of $5.80 \mathrm{~km} / \mathrm{s}$ and $5.67 \mathrm{~km} / \mathrm{s}$, respectively. These velocities correspond to "basement" (see discussion in Fuis and others, in press). Note the prominent gap in clear first arrivals on $6 \mathrm{NW}$ between 27 and $53 \mathrm{~km}$, although two weak arrivals at 42 and $45 \mathrm{~km}$ can be seen which may define a higher velocity of $6.9 \mathrm{~km} / \mathrm{s}$ for this portion of the traveltime curve (figs. 2a and 3). A prominent gap in clear first arrivals is also seen on 1SE between 16 and $34 \mathrm{~km}$, within the $5.67 \mathrm{~km} / \mathrm{s}$ branch (figs. $2 \mathrm{~b}$ and 3 ). Indeed, arrivals between 10 and $16 \mathrm{~km}$ on this profile are also so weak that they would be obscured were it not for relatively low background noise. On 1NW, a straight line with an apparent velocity of $5.8 \mathrm{~km} / \mathrm{s}$ can be fitted through the scatter of arrivals between 5 and $45 \mathrm{~km}$ (figs. $2 \mathrm{~b}$ and 3 ). The uncertainty in the latter apparent velocity certainly exceeds $0.1 \mathrm{~km} / \mathrm{s}$, and it is our convention to report such velocities to only one decimal place. On this branch note the arrival at $15 \mathrm{~km}$, which is early by $0.2 \mathrm{~s}$, and the arrivals between 25 and $34 \mathrm{~km}$, which are late by up to $0.5 \mathrm{~s}$. The latter arrivals appear to correlate with the part of the profile that lies northeast of the Coyote Creek fault.

On $6 \mathrm{NW}$, the strongest arrivals in the range 39 to $53 \mathrm{~km}$ appear to be second arrivals with an apparent velocity of $8.00 \mathrm{~km} / \mathrm{s}$ (figs. $2 a$ and 3 ). Beyond a possible offset at $53 \mathrm{~km}$, this branch appears to emerge as a first-arrival branch with an average apparent velocity, through considerable scatter, of $7.2 \mathrm{~km} / \mathrm{s}$. Note that the character of the first arrival changes at the $53 \mathrm{~km}$ cross-over point from a very weak arrival with a characteristic frequency less than $4 \mathrm{hz}$ to a moderately strong arrival with a characteristic frequency greater than $5 \mathrm{hz}$. Note also that an arrival $0.4 \mathrm{~s}$ early at $69 \mathrm{~km}$ correlates well with an early arrival on $1 \mathrm{NW}$, and a region of arrivals late by up to $0.65 \mathrm{~s}$ between 75 and $86 \mathrm{~km}$ correlate well with a region of late arrivals on $1 \mathrm{NW}$ and with the segment of the profile that lies northeast of the Coyote Creek fault. The $7.2-8.00$ $\mathrm{km} / \mathrm{s}$ branch will be referred to as the "subbasement" branch (see discussion in Fuis and others, in press). 
One striking feature in fig. 3 is the progressive decrease in intercept times for basement arrivals from $6 \mathrm{NW}(2.55 \mathrm{~s})$ to $1 \mathrm{SE}(1.80 \mathrm{~s})$ to $1 \mathrm{NW}$ $(1.28 \mathrm{~s})$.

The relatively steep slope of the subbasement branch on $6 \mathrm{NW}$ combined with an apparent offset near shotpoint 1 produces a reduced traveltime of $2.18 \mathrm{~s}$ at shotpoint 1 . In order to attempt to match this time on 1SE at shotpoint 6 , we drew the steepest branches through the weak arrivals beyond $40 \mathrm{~km}$ on $1 \mathrm{SE}$ that appear consistent with data on these and other profiles, including a postulated $7.2 \mathrm{~km} / \mathrm{s}$ subbasement velocity and an offset exceeding $0.18 \mathrm{~s}$ across the Imperial fault. The projected reduced traveltime at shotpoint 6 is $2.28 \mathrm{~s}$.

A series of late arrivals are prominent on $6 \mathrm{NW}$ and 1SE (figs. 2a, $2 \mathrm{~b}$, and 3 ). On $6 \mathrm{NW}$, second arrivals are prominent from 10 to $21 \mathrm{~km}$, and third arrivals, from 17 to $37 \mathrm{~km}$. Fourth arrivals can be seen from 18 to $27 \mathrm{~km}$. On 1SE, second arrivals are prominent from 7 to $16 \mathrm{~km}$, and third arrivals, from 13 to $18 \mathrm{~km}$. On $1 \mathrm{NW}$, in contrast, only a series of second arrivals are clear, in the range 11 to $18 \mathrm{~km}$ (figs. $2 \mathrm{~b}$ and 3 ). Questionable third arrivals may be present at $21-22 \mathrm{~km}$. On all three lines, these series of late arrivals are explainable as multiply refracted arrivals (see the next section); that is, their ray paths involve one or more reflections from the free surface during propagation. Consequently, in fig. 3, these arrivals are labeled as "1st", "2nd", and "3rd" multiple refractions. On all three lines, these late arrivals appear to reproduce the first-arrival curve with successively lower curvature, as if the first-arrival curve were being successively stretched out. On $6 \mathrm{NW}$ and $1 \mathrm{SE}$, these arrivals have a characteristic frequency of $6 \mathrm{hz}$ and a duration of two wavelengths. On 1NW they are higher in frequency and much longer in duration.

Certain amplitude fluctuations are striking on this profile. On $6 \mathrm{NW}$, first arrivals--that is, the first upswings on the trace--become abruptly weak beyond the Imperial fault (fig. 2a). First arrivals are not strong until the crossover of the subbasement branch at $53 \mathrm{~km}$. The first multiple refraction becomes abruptly weak beyond $21 \mathrm{~km}$ and the $2 \mathrm{nd}$ multiple refraction may die out beyond $38 \mathrm{~km}$. On $15 E$, first arrivals undergo a transition in amplitude from strong, $0-5 \mathrm{~km}$, to moderately strong $5-7 \mathrm{~km}$, to moderate, $7-10 \mathrm{~km}$, to very weak, beyond $10 \mathrm{~km}$ (fig. 2b). Beyond $34 \mathrm{~km}$, these arrivals pick up again, becoming weak to moderate in amplitude. The first multiple refraction undergoes a similar but more exaggerated transition from strong, $7-10 \mathrm{~km}$, to moderate, $10-13 \mathrm{~km}$, to weak, $13-18 \mathrm{~km}$, to imperceptible beyond $18 \mathrm{~km}$. A similar transition can be seen in amplitudes of the second multiple refraction. On 1NW, amplitudes also undergo a transition from strong $0-3 \mathrm{~km}$, to moderate, 3-7 km, to weak, beyond $7 \mathrm{~km}$ (fig. 2b). On the lower branch of the first multiple, only one trace is pickable. On the upper branch, amplitudes die out at $18 \mathrm{~km}$. 
Interpretation

Traveltimes of all perceptible arrivals were used as the primary constraints in modeling velocities along lines 6NW, 1SE, and 1NW. Amplitudes were used as constraints only in a qualitative way.

The starting model was obtained from a flat-layer interpretation 1 /

of apparent velocities and intercept times at each shot point. In this starting model a drastic difference in the depth to basement is indicated between $1 \mathrm{SE}, 3.7 \mathrm{~km}$, and $1 \mathrm{NW}, 1.6 \mathrm{~km}$, requiring a basement scarp under shotpoint 1 of about $2 \mathrm{~km}$. From $6 \mathrm{NW}$, one must add as a minimum to the basement intercept time the observed offset across the Imperial fault to obtain a reasonable depth to basement. This depth, $5.55 \mathrm{~km}$, agrees well with the depth calculated from 6NNW (see Mooney and McMechan, in press). The Imperial fault scarp itself has a calculated height

$$
\underline{\underline{h}}=\Delta \underline{\mathbf{t}} \cdot \underline{\mathbf{v}}_{1} \underline{\mathbf{v}}_{2} / \sqrt{\underline{v}_{2}^{2}-\underline{\mathbf{v}}_{1}^{2}}
$$

where $\Delta \underline{t}$ is the traveltime offset, $\underline{v}_{1}$ is the velocity of the medium that just buries the scarp, and $\underline{v}_{2}$ is the velocity of the medium below. Using $\Delta \underline{t}=0.18 \mathrm{~s}, \underline{v}_{1}=3.5 \mathrm{~km} / \mathrm{s}$ (an average sediment velocity) to $4.8 \overline{5} \mathrm{~km} / \mathrm{s}$ (the deepest sedimentary layer) and $\underline{v}_{2}=5.80$ $\mathrm{km} / \mathrm{s}$, one obtains a scarp height of $0.8 \mathrm{~km}$ to $1.6 \mathrm{~km}$.

The final model ( $\mathrm{fig} 2 \mathrm{c}$ ) was obtained by tracing rays through the starting model and numerous subsequent models (approximately 50) to obtain traveltimes that agreed with the data. This final model produces traveltime agreement with the data that is not worse than $0.05 \mathrm{~s}$ in most places and nowhere is worse than $0.15 \mathrm{~s}$ except along the lines northwest of shotpoint 1, where no attempt was made to model the bumpy arrival times. (The latter modeling exercise is rather straightforward, once the basic velocity model has been established.)

The final model consists of two sections of sediments, a sedimentbasement transition zone, a basement, a basement-subbasement transition zone, and a subbasement. Cross sections through this model at various points, or velocity-depth curves, can be compared to the original velocity model obtained from flat-layer interpretation (fig. 8a, table 3). The cross section $1 \mathrm{~km}$ northwest of shotpoint 1 (labeled -1 in $\mathrm{fig} .8 \mathrm{a}$ ) and the cross section at shotpoint 6 (labeled 53 in $\mathrm{fig} .8 \mathrm{a}$ ) appear to be averages of the flat-layer models. Note that in both cases the flatlayer depth to basement falls within the transition zone of our model. The velocity-depth curve at shotpoint 6 is, $\underline{v}=1.8 \mathrm{~km} / \mathrm{s}+0.69 \mathrm{~km} / \mathrm{s} / \mathrm{km} \cdot \underline{z}$, which agrees well with the curve obtained from velocity logs to a depth of $2.4 \mathrm{~km}$ in the Grupe-Engebretson well, $13 \mathrm{~km}$ northwest of shotpoint 6 (Kovach and others, 1962: $\underline{v}=1.76 \mathrm{~km} / \mathrm{s}+0.65 \mathrm{~km} / \mathrm{s} / \mathrm{km} \cdot \underline{\mathrm{z}}$ ). The cross

If Flat-layer interpretation assumes all apparent velocities are true velocities and all interfaces are horizontal. Layer thicknesses are calculated from intercept times in a standard fashion. 
sections $1 \mathrm{~km}$ and $17 \mathrm{~km}$ southeast of shotpoint 1 (labeled 1 and 17 in fig. 8a) appear to be averages of the upper $1.3 \mathrm{~km}$ of the flat-layer curve, but diverge below this depth to form extremes that bracket this curve. If one considers the center of the transition zone as a depth to basement, then this depth is $2.8 \mathrm{~km}$ at $1 \mathrm{~km}$ southeast of shotpoint 1 and $4.3 \mathrm{~km}$ at $17 \mathrm{~km}$ southeast of shotpoint 1. The average of these depths agrees within $0.15 \mathrm{~km}$ with the flat-layer depth. Thus, flat-layer interpretation is seen to provide average velocities and depths in a case of laterally varying structure. In the region southeast of shotpoint 1, our model indicates a dip of $5.4^{\circ}$ to the southeast; under shotpoint 1 , a scarp of about $1 \mathrm{~km}$ in height is indicated.

In the following discussion, we shall describe features of the model (fig. 2c) in terms of the observations that lead to them (figs. $2 a$ and $2 b)$, beginning at the top of the model and progressing downward.

The sediments were modeled in two sections with a boundary between them at 1.2 to $1.3 \mathrm{~km}$. Total sediment thickness ranges from about $4.8 \mathrm{~km}$ at shotpoint 6 to about $1.4 \mathrm{~km}$ northwest of shotpoint 1 . The velocity increases with depth through both sections, but the gradients are different and change from place to place. The upper section has very low velocity and in most places a lower gradient $(0.4$ to $0.7 \mathrm{~km} / \mathrm{s} / \mathrm{km})$ than the lower section $(0.7$ to $1.8 \mathrm{~km} / \mathrm{s} / \mathrm{km})$. Surficial velocity of 1.7 to 1.9 $\mathrm{km} / \mathrm{s}$ is seen near shotpoint 1 , with the higher surficial velocity at the shotpoint. The velocity at the base of the sediments is about $5 \mathrm{~km} / \mathrm{s}$ in the valley, at depths ranging from 2.5 to $4.8 \mathrm{~km}$ but is about $2.4 \mathrm{~km} / \mathrm{s}$ on West Mesa at a depth of about $1.4 \mathrm{~km}$.

On 1SE, arrivals corresponding to rays that bottom in the upper sedimentary section lie on curves labeled $A B, A L$, and $A P$; arrivals corresponding to rays that bottom in the lower sedimentary section lie on curves $C D, M N$, and $Q R$ (fig. $2 b$ ). A sharp change in gradient between the two sections along 1SE would, in theory, give rise to triplications $A B C D$, ALMN, and APQR. Only along ALMN does there appear to be evidence in the data for such a triplication. On $6 \mathrm{NW}$ and $1 \mathrm{NW}$ the upper section is apparently indistinguishable in gradient from the lower section. Arrivals corresponding to rays in both sedimentary sections lie on curves labeled $A B, A N$, and $A P$ (fig. $2 a$ ) and $A B, A I$, and $A L$ (fig. 2b).

The multiple refractions in these profiles provide powerful constraints on the velocity model, because a ray that bottoms at a given horizon emerges at an even multiple of the traveltime and distance of a first-arrival ray bottoming at that same horizon (see figs. $9 c$ and $9 \mathrm{f}$ ). Thus, time and distance scales are multiplied and velocity resolution is enhanced. Hence the "stretched-out" appearance of the multiple refractions. Lateral velocity changes alter this picture, and only the multiple refractions can reveal these. To illustrate how sensitive multiple refractions are to small model changes, one discovers that moving the boundary between the upper and lower sedimentary section up or down $0.1 \mathrm{~km}$, keeping the sediment velocity constant at the boundary, 
produces a traveltime disagreement between model and data of up to $0.15 \mathrm{~s}$ on the second multiple refraction. Changing the local surficial velocity by $0.1 \mathrm{~km} / \mathrm{s}$ also produces disagreement of up to $0.15 \mathrm{~s}$ on the second multiple refraction. Agreement with well data discussed above is primarily due to the constraints provided by these multiple refractions.

Velocity contours in both sections of sediments dip to the southeast from shotpoint 1 (fig. 2c). In the lower section, they apparently pinch out at the basement scarp at shotpoint 1 . The contours appear to be offset at the Imperial fault by about $1 \mathrm{~km}$ at the base of the sedimentary section and progressively less upward in the section.

A transition zone, ranging in thickness from $0.6 \mathrm{~km}$ to $1 \mathrm{~km}$, is modeled between the sediments and basement. On 1NW, beneath West Mesa, this zone has a velocity discontinuity at its upper boundary, but in the Imperial Valley the discontinuity is small or nonexistent, with velocity increasing from about $5 \mathrm{~km} / \mathrm{s}$ at the base of the sediments to that of basement, 5.65 to $5.80 \mathrm{~km} / \mathrm{s}$. The gradient, 0.5 to $1.1 \mathrm{~km} / \mathrm{s} / \mathrm{km}$, is in all cases somewhat lower than that in the sediments, but considerably higher than that in the basement. Arrivals corresponding to refracted rays that bottom in the transition zone lie on curve segments DE, NO, and RS on 1SE (fig. 2b), CD, JK, and $M N$ on $1 N W$ (fig. 2b), and $B C$, NO, and $P Q$ on $6 N W$ (fig. 2a). On 1SE and 6NW, these curve segments appear to be smooth continuations of the traveltime curves for sediment arrivals, with no clear evidence of reflections that would result from a velocity discontinuity between sediments and basement. In contrast, on 1NW, the sharp kink in the travel-time curve at $4-5 \mathrm{~km}$ requires such a discontinuity. The associated reflections are permitted by the data, but are not easy to pick out because of other high amplitude energy on the seismograms.

At this point, it becomes necessary to use amplitudes in a qualitative way to put limits on the thickness of and velocity gradient within the transition zone. Wesson (1970) described a method for determining amplitudes based on the spreading of seismic rays. Basically, for a solid angle defined by a bundle of rays taking off from the source, seismic intensity will be inversely proportional to the area of the wavefront defined by this bundle as the rays spread. A correction must, of course, be made for transmission losses at boundaries. Thus, in our ray diagrams (fig. 9), amplitudes will be inversely correlated to the separation of rays emerging at the surface. One perceives at a glance that rays bottoming in the transition zone (figs. 9a, 9c, $9 d$ and $9 f$ ) are expected to be intermediate in amplitude between those bottoming in sediments and those bottoming in the basement. The velocity gradient in the transition zone determines the spreading of the rays and hence the amplitudes, and the combination of velocity gradient and layer thickness determines the distance interval over which these arrivals will persist. For example, decreasing the gradient in the transition zone by an average of 0.4 $\mathrm{km} / \mathrm{s} / \mathrm{km}$ southeast of shotpoint 1 would extend the distance 
interval for transition-zone arrivals by about $2 \mathrm{~km}$ for the first arrival, $4 \mathrm{~km}$ for the first multiple, and so forth. The data do not appear to favor this large a change in gradient. On the other hand, if the gradient is held constant and the thickness is decreased, then the distance interval shrinks in proportion to this decrease. For example, halving the thickness of the transition zone southeast of shotpoint 1 would halve the intervals DE, NO, and RS on 1SE (fig. 2b). Again, the data do not appear to favor this large a change in thickness. Note that multiple refractions on 1SE that sample the transition zone have only their first path leg actually penetrating this zone owing to the southeast dip of the zone (fig. 9c). The opposite is true on $6 \mathrm{NW}$, where the only second and successive paths legs actually penetrate this zone owing to the presence of the Imperial fault scarp (fig. 9f). Note that there are some features in the transition zone northwest of shotpoint 6 that are not adequately modeled. For example, arrivals along the curve $B C$ of $6 \mathrm{NW}$ (fig. 2a) become successively late compared to the model curve, with a maximum disgreement of $0.1 \mathrm{~s}$. Perhaps delays near the fault would improve the fit. In addition, the first and second multiple refractions, which sample the transition zone northwest of the fault appear to disagree on the velocity gradient and (or) thickness of the transition zone there: the distance interval No for arrivals sampling this zone appears to be consistent with the data, but the interval $P Q$ appears too short. The disagreement could be caused by lateral variation in the sediments and (or) transition zone northwest of the fault.

Upper basement velocity ranges from $5.6 \mathrm{~km} / \mathrm{s}$ southeast of the Imperial fault to $5.8 \mathrm{~km} / \mathrm{s}$ northwest of the fault. Depth to the basement-transition zone boundary ranges from about $5.8 \mathrm{~km}$ southeast of the Imperial fault to about $2.1 \mathrm{~km}$ northwest of shotpoint 1 . As noted above, the depth to basement that one calculates from a flat-layer interpretation of the traveltime curves lies within the transition zone. The velocity gradient in the basement ranges from $0.15 \mathrm{~km} / \mathrm{s} / \mathrm{km}$ under shotpoint 6 to about $0.08 \mathrm{~km} / \mathrm{s} / \mathrm{km}$ northwest of shotpoint 1 , although, as discussed below, these gradients are not certain. The velocity of lower basement, at $12.5 \mathrm{~km}$, is $6.6 \mathrm{~km} / \mathrm{s}$ in this model.

Arrivals that bottom in the basement lie along curves DEFGH on $6 \mathrm{NW}$, FGHI on 1SE, and DEFG on 1NW. Rays corresponding to these arrivals are shown in figs $9 a, 9 b$, and $9 d$. Owing to the wide spacing of rays emerging from the basement compared to those from the transition zone and sediments, one expects, and sees, a lower amplitude for these arrivals. In fact a lack of energy in the intervals $C D$ on $6 \mathrm{NW}$ and $E F$ on $1 \mathrm{SE}$ is consistent with a shadow or scattering effect of the Imperial fault scarp and a southeast dip, respectively. The shadow effect due to a southeast dip is illustrated in fig. 9b, where the increment for take-off angle is reduced to nearly the smallest allowable increment in our program, and yet a shadow still exists between successive rays at about 10 and $30 \mathrm{~km}$ from shotpoint 1. Note that some very low-amplitude arrivals are seen in the predicted shadow between 10 and $16 \mathrm{~km}$ on 1SE. These could be 
diffracted energy. Similarly on 6NW, low-amplitude arrivals (referring to the first peak only) are seen in the predicted shadow between 18 and $27 \mathrm{~km}$.

Perceptible multiple refractions from the basement are not expected on $6 \mathrm{NW}$ and 1SE owing to the shadow effects of the Imperial fault and the southeast dip (refer to figs. $9 c$ and $9 \mathrm{f}$ ). This shadow is predicted beyond 0 and $Q$ on $6 \mathrm{NW}$ ( $\mathrm{fig} .2 \mathrm{a}$ ) and beyond 0 and $S$ on 1SE ( $\mathrm{fig} .2 \mathrm{~b}$ ). There appears to be reasonable agreement with the data except at $Q$ on $6 \mathrm{NW}$, as discussed above. On the other hand, very low-amplitude multiple refractions from basement are predicted on 1NW along the branches northwest of $K$ and $N$, but the seismic traces are too noisy to see them.

Scarps on the transition zone and basement are located near the Imperial fault and under shotpoint 1; each appears to be about $1 \mathrm{~km}$ in height (fig. 2c). The scarp near the Imperial fault was located in our model halfway between the offsets in the arrivals at $C$ on $6 \mathrm{NW}$ (fig. 2a) and $\mathrm{H}$ on 1SE (fig. $2 \mathrm{~b}$ ). This location is about $3.8 \mathrm{~km}$ southeast of the surface expression of the Imperial fault. This distance interval is close to the horizontal distance $(4.5 \mathrm{~km})$ between the emergence of a ray from the transition zone to its emergence at the surface. The offset appears to affect primarily the lower sediments, transition zone, and basement, as the multiple refractions, which travel in the upper sediments through this area (fig. 9f), are not conspicuously offset. The apparent dip of the fault that one calculates from the model is about $52^{\theta}$. Correcting for the angle at which line $6 \mathrm{NW}$ crosses the fault, about $30^{\circ}$, gives a true dip of about $68^{\circ}$ to the northeast. A northeast fault dip is consistent with earthquake epicenters that are located consistently northeast of the fault (see Johnson, 1979, and Johnson and Hutton, in press). A scarp height of $1 \mathrm{~km}$ is intermediate between the extremes $(0.8 \mathrm{~km}$ and $1.6 \mathrm{~km}$ ) calculated from the traveltime offset and is also required, in combination with a $5.8 \mathrm{~km} / \mathrm{s}$ velocity for upper basement, to fit the arrival times along the branch FGH on 1SE ( $f i g \cdot 2 b$ ).

The location and height of the scarp under shotpoint 1 is a bit more uncertain, because lacking identifiable near-vertical reflections, shotpoint 1 is not in an advantageous position to resolve structure directly beneath it. The scarp could be moved southeastward a maximum of about 1 $\mathrm{km}$ if its slope were lessened and its height increased to about $2 \mathrm{~km}$. This configuration would fit better the early arrival at $53 \mathrm{~km}$ on $6 \mathrm{NW}$ (fig. 2a), but would produce a shadow for basement arrivals 15 to $20 \mathrm{~km}$ longer than the observed one on 1SE (fig. 2b) without an unreasonably high velocity gradient in the basement.

There appears to be a slight difference in basement velocity across the Imperial fault. An upper basement velocity of $5.6 \mathrm{~km} / \mathrm{s}$ was chosen for the region southeast of the fault to be consistent with analysis of the profile 6NNW-13SSE (Mooney and McMechan, in press) where this velocity is well constrained. Northwest of the fault, however, an upper basement velocity of $5.8 \mathrm{~km} / \mathrm{s}$ appears necessary to fit branches $E F$ on $6 \mathrm{NW}$ 
(fig. 2a) and FGH on 1SE (fig. 2b), although the structural complexity between shotpoints 1 and 6 make this velocity uncertain by at least 0.1 $\mathrm{km} / \mathrm{s}$. Northwest of shotpoint 1 , a $5.8 \mathrm{~km} / \mathrm{s}$ velocity fits the branch DEFG on 1NW (fig. 2b), but owing to lack of reversal on this branch and to considerable scatter, this velocity is also uncertain by at least 0.1 $\mathrm{km} / \mathrm{s}$. Upper basement velocity on West Mesa is best determined from lines $5 \mathrm{~N}$ and 13S, west of shotpoint 1 (fig. 1), which record blasts at shotpoints 5 and 13 (fig. 7). As on 1NW, arrivals on these lines define bumpy traveltime curves, but average basement branches can fitted through them with apparent velocities of 5.96 and $5.90 \mathrm{~km} / \mathrm{s}$, (fig. 7, solid lines), or, if one considers only stations recording both blasts, 6.1 and $5.9 \mathrm{~km} / \mathrm{s}$ (fig. 7, dashed lines). True upper basement velocity, then appears to range from 5.93 to $6.00 \mathrm{~km} / \mathrm{s}$. Hamilton (1970) obtained an average basement velocity of $5.92 \mathrm{~km} / \mathrm{s}$ from time-term analysis of a slightly larger region on the west flank of the Salton Trough. In conclusion, upper basement velocity in the central Imperial Valley east of the Imperial fault appears to be resolvably different from that on West Mesa, $5.6 \mathrm{~km} / \mathrm{s}$ compared to $5.93-6.00 \mathrm{~km} / \mathrm{s}$. Between the Imperial fault and West Mesa, upper basement velocity may or may not be intermediate between these two velocities.

It is interesting to note that the bumpiness in the arrival times on $5 \mathrm{~N}$ and $13 \mathrm{~S}$ also shows up in arrivals in this area from shotpoint 1, which are contoured in fig. 10 (see section on a traveltime contour map). Contouring indicates that northeast-trending grabens and horsts on West Mesa are responsible for this bumpiness. Note the change to low frequency for late arrivals above grabens.

The velocity gradient in basement for profile $6 \mathrm{NW}-1 \mathrm{SE}-1 \mathrm{NW}$ ranges from 0.08 to $0.15 \mathrm{~km} / \mathrm{s} / \mathrm{km}$ ( $\mathrm{fig}$. 2c) and is considerably above the range in gradient, 0.02 to $0.05 \mathrm{~km} / \mathrm{s} / \mathrm{km}$, determined by Mooney and McMechan (in press) for basement along the axis of the Salton Trough on profile $6 N N W-13 S S E$. On line $6 \mathrm{NW}$, a higher gradient is required to fit the weak first arrivals EF ( $\mathrm{fig} . \mathrm{2a}$ ) and is also required on 1 SE to turn rays back to the surface at $F$ (fig. 2b; fig. 9b). If one discounts the weak arrivals at $E F$ on $6 \mathrm{NW}$, then one must attempt to explain the sudden change of character in the first arrivals at $G$ on $6 \mathrm{NW}$ as an effect of structure rather than an effect of crossover between basement and subbasement arrivals. One does not, however, see a strong structural effect on ray spacing, and hence amplitudes, on either side of G (fig. 9e), and we favor the interpretation that the change at $G$ is due to arrival crossover. On ISE one might be able to produce the arrivals beyond $F$ by diffracted, rather than refracted energy as we have done. It is not clear, however, that diffracted arrivals would produce the observed shadow EF. In summary, although we favor a relatively higher velocity gradient in the basement on profile 6NW-1SE-1NW than on 6NNW-13SSE, the evidence is not compelling. The higher gradient on $6 \mathrm{NW}-1 \mathrm{SE}-1 \mathrm{NW}$ results in a velocity for lower basement of $6.6 \mathrm{~km} / \mathrm{s}$, compared to $5.85 \mathrm{~km} / \mathrm{s}$ on 6NNW-13SSE. 
A subbasement represented by a velocity step from $6.6 \mathrm{~km} / \mathrm{s}$, that of lower basement, to $7.0 \mathrm{~km} / \mathrm{s}$ is present at about $12.5 \mathrm{~km}$ depth (fig. 2c). Within $1 \mathrm{~km}$, the velocity of this layer increases to $7.2 \mathrm{~km} / \mathrm{s}$. Arrivals corresponding to refractions in this layer lie along the curve IGJKL on $6 \mathrm{NW}$ ( fig. 2a) and JI on 1SE (fig. 2b). Reflections from the top of this body are seen along the dashed curve IH on 6NW and JI on 1SE, with critical reflections predicted at $I$ and $J$, respectively. Moving the top of the subbasement up or down by $1 \mathrm{~km}$, keeping the basement velocity gradient constant, advances or delays the arrivals about $0.1 \mathrm{~s}$ and moves the critical reflection toward or away from the shotpoint by 3 to $5 \mathrm{~km}$. The position of the critical point can, of course, be adjusted by changing the velocity step at the top of the layer, but a velocity of at least 7.2 $\mathrm{km} / \mathrm{s}$ must be reached somewhere within the upper kilometer or so of the layer to satisfy the data (figs. $2 a$ and 3 ). Refractions from the subbasement cross over basement refractions at about shotpoint 1 (G on $6 \mathrm{NW}$, fig. 2a) and may be responsible for the change in character of the first arrival here. Note the prominent jump in arrival time at this point due to the basement scarp under shotpoint 1. Note also that the presence of the subbasement cuts off basement refractions and supercritical reflections at $\mathrm{H}$ on $6 \mathrm{NW}$ (fig. 2a).

Hamilton (1970) detected a subbasement with an apparent velocity of $7.1 \mathrm{~km} / \mathrm{s}$ and calculated a depth of $14 \mathrm{~km}$ at a location about $50 \mathrm{~km}$ northwest of shotpoint 1. The models developed in this report and that of Mooney and McMechan (in press), appear consistent with Hamilton's interpretation. 


\section{Profile 1E-2W}

Data

Explosions at shotpoints 1 and 2 were recorded along lines $1 \mathrm{E}$ and 2W, which cross the Imperial Valley and East Mesa (fig. 1). Shotpoint 2 is $21 \mathrm{~km}$ east of Brawley, on the edge of East Mesa. Geologically, the shotpoints are on opposite shorelines of ancient Lake Cahuilla and penetrate basin sediments. The parts of the lines between shotpoints cross, at the extreme west end, the Superstition Mountain and Superstition Hills faults, and in the center, the Imperial and Brawley faults. Near shotpoint 2, they cross a seismicity lineament along the East Highline canal that is interpreted as a fault (see Johnson and Hutton, in press). East of shotpoint 2, $1 E$ crosses several inferred faults including the Sand Hills and the Algodones faults(?).

Line $1 \mathrm{E}$ is $84 \mathrm{~km}$ long and contains 93 seismograms, of which 77 are shown (fig. 4b). This line was recorded on three occasions, as records from the first occasion were complicated by the occurrence of a small earthquake. Line $2 \mathrm{~W}$ is $40 \mathrm{~km}$ long and contains 24 traces, all of which are shown (fig. 4a). $1 \mathrm{E}$ extends $40 \mathrm{~km}$ east of shotpoint 2, but $2 \mathrm{~W}$ stops about $5 \mathrm{~km}$ east of shotpoint 1, leaving the region below shotpoint 1 unsampled.

As on lines $6 \mathrm{NW}$ and 1SE, all arrivals on $1 \mathrm{E}$ and $2 \mathrm{~W}$ define smooth traveltime curves with little scatter where these lines cross the Imperial Valley. On $1 E$ east of shotpoint 2, however, the arrivals define a bumpy travel-time curve. Bumps are seen on all scales. On one hand, adjacent traces in many places differ in traveltime by over $0.1 \mathrm{~s}$, measured from the local average traveltime curve. On the other hand, a major offset in the traveltime curve exceeding $0.2 \mathrm{~s}$ is seen between arrivals at 61 and $64 \mathrm{~km}$, near the proposed trace of the Algodones fault(?), indicating a larger structure there.

Between 0 and $18 \mathrm{~km}$ on $1 E$, and 0 and $13 \mathrm{~km}$ on $2 W$ arrivals are strong and lie along a smooth traveltime curve with strong curvature. Apparent velocities along these curves range progressively from 1.9 to $4.66 \mathrm{~km} / \mathrm{s}$ indicating sediment arrivals. Beyond these distances, arrivals are moderately strong to weak and can easily be fitted by straight lines out to about $33 \mathrm{~km}$ having similar apparent velocities on both profiles of about $5.55 \mathrm{~km} / \mathrm{s}$. Beyond $33 \mathrm{~km}$ on both profiles, the apparent velocity increases. Beginning at about $30 \mathrm{~km}$ on $1 \mathrm{E}$, some coherent second arrivals are apparent. These arrivals are most strikingly coherent between 39 and $43 \mathrm{~km}$ where some $15 \mathrm{hz}$ energy appears to ride on a 5 to 6 hz wavelet that is several wavelengths long. East of shotpoint 2 the first arrivals have the same distinctive appearance as on $6 \mathrm{NW}$ beyond shotpoint 1: they consist of a $5-6 \mathrm{hz}$ wavelet about 2 wavelengths long. The second arrivals from 30 to $45 \mathrm{~km}$ and the first arrivals beyond $45 \mathrm{~km}$ appear to have similar apparent velocities of around $8.5 \mathrm{~km} / \mathrm{s}$. Unfortunately, $2 W$ is not long enough or recorded densely enough to see clearly a second arrival similar to the one on $1 \mathrm{E}$. 
First, second, and third multiple refractions are seen on both $1 E$ and $2 W$. Their amplitude behavior is similar to, but more complicated than, that of the first arrivals.

Note that no clear offsets (exceeding a few hundredths of a second) appear to be associated with the any of the faults crossed, with the possible exceptions of the Sand Hills and Algodones faults(?).

Some clear differences are seen between $1 E$ and $1 S E$ (figs. 4b and 2b). When superimposed, the traveltime curves cross each other at about $8 \mathrm{~km}$ : arrivals on $1 \mathrm{E}$ are earlier from 0 to $8 \mathrm{~km}$ by as much as $0.18 \mathrm{~s}$ and later beyond $8 \mathrm{~km}$ by up to $0.4 \mathrm{~s}$ at $35 \mathrm{~km}$. The basement intercept time for $1 \mathrm{E}$ is later by $0.3 \mathrm{~s}$. Of course, multiple refractions on $1 \mathrm{E}$ and $1 \mathrm{SE}$ diverge from each other at multiples of $8 \mathrm{~km}$. There is no prominent first-arrival shadow on $1 E$ and hence no cutoff in the multiple refractions, as was seen on 1SE. These differences lead to marked model differences at shotpoint 1 , as discussed below.

\section{Interpretation}

The starting model for $1 E$ and $2 W$ was obtained from a flat-layer interpretation of the traveltime curves. In addition, flat-layer interpretations of profiles reported by Kovach and others (1962) along the East Highline canal south of shotpoint 2 and along the Coachella canal 10 $\mathrm{km}$ east of shotpoint 2 were used to control relevant segments of the model. Depths to basement inferred from such interpretations are: 4.8 $\mathrm{km}(1 \mathrm{E}), 4.3 \mathrm{~km}$ (2W), $3.1 \mathrm{~km}$ (East Highline canal), and $2.8 \mathrm{~km}$ (Coachella canal).

The final model (fig. 4c) is similar in its major features to that for profile $6 \mathrm{NW}-1 \mathrm{SE}-1 \mathrm{NW}$, in that it contains two sections of sediments, a transition zone, a basement, a second transition zone, and a subbasement. Cross sections through the model, or velocity-depth curves, indicate some similarities and some differences when compared to $6 \mathrm{NW}-1 \mathrm{SE}-1 \mathrm{NW}$ (figs. $8 \mathrm{~b}$ and $8 \mathrm{c}$, table 3). There is an overall similarity in the shape of the velocity-depth curves between the two models. In particular, the velocity-depth curve near shotpoint 2 (labeled 43 , fig. 8c) is intermediate between the curves 1 and $17 \mathrm{~km}$ southeast of shotpoint 1 ( 1 and 17, fig. 8b) The curve $25 \mathrm{~km}$ east of shotpoint 1 , in the center of the Imperial Valley, is essentially the same as that at shotpoint 6 which is in the center of the Salton Trough. Differences include a higher velocity gradient in the upper section of sediments $(1.0 \mathrm{~km} / \mathrm{s} / \mathrm{km}$ versus $0.7 \mathrm{~km} / \mathrm{s} / \mathrm{km})$, a lower velocity gradient in the basement $(0.05 / \mathrm{s}$ versus $0.1 / \mathrm{s})$, and a different velocity step at the top of the subbasement $(5.95$ to $6.6 \mathrm{~km} / \mathrm{s}$ versus 6.6 to $7.0 \mathrm{~km} / \mathrm{s}$ ). Note that the velocity-depth curve $2.5 \mathrm{~km}$ east of shotpoint 1 is very different from those $1 \mathrm{~km}$ northwest and $1 \mathrm{~km}$ southeast of shotpoint 1 , reflecting the extreme structural complexity beneath shotpoint 1. Note also that the two sections of sediments are distinguishable only at shotpoint 1 (and east of shotpoint 2, where we must rely entirely on the data of Kovach and others (1962). 
Total sediment thickness ranges from about $4.55 \mathrm{~km}$ just east of shotpoint 1 to a feather edge on the east side of the Salton Trough (fig. 4c). Velocity contours dip toward the center of the Imperial Valley from both sides of the model. The small oscillation in the contours just west of shotpoint 2 may correlate with a fault along the East Highline canal that is inferred from seismicity. The surficial velocity is $1.8 \mathrm{~km} / \mathrm{s}$ everywhere except at shotpoint 1 where it is higher (similar to the model for $6 \mathrm{NW}-1 \mathrm{SE}-1 \mathrm{NW})$. The velocity at the base of the sediment apparently reaches about $5 \mathrm{~km} / \mathrm{s}$ everywhere but at the east edge of the Salton Trough.

Arrivals from rays that bottom in the upper sediments on $1 \mathrm{E}$ lie along curve segments $A B, A I$, and $A L$, and those from the lower sediments, along segments BC, IJ, and LM (fig. 4b). On $2 \mathrm{~W}$, where there is apparently no distinction between upper and lower sediments, arrivals from the sediments lie along segments $A B C$, AGH, and AJK. A change to lower amplitudes is expected for arrivals on $1 E$ bottoming in the lower sediments between 0 and $15 \mathrm{~km}$ owing to the change to a lower velocity gradient in this region. This predicted reduction is difficult to test on the first arrivals in the region $\mathrm{BC}$, as most are clipped. One might expected this effect to be smaller on the first multiple refraction (IJ) and smaller yet on the second (LM), as more of these ray paths are out of this region. In fact, amplitudes on the second multiple refraction (LM) appear quite high.

A transition zone, $1 \mathrm{~km}$ in thickness under the Imperial Valley and tapering to a feather edge on the east side of the Salton trough, is included in the model between the sediments and basement. Except on the edge of the trough where velocity discontinuities are seen, this zone involves an increase in velocity from about $5 \mathrm{~km} / \mathrm{s}$ at the base of the sediments to $5.65 \mathrm{~km} / \mathrm{s}$ in the upper basement. Arrivals corresponding to rays bottoming in this zone lie along curve segments $C D, J K$, and $M_{+}$on $1 E$ (fig. 4b) and along CD, HI, and $\mathrm{K}+$ on $2 \mathrm{~W}$ (fig. 4a). As on 6NW and 1SE, these segments appear to be smooth continuations of the traveltime curves for the sediments with no clear evidence for reflections that would result from a velocity discontinuity between the sediments and basement. As on $6 \mathrm{NW}$ and $1 \mathrm{SE}$, one expects a reduction in amplitudes owing to a reduction in velocity gradient to $0.55 \mathrm{~km} / \mathrm{s} / \mathrm{km}$ in this zone. This reduction might not be dramatic in the first arrivals on $1 \mathrm{E}$, owing to the fact that the lower-sediment gradient in the region $0-15 \mathrm{~km}$ ranges through the value of the gradient in the transition zone, but the reduction might be more prominent in the first and second multiple refractions owing to longer path legs in the region beyond $15 \mathrm{~km}$. The data is roughly consistent with these expectations, but irregularities are apparent, such as the abrupt increase in amplitudes at $K$ and persistence of high amplitudes beyond $M$ (fig. 4b). Arguments similar to those in the discussion of the transition zone for $6 \mathrm{NW}-1 \mathrm{SE}-1 \mathrm{NW}$ can be made here justifying the thickness and gradient chosen for this zone. 
Upper basement has a model velocity of about $5.65 \mathrm{~km} / \mathrm{s}$, which is consistent with an observed apparent velocity of $5.55 \mathrm{~km} / \mathrm{s}$ on both $1 E$ and $2 W$ coupled with dips of velocity contours in the sediments toward the center of the valley. Higher apparent velocities beyond $33 \mathrm{~km}$ on both lines are also consistent with this model. On 1E, basement apparently rises from its depth of about $5.6 \mathrm{~km}$ in the center of the valley to a plateau at about $4.3 \mathrm{~km}$ depth under shotpoint 2. If one takes the center of the transition zone to be the equivalent of a flat-layer interpretation of depth to basement, then this depth under shotpoint $2,3.8 \mathrm{~km}$, is somewhat deeper than that of Kovach and others (1962), $3.1 \mathrm{~km}$, for their profile south of shotpoint 2. The velocity gradient in basement, 0.05 $\mathrm{km} / \mathrm{s} / \mathrm{km}$ is lower than that found for $6 \mathrm{NW}-1 \mathrm{SE}-1 \mathrm{NW}$, bringing the velocity at the bottom of the basement layer, at $11.3 \mathrm{~km}$ depth, up to only 5.95 $\mathrm{km} / \mathrm{s}$.

Arrivals that bottom in the basement lie along curve $D E$ and beyond $K$ on $1 E$ (fig. 4b) and along curve $D E$ and beyond $I$ on $2 W$ (fig. 4a). The reduction in amplitude that one expects from the reduction in velocity gradient is clearly seen.

A subbasement, represented by a velocity step from $5.95 \mathrm{~km} / \mathrm{s}$, that of lower basement, to $6.6 \mathrm{~km} / \mathrm{s}$ is present at about $11.3 \mathrm{~km}$ depth (fig. 4c). Within $1 \mathrm{~km}$, the velocity of this layer increases to $7.2 \mathrm{~km} / \mathrm{s}$. Arrivals corresponding to refractions from this layer lie along curve GEH on $1 E$ (fig. 4b) and along $F E$ on $2 W$ (fig. 4a). Reflections from the top of this layer are predicted along the dashed curve $G F$ on $I E$ and beyond $F$ on $2 \mathrm{~W}$, with critical reflections at $G$ and $F$, respectively. As appeared to be the case on $6 \mathrm{NW}$, the cross-over of subbasement arrivals on $1 E$ at $E$ may be responsible for the change in character of the first arrival there. Note the scattering of arrival times on $1 E$ along curve EH (fig. 4b). Like the structure northwest of shotpoint 1, the structure here appears complicated, but was not modeled in detail. 


\section{Profile 10SE-2NW}

$\underline{\text { Data }}$

Explosions at shotpoints 2 and 10 were recorded along lines 2NW and 10SE, which cross the northern part of the Imperial Valley obliquely (fig. 1). Shotpoint 10 is $14 \mathrm{~km}$ northwest of Brawley, within Imperial Valley, but slightly west of the axis of the Salton Trough. Both shotpoints penetrate basin sediments. Shotpoint 10 is located in the Westmorland geothermal area and is $9 \mathrm{~km}$ south of Obsidian Butte, a Holocene rhyolite extrusion. The refraction lines cross the Brawley seismic zone and the East Highline canal seismicity lineament.

Line 2NW is $38 \mathrm{~km}$ long and contains 38 traces of which 34 are shown (fig. 5a). 10SE is $34 \mathrm{~km}$ long and contains 34 traces of which 32 are shown (fig. 5b). 2NW extends beyond shotpoint 10 and samples the region under that shotpoint; 10SW does not extend beyond shotpoint 2, leaving the region below unsampled.

As on segments of other lines within the Imperial Valley, arrivals on 2NW and 10SE show little scatter (figs. 5a and 5b). Except for the kinks at 4 to $5 \mathrm{~km}$ on each line, first arrivals lie on smooth traveltime curves. Apparent velocities ranging progressively from 1.6 to $4.9 \mathrm{~km} / \mathrm{s}$ are seen from 0 to $20 \mathrm{~km}$ on $2 \mathrm{NW}$ and from 0 to $16 \mathrm{~km}$ on 10SE; dominant velocities are 2.1 and $4.3 \mathrm{~km} / \mathrm{s}$, on either side of the kink. Apparent velocities of around $5.6 \mathrm{~km} / \mathrm{s}$ are seen between 20 and $26 \mathrm{~km}$ on $2 \mathrm{NW}$ and between 16 and $21 \mathrm{~km}$ on 10SE, and higher apparent velocities, $6.6 \mathrm{~km} / \mathrm{s}$ on 2NW and $6.5 \mathrm{~km}$ on 10SE, are seen beyond those points. It is noteworthy that first arrivals beyond the kinks are generally later on 10SE than on 2NW by a maximum of $0.4 \mathrm{sec}$. at $7 \mathrm{~km}$. Reciprocal travel times at the shotpoints are the same on both lines, however. In contrast to the overall continuity of the traveltime curves, there are marked fluctuations in amplitude on all arrival branches on both lines.

Comparing the traveltime curve of $2 \mathrm{NW}$ with that of $2 \mathrm{~W}$, one notes similarity with the exception that sedimentary arrivals are slightly later on $2 W$ by a maximum of $0.15 \mathrm{~s}$ at $10 \mathrm{~km}$; the basement intercept time on $2 W$ is 0.1 s later.

\section{Interpretation}

We obtain the starting model for profile 10SE-2NW from flat-layer interpretation of the traveltime curves, which gives a depth to basement of $4.3 \mathrm{~km}$ for both lines.

The final model ( $\mathrm{fig} 5 \mathrm{c}$ ) is similar to previously described models, but sediments are modeled in 3 sections rather than 2 owing primarily to the observed kinks in the traveltime curves. Velocity-depth curves (fig. 8d) can be compared and contrasted with the other models. The velocity-depth curve at shotpoint 2 (labeled 33, fig. 8d, table 3) should 
agree closely with the one near shotpoint 2 for $1 E-2 W$ ( 43 , fig. $8 \mathrm{c}$ ), and it does. The curve $15 \mathrm{~km}$ southeast of shotpoint 10 (15, fig. 8d) is essentially the same as the one in the center of valley for 1E-2W (25, fig. $8 \mathrm{c}$ ) and the one at shotpoint 6 (53, fig. $8 \mathrm{~b})$, although it involves a few slight changes in gradient. The velocity profile at shotpoint $10(0$, fig. $8 d$ ) is essentially the same as the one $17 \mathrm{~km}$ southeast of shotpoint 1 (17, fig. $8 \mathrm{~b})$. One can thus begin to classify the profiles as shown in fig 8 according to geologic setting in the Imperial Valley region. The reader is referred to the summary at the end of this report for this classification.

Total sediment thickness ranges from $4.6 \mathrm{~km}$ halfway between shotpoints 2 and 10 to about $4 \mathrm{~km}$ at shotpoint 10 and $3 \mathrm{~km}$ at shotpoint 2 , although the depth under shotpoint 2 is not constrained by our data owing to the lack of data beyond it from shotpoint 10. Velocity contours have an apparent dip generally northwest. As in the model for 6NW-1SE-1NW, the upper section of sediments, here 0.6 to $1.2 \mathrm{~km}$ thick, are characterized by a low velocity, 1.9 to $2.0 \mathrm{~km} / \mathrm{s}$ at the surface in most places, and a low gradient, 0.2 to $0.3 \mathrm{~km} / \mathrm{s} / \mathrm{km}$. These sediments overlie a section characterized by a higher gradient of about $1.3 \mathrm{~km} / \mathrm{s} / \mathrm{km}$. This section in turn overlies a section whose gradient is lower again and variable from place to place, $0.5 \mathrm{~km} / \mathrm{s} / \mathrm{km}$ to $0.8 \mathrm{~km} / \mathrm{s} / \mathrm{km}$. The large bump in the contours in this section centered about $7 \mathrm{~km}$ southeast of shotpoint 10, appears significant and may reflect a structure (fold, fault, or intrusion) associated with the Brawley seismic zone. At the base of the sediments, the velocity is about $5 \mathrm{~km} / \mathrm{s}$, as in the other models.

First arrivals from rays bottoming in the upper sediments lie along curves $A B C$ in both profiles (figs. $5 a$ and $5 b$ ) and those bottoming in sediments below lie along curves DBE. The large increase in velocity gradient at about $1 \mathrm{~km}$ depth produces a marked triplication reflected by the kink in the traveltime curve at about $5 \mathrm{~km}$ on both profiles. This triplication is repeated in each of the traveltime curves for the multiple refractions, creating a locus $A J$ (10SE) and $A K$ (2NW) of stretchedout and overlapping triplications, along which many arrivals having nearly the same travel time interfere with one another. A similar but less prominent triplication is consistent with the data on profile 1SE (fig. 2b) and perhaps also on $2 \mathrm{~W}$ (fig. 4a), although the latter profile was modeled without one.

A transition zone, ranging in thickness from 0.5 to $1.4 \mathrm{~km}$, is included in this model, as in the other models, to produce the observed smooth transitions EF and HI (figs. $5 \mathrm{a}$ and $5 \mathrm{~b}$ ) on the traveltime curves from sediment to basement arrivals. An increase in velocity from around $5 \mathrm{~km} / \mathrm{s}$ at the base of the sediments to $5.65 \mathrm{~km} / \mathrm{s}$ in the upper basement is accomplished by gradients which in the southeast half of the model are lower $(.5-.6 \mathrm{~km} / \mathrm{s} / \mathrm{km})$ and in the northwest half are higher $(1.0-1.3$ $\mathrm{km} / \mathrm{s} / \mathrm{km}$ ) than those in the sediments immediately above. For arrivals 
from this zone, one might expect lower amplitudes on $2 \mathrm{NW}$ and higher amplitudes on 10SE compared to adjacent arrivals from the sediments, but instead the observed amplitude fluctuations are somewhat erratic, indicating complications that are not modeled.

The upper basement has an average model velocity of $5.65 \mathrm{~km} / \mathrm{s}$, consistent with observed apparent velocities of around $5.6 \mathrm{~km} / \mathrm{s}$ past $F$ on both profiles (figs. $5 \mathrm{a}$ and $5 \mathrm{~b}$ ). The model produces this apparent velocity by the competing effects of an apparent dip on basement of about 1 southeast from shotpoint 10 and an apparent dip on sediments of about 1.5 northwest from shotpoint 2. A marked reversal in basement dip near shotpoint 2 gives rise to an observed $6.5 \mathrm{~km} / \mathrm{s}$ velocity on $10 \mathrm{SE}$ and a slight increase in dip near shotpoint 10 give a similar high apparent velocity on 2NW. (Refer to arrivals near $G$ on both profiles). Thus the overall basement structure appears to be a slightly assymmetric basin with its deepest part, $5.4 \mathrm{~km}$, located 10 to $15 \mathrm{~km}$ northwest of shotpoint 2.

Comparing this model with the one for $1 \mathrm{E}-2 \mathrm{~W}$ in the vicinity of shotpoint 2, one notes some similarities and some differences. All velocity contours from 2.0 to $4.5 \mathrm{~km} / \mathrm{s}$ are similar to a distance of about $10 \mathrm{~km}$ from shotpoint 2. The $5.0 \mathrm{~km} / \mathrm{s}$ contour, however, is depressed about 0.4 $\mathrm{km}$ in depth for 10SE-2NW compared to $1 \mathrm{E}-2 \mathrm{~W}$, but has a similar shape, deepening more or less gradually to the northwest. Worse yet, the 5.5 $\mathrm{km} / \mathrm{s}$ contour, along with the upper-basement interface appears to be nearly a kilometer deeper on $10 \mathrm{SE}-2 \mathrm{NW}$ than on $1 \mathrm{E}-2 \mathrm{~W}$ at a point $5 \mathrm{~km}$ from shotpoint 2. As pointed out in the discussion of the scarp under shotpoint 1, it is difficult to model uniquely a structure directly beneath a shotpoint, as the data are unreversed, if the region is sampled at all. In the case of shotpoint 1, we were able to move the scarp a kilometer or so outward and lessen its slope while still satisfying the data. Perhaps we have an analogy at shotpoint 2, where models for 1E-2W and 10SE-2NW represent the two extremes in modeling the region below. This possibility has not yet been tested. On the other hand, the discrepancy may be in part real and related to faulting along the East Highline canal seismicity lineament.

The large bump in the velocity contours centered $7 \mathrm{~km}$ southeast of shotpoint 10 (fig. 5c) results from an attempt to model a region of apparently highly complicated structure. The data from shotpoint 10 require a local high velocity in this region to fit first arrivals near $10 \mathrm{~km}$ (fig. 5b), whereas arrivals from shotpoint 2, which sample this region less comprehensively, indicate a normal regional average velocity (fig. 5a). This feature is, thus, relatively localized and possibly related to the Brawley seismic zone. 


\section{Profile 1ESE}

\section{Data and Interpretation}

Description and analysis of unreversed profile 1ESE is included primarily because this profile exhibits the most dramatic evidence of arrivals from the subbasement. Refractions and reflections from the subbasement lie along model curves $C D$ and $C B$, respectively (fig. $6 a$ ).

This profile extends 60 kilometers east-southeast of shotpoint 1 through the central Imperial Valley, intermediate in azimuth between 1SE and $1 \mathrm{E}$ (fig. 1). It was recorded on two separate occasions. On the first occasion, it was recorded, from 12 to $60 \mathrm{~km}$ and contains 26 traces (fig. 6a). On the second occasion it was recorded from 0 to $25 \mathrm{~km}$ and contains 400 traces, which are not shown here but which were used to constrain the sedimentary sections of the model. The second recording was part of an effort, still under way, to trace reflections from the subbasement to subcritical distances.

The subbasement arrivals on 1ESE are interesting not only because they are so strong but also because they are seen first at a range of 25 $\mathrm{km}$ from the shotpoint, $5 \mathrm{~km}$ ahead of similar arrivals on $1 E$ and $6 \mathrm{NNW}$ (see Mooney and McMechan, in press) and more than $10 \mathrm{~km}$ ahead of similar arrivals on 6NW. All of these lines sample nearby parts of the central Imperial Valley, and it is of interest to compare inferred depths to subbasement for consistency. In addition to the strong subbasement arrivals, other features on IESE that are of interest in modeling include the offset in the first arrivals, and in the second multiple refraction at about $25 \mathrm{~km}$, just past the Imperial fault, and also the amplitude decrease in all arrivals (except those from the subbasement) beginning at about the Imperial fault.

Comparing the record sections of 1ESE with nearby 1 SE and $1 E$ similarities and contrasts are noted. The first arrivals of 1ESE are very similar in time to those of 1SE except that they diverge at about $8 \mathrm{~km}$ to become $0.25 \mathrm{~s}$ later; basement intercept time is correspondingly later. Basement apparent velocity on IESE is nearly $6.00 \mathrm{~km} / \mathrm{s}$, compared to 5.67 $\mathrm{km} / \mathrm{s}$ on 1SE. First arrivals on 1ESE do not show the abrupt amplitude drop at $10 \mathrm{~km}$ seen on 1SE. First arrivals on $1 E$ diverge in turn from 1ESE beyond $8 \mathrm{~km}$, becoming $0.2 \mathrm{~s}$ later, but are markedly earlier from 0 to $8 \mathrm{~km}$. Basement apparent velocity on $1 E$ is only $5.55 \mathrm{~km} / \mathrm{s}$. Beyond the Imperial fault, which produces a traveltime offset of about $0.18 \mathrm{~s}$, (similar to that on 6NW), arrival times on 1ESE and $1 E$ agree well. The multiple refractions on 1ESE agree in time with those of 1SE, where they overlap, but continue considerably farther. They are generally slightly earlier than those of $I E$ and do not continue as far. In summary, data suggests that the correct model for 1ESE might be one with velocity gradients similar to $6 \mathrm{NW}-1 \mathrm{SE}-1 \mathrm{NW}$, but interface depths that are intermediate between those of $6 \mathrm{NW}-1 \mathrm{SE}-1 \mathrm{NW}$ and $1 \mathrm{E}-2 \mathrm{~W}$. 


\section{TRAVELTIME CONTOUR MAP}

A few shotpoints were recorded widely enough to permit contouring of reduced travel time. To date, only the contour map for shotpoint 1 has been constructed (fig. 10). A reducing velocity of $6 \mathrm{~km} / \mathrm{s}$ is used, similar to (but not identical to) basement velocity. Such a contour map is roughly similar to a sedimentary isopach map, where greater reduced travel time correlates with greater sediment thickness.

In constructing the map, all reduced arrival times from shotpoint 1 with estimated errors less than $0.1 \mathrm{~s}$ were plotted at their respective locations on a map. Triangles were drawn among triads of locations which were judged to be nearest neighbors. Contour intervals were then interpolated on the legs of the triangles, and contour lines were drawn. A contour interval of $0.1 \mathrm{~s}$ was chosen equivalent to the maximum estimated reading error. In interpreting the map, then, one must keep in mind that at distances beyond about 30 to $50 \mathrm{~km}$, depending on background noise, reading error increases (refer to figs. 2,4,5,6, and 7), and contours could be in error by an amount estimated to be one contour interval.

Interpretation of this map is made difficult by the complex structure beneath shotpoint 1 . The reduced travel time of the first basementrefracted arrival varies drastically with azimuth: $1.35 \mathrm{~s}$ on $1 \mathrm{NW}, 1.9 \mathrm{~s}$ on 1SE, $2.25 \mathrm{~s}$ on 1ESE, and $2.4 \mathrm{~s}$ on 1E. (refer to figs. 2b,6a, and 4b) Such variation precludes the use of the map as an equivalent of a timeterm map, as the fundamental assumption of time-term analysis is that "down-times" be independent of azimuth at each source and receiver site (Berry and West, 1966). Furthermore, traveltimes for rays bottoming in several different refractors are represented, and the reducing velocity of $6 \mathrm{~km} / \mathrm{s}$ does not exactly match that of any one refractor. Thus in interpreting the map one must also keep the following facts in mind:

1) At different azimuths, a given contour does not reflect the same depth to a refractor. Indeed, even along a single azimuth structural complications in the media above the refractor must be modeled first before a depth to the refractor can be inferred (as is evident in the first part of this report).

2) At different azimuths, arrivals from different refractors are seen in different distance intervals from shotpoint 1:

a) At azimuths from northwest counter-clockwise (CCW) to south, basement arrivals are seen at distances beyond $7 \mathrm{~km}$.

b) At azimuths from south CCW to north, basement arrivals are seen in distance intervals from between 11 and $18 \mathrm{~km}$ to between 45 and $55 \mathrm{~km}$. Beyond 45 to $55 \mathrm{~km}$, arrivals from the subbasement refractor are seen.

c) At azimuths from north CCW to northwest the interval in which arrivals from a basement refractor are seen is uncertain due to structural complexity in the San Jacinto fault zone.

3) Within the distance interval in which basement arrivals are seen in the central Imperial Valley, a slow drift to higher contours is expected with distance, even with no increase in depth to basement, owing to the choice of $6 \mathrm{~km} / \mathrm{s}$ reducing velocity. 
The starting model for 1ESE was the final model for 6NW-1SE-1NW with the scarp on the transition zone and basement associated with the Imperial fault moved to a position about $1 \mathrm{~km}$ east of the surface trace of the Imperial fault on 1ESE. In the final model for 1ESE (fig. 6b), velocity gradients like those in 6NW-1SE-1NW do indeed fit the data, and transition zone and basement interfaces are intermediate in depth between models for $6 \mathrm{NW}-1 \mathrm{SE}-1 \mathrm{NW}$ and $1 \mathrm{E}-2 \mathrm{~W}$. In particular, the scarp height under shotpoint 1 is increased by $1.4 \mathrm{~km}$ over that of 6NW-1SE-1NW, making basement 4.5 deep east of the shotpoint The height of the Imperial fault scarp is apparently less than that in $6 \mathrm{NW}-1 \mathrm{SE}-1 \mathrm{NW}$, and a zone of lower velocity ( 4 percent lower) through the fault zone was required to fit multiple refraction times at around $30 \mathrm{~km}$. Note that in the model for $6 \mathrm{NW}-1 \mathrm{SE}-1 \mathrm{NW}$ a scarp height of $1 \mathrm{~km}$ was used with no decrease in the fault-zone velocity to model the same traveltime offset of $0.18 \mathrm{~s}$. To some extent models for 1ESE and 6NW-1SE-1NW may represent extremes in modeling possibilities, although this idea has not been tested. The apparent dip on the fault on 1ESE is $75^{\circ}$ northeast. Correcting for the angle at which the profile crosses the fault, a true dip of about $78^{\circ}$ northeast is calculated.

Amplitudes of the multiple refractions do fall off at $F$ and $I$ as one would predict from entry of ray paths into the basement where the velocity gradient drops. Upper-basement velocities are similar to those for $6 \mathrm{NW}-1 \mathrm{SE}-1 \mathrm{NW}$, but the basement velocity gradient is lower, leading to a lower-basement velocity of only $6.15 \mathrm{~km} / \mathrm{s}$, in rough agreement with that found on 1E. Most importantly, a subbasement depth of $11.3 \mathrm{~km}$ agrees exactly with that found along nearby $1 E$. The reflection from the subbasement is so strong that it shows up as a multiple reflection at $G$.

In summary, the model for 1ESE is a blend of many features of both those for $6 \mathrm{NW}-1 \mathrm{SE}-1 \mathrm{NW}$ and $1 \mathrm{E}-2 \mathrm{~W}$ which lie to either side. In spite of the differing strength and onset distance for subbasement arrivals on $1 E$ and 1ESE, similar subbasement depths are indicated. 
4) Features in the contours are displaced radially away from shotpoint 1 from the structures that cause them. The amount of displacement depends on the depth of the structure and the ray path sampling it (eg. for a structure in the upper basement in the center of the valley, the distance is generally 6 to $8 \mathrm{~km}$ ).

Even with this burdensome list of things to keep in mind, a number of simple and interesting observations can be easily made from the map.

The contour map (fig. 10) is roughly an inverse of the surficial topography, with a "ridge" of reduced traveltimes as high as $2.5 \mathrm{~s}$ along the axis of the Salton Trough and a "valley" of low values, around $1.3 \mathrm{~s}$, on West Mesa. The southwest flank and crest of the "ridge" are within the interval where first arrivals are from basement. The northeast flank of the ridge is within the interval for subbasement first arrivals. If one assumes the "ridge" crest represents the axis of a sedimentary trough and translates all points of this crest radially toward shotpoint 1 by about $8 \mathrm{~km}$ (the horizontal distance an upcoming ray would travel through these sediments), this axis coincides roughly with the seismogenic belt in the Imperial Valley (see Johnson, 1979, and Johnson and Hutton, in press).

The "valley" of low contour values on West Mesa is separated from the "ridge" by a steep slope which trends north-south south of shotpoint 1 but is deflected northwest by both the Superstition Mountain and Superstition Hills faults to the north. To the south, this slope presumably reflects the buried basement scarp discovered under shotpoint 1, and to the north, it probably reflects basement scarps along the faults. Superstition Mountain, an uplifted basement block, shows up clearly as a small area of depressed contours northwest of shotpoint 1. It appears to be part of a somewhat larger basement block near the surface as indicated by the region of low contour values between the northwest segments of the Superstition Hills and Superstition Mountain faults. Northwest of Superstition Mountain, a very steep gradient, resulting in a jump of up to 0.7 $s$ in traveltime, appears to trend east to northeast from near the end of the Coyote Creek fault. This feature roughly parallels the northwest boundary of the Superstition Hills. Steep contour gradients are also observed along the Elsinore fault system. The northeast trend of contours in the area to the west of shotpoint 1 suggests basement structures at right angles to the San Jacinto and Elsinore fault systems. One such structure was noted by Kovach and others (1962).

Closer examination of the map reveals some subtle features. The "ridge" in the center of the trough is indented by "valleys" and "saddles" that trend northeast. These features are perpendicular to the major faults and have linear dimensions exceeding $15 \mathrm{~km}$ in some cases. They correlate with four of the major geothermal resource areas in the Imperial Valley. The geothermal areas plotted in fig. 10 include all those in the Imperial Valley listed in Renner and others (1975) and Brook and others (1978) with indicated subsurface temperatures above $150^{\circ} \mathrm{C}$. 
The Salton Sea and Westmorland geothermal areas (S, W, fig. 10) are associated with the strongest of the features on the map, a "saddle" with a relief of up to $0.3 \mathrm{~s}$. These areas also have the largest estimated heat reservoirs (Brook and others, 1975). The Heber area (H, fig. 10), with the next largest heat reservoir, is associated with a "valley" that also has a relief of about $0.3 \mathrm{~s}$. The Brawley and East Mesa areas (B, EM, fig. 10), with the smallest heat reservoirs, are the weakest features, "saddles" having a relief of $0.1 \mathrm{~s}$, which is barely resolvable given the reading error. Note the apparent connection between the East Mesa and Heber areas, as well as the apparent right-lateral offset between these areas across the Imperial fault. 
A GRAVITY MODEL ACROSS THE IMPERIAL VALLEY REGION

The velocity structure derived from lines 1NW, 1E, and $2 W$ has been used to constrain a gravity model across the Imperial Valley region. This model supercedes previous ones (Kovach and others, 1962; Biehler and others, 1964; Plawman, 1978) in that it includes a high density subbasement $(3.1 \mathrm{~g} / \mathrm{cc})$ beneath the region.

A gravity profile across southernmost California taken from Oliver and others (in press) shows that the central Imperial Valley is characterized by a slightly negative Bouguer anomaly of -30 to -40 mgal, the Chocolate Mountains by an anomaly of $-50 \mathrm{mgal}$, and the Peninsular Ranges (west of fig. 1) by an anomaly of up to $-90 \mathrm{mgal}$ ( $\mathrm{fig}$. 11a). Therefore the Imperial Valley, despite its thick sediments, is a slight gravity high relative to the regions which flank it. Previous gravity models across the valley have explained the lack of a strong negative anomaly by a mantle upwelling whose high density compensates for the light sediments. We here present a model in which the subbasement compensates for the light sediments.

In constructing the gravity model (fig. 11b), compressional wave velocities were converted to densities using the relationships summarized by Hamilton (1978) and Batemen and Eaton (1967) and layers with differences in $P$-wave velocity of less than $0.5 \mathrm{~km} / \mathrm{s}$ were assigned the same density. For example, the crustal structure of western Arizona consists of "layers" with velocities of $5.8,6.1$, and $6.3 \mathrm{~km} / \mathrm{s}$ (Warren, 1969; Keller, personal communication, 1980). The average of these crustal velocities is $6.1 \mathrm{~km} / \mathrm{s}$ and the entire crustal section has been assigned a density of $2.75 \mathrm{~g} / \mathrm{cc}$. The complex gravity field over the California Borderland has not been modeled in detail because this is outside the region of present concern; the interested reader is referred to Plawman (1978) for a detailed model of that region.

The gravity calculation presumes a two-dimensional structure and a standard mass column of $70 \mathrm{~km}$ with a zero Bouguer gravity anomaly of 9255 mgal (Baraday, 1974; Whitsett, 1975). Iterative adjustments of layer boundaries, constrained by surface geology and seismic refraction data were made until the computed gravity agreed with the observed Bouguer gravity.

It is evident from the computed gravity model (fig. 11b) that the subbasement $(3.1 \mathrm{~g} / \mathrm{cc})$ compensates gravitationally for both the valley sediments $(2.3$ and $2.55 \mathrm{~g} / \mathrm{cc}$ ) and the low density basement $(2.65 \mathrm{~g} / \mathrm{cc})$. Furthermore, it is of particular note that the scarp in the basement under shotpoint 1 (distance $0 \mathrm{~km}$ in fig. 11) is mirrored in both the subbasement and mantle. Also note that the negative anomalies over the Chocolate Mountains and Peninsular Ranges require that the subbasement deepen and (or) pinch out in those directions. 
Mantle is modeled at an average depth of $23 \mathrm{~km}$ beneath the Imperial Valley, the same depth as is reported for western Arizona from seismic refraction measurements (Warren, 1969; Keller, personal communication, 1980). Because of the uncertainties inherent in any gravity model, the depth to mantle needs to be confirmed by seismic refraction measurements. 


\section{SUMMARY}

A combination of new instrumentation and improved methods of analysis have enabled us to conduct a extensive and detailed seismic refraction survey of the Imperial Valley region, California. The use of 100 cassette-tape-recorded seismometers that can be programed to turn on at prearranged shot times, deployed rapidly, and played back in the field enabled us to cover an extensive area in the Imperial Valley region with dense lines and arrays of instruments recording shots in numerous places. In addition, with the ability to produce digital record sections in the field, we could modify the survey as it progressed. In all, more than 1300 recording locations were occupled and more than 3000 usable seismograms obtained. With the adaptation of a standard method of ray-tracing to Interactive computing, numerous models could be quickly tested for traveltime consistency with the data. Not only first arrivals but, importantly, multiple refractions were used to constrain the model. In addition, this method of interactive ray tracing enabled us to use amplitudes in a qualitative way (and, with some modification, in a quantitative way; Mooney and McMechan, in press) to further constrain the models. Our models are not unique but are largely consistent with one another where profiles cross.

Models are developed for four profiles that cross the Imperial Valley and bordering mesas at several angles. (A model is developed for a fifth profile along the axis of the Salton trough by Mooney and McMechan, in press). All models have in common a sedimentary section (modeled in one to three parts), a transition zone, a basement, and a subbasement.

Sediment velocity appears to increase with depth without discontinuities but with changes in gradient. Velocity-depth curves in the sediments differ somewhat from place to place, but one can classify them. Referring to fig. 8, they can be grouped as follows:

1) Velocity curves from the platforms along the border of the Salton Trough (East and West Mesas) are typifled by the curve labeled -1 , although these curves change considerably from place to place. On this curve the velocity ranges from $1.7 \mathrm{~km} / \mathrm{s}$ at the surface to $2.4 \mathrm{~km} / \mathrm{s}$ at the base of the sediments $(1.4 \mathrm{~km}$ deep) with a low gradient of 0.5 $\mathrm{km} / \mathrm{s} / \mathrm{km}$.

2) Velocity curves from the deepest parts of the trough, including those labeled 53, 25, and 15, show velocity gradients that are nearly linear at $0.67 \mathrm{~km} / \mathrm{s} / \mathrm{km}$ from a velocity of $1.8 \mathrm{~km} / \mathrm{s}$ at the surface to about $5 \mathrm{~km} / \mathrm{s}$ at the base, over $4.5 \mathrm{~km}$ deep.

3) Velocity curves in intermediate regions include those labeled 1 , 17,43 , and 0 . On these curves the velocity increases from $1.8 \mathrm{~km} / \mathrm{s}$ at the surface to about $5 \mathrm{~km} / \mathrm{s}$ at the base, which varies in depth from place to place. The velocity gradient is generally lower in the upper kilometer or so of sediments $(0.4$ to $0.7 \mathrm{~km} / \mathrm{s} / \mathrm{km})$ and steeper in lower sections $(0.7$ to $1.8 \mathrm{~km} / \mathrm{s} / \mathrm{km})$.

The velocity curve $2.5 \mathrm{~km}$ east of shotpoint 1 (labeled 2.5 ) is the only 
one that does not fall into one of these categories; it apparently reflects a structural complication. Velocity contours generally dip toward the center of the valley.

Along the axis of the trough, sediment thickness ranges from about 4.8 $\mathrm{km}$ at the U.S.-Mexican border to $3.7 \mathrm{~km}$ along the southwest shore of the Salton Sea with an overall plunge along the axis of about $0.8^{\circ}$ southeast (Mooney and McMechan, in press). Across the trough between Brawley and El Centro, sediment thickness undergoes more or less abrupt changes from an average of around $1.4 \mathrm{~km}$ on West Mesa to $4.5 \mathrm{~km}$ in the center of the valley to around $3 \mathrm{~km}$ on East Mesa. The changes in thickness occur at buried scarps located at or near the shore lines of ancient Lake Cahuilla, which separate the Imperial Valley from the mesas.

In the Imperial Valley the smooth continuity of the traveltime curves from low apparent velocities (less than $5 \mathrm{~km} / \mathrm{s}$ ) to higher ones $(5.55 \mathrm{~km} / \mathrm{s}$ to $5.80 \mathrm{~km} / \mathrm{s}$ ) is modeled by a transition zone generally $1 \mathrm{~km}$ thick in which velocity increases from that at the base of the sediments, about 5 $\mathrm{km} / \mathrm{s}$, to an upper basement velocity of $5.65 \mathrm{~km} / \mathrm{s}$ in most places. In most places, the velocity gradient in this zone decreases slightly from that in the sediments above. On West Mesa and in other places where the sediments thin to less than about $2.5 \mathrm{~km}$, a prominent velocity discontinuity is present at the top of this zone.

Basement has a velocity of $5.65 \mathrm{~km} / \mathrm{s}$ in most places in the Imperial Valley, based on several reversed profiles, but on West Mesa it has a velocity of $5.92-6.00 \mathrm{~km} / \mathrm{s}$ based on a reversed profile segment and a time-term study by Hamilton (1970).

No evidence of velocity anisotropy has been found among the five profiles analyzed. Azimuths sampled in the central valley, however, range only from $80^{\circ}$ to $130^{\circ}$; northerly and northeasterly azimuths have not yet been sampled. Because of structural complications on profiles crossing the valley, it is probably not possible to distinguish a difference of less than $0.2 \mathrm{~km} / \mathrm{s}$ in basement velocity, representing a change of 3.5 percent.

Basement velocity gradients may differ between the central valley and West Mesa areas. In the central valley, the velocity gradient is low, around $0.04 \mathrm{~km} / \mathrm{s} / \mathrm{km}$; a velocity of $5.85-5.95 \mathrm{~km} / \mathrm{s}$ is attained in the lower basement at depths ranging from 10 to $16 \mathrm{~km}$. Southwest of the Imperial fault and on West Mesa, there is weak evidence for a higher gradient of around $0.1 \mathrm{~km} / \mathrm{s} / \mathrm{km}$, corresponding to a lower-basement velocity of $6.6 \mathrm{~km} / \mathrm{s}$ at $12.5 \mathrm{~km}$.

Several structures are seen which affect the basement and transitionzone boundaries as well as deeper velocity contours in the sediments.

1) A scarp is present along the Imperial fault from at least $12 \mathrm{~km}$ southeast of El Centro to about $9 \mathrm{~km}$ north-northeast of El Centro. Its height apparently decreases from about $1 \mathrm{~km}$ at the southeast end to 
less than $0.5 \mathrm{~km}$ at the northwest end. A dip on the fault of about $70^{\circ}$ north-east fits data at the southeast end and $78^{\circ}$ fits data at the north-west end; uncertainty in dip is estimated to be less than $10^{\circ}$. No scarp was detected across the fault where it splays out southwest of Brawley. A decrease in velocity for waves passing through the fault zone was needed in the model for IESE and would probably have improved the fit in model for 6NW-1SE-1NW.

2) An anomalous bump in the velocity contours in the lower sediments $10 \mathrm{~km}$ north of Brawley correlates spacially with the Brawley seismic zone of Johnson (1979).

3) A large scarp beneath shotpoint 1 is required because of the drastic difference in inferred depth to basement east and west of the shotpoint. The precise height, shape, and location of this scarp is more uncertain than most features in the models. Scarp height appears to increase from $1 \mathrm{~km}$, southeast of shot point 1 , to $3.5 \mathrm{~km}$, east and northeast of shotpoint 1. Southeast of the shotpoint, the scarp appears to be part of a north-south trending bench on basement and transition-zone rocks which does not correlate with any structure mappable at the surface. East and northeast of the shotpoint, the scarp may be associated with the Superstition Mountain fault.

4) There are no conspicuous scarps in the models along other mapped faults, although the Brawley, Sand Hills, and Algodones faults appear to correlate with changes in slope on basement and transition-zone rocks.

Evidence for a subbasement is seen on all profiles longer than about $40 \mathrm{~km}$. Strong to weak secondary arrivals at distances beginning between 25 and $40 \mathrm{~km}$ followed by cross-overs at between 40 and $55 \mathrm{~km}$ to branches having apparent velocities of 7.2 to $8.5 \mathrm{~km} / \mathrm{s}$ indicate the presence of a subbasement at depths ranging from 10 to over $15 \mathrm{~km}$. This layer can be modeled by a velocity step from a velocity between 5.85 and $6.6 \mathrm{~km} / \mathrm{s}$, that of lower basement, to a velocity between 6.6 and $7.0 \mathrm{~km} / \mathrm{s}$. Below this step is a $1-\mathrm{km}$-thick zone in which velocity increases rapidly to 7.2 $\mathrm{km} / \mathrm{s}$. Such a model is consistent with an interpretation by Hamilton (1970) of a $14 \mathrm{~km}$ depth to a $7.1 \mathrm{~km} / \mathrm{s}$ subbasement in the Borrego ValleyWest Mesa area. Plotting only the best-determined depths to subbasement to obtain a rough picture of its topography, one sees a dome between Brawley and El Centro, where the top of the dome is situated at a depth of about $11 \mathrm{~km}$. This dome has a relief on its south side of about $1 \mathrm{~km}$, an amount barely resolvable, and on its north side of about $5 \mathrm{~km}$. Gravity indicates a sharp step downward of the subbasement on the west side and a more gradual deepening to the east. Thus the vicinity of the convergence of the Imperial, Brawley, Superstition Hills, and Superstition Mountain faults appears to be subbasement high.

A contour map of reduced traveltime from shotpoint 1 is roughly equivalent to a sediment isopach map, where greater reduced travel time correlates with greater sediment thickness. This map is difficult to interpret quantitatively, however, because of structural complexity beneath shotpoint 1. Qualitatively it reveals some intriguing features. The map mirrors the surficial topography, in that a "ridge" of high reduced traveltime corresponds to the Imperial Valley, and a "valley" of 
low reduced traveltime correponds to West Mesa. The "ridge" reflects a sedimentary trough whose axis coincides roughly with the seismogenic belt in the Imperial Valley. A steep gradient in the contours separates the "ridge" from the "valley". This steep gradient has a roughly north-south trend south of shotpoint 1 and is interpreted to correspond to a buried scarp with this trend. North of shotpoint 1 this gradient appears deflected successively along the Superstition Mountain and Superstition Hills faults, probably reflecting buried scarps along those faults. Steep gradients are also associated with the Coyote Creek fault and the northwest margin of the Superstition Hills and with the Elsinore fault.

Small "valleys" and "saddles" indent the "ridge" in northeast directions, with relief up to $0.3 \mathrm{~s}$ and linear dimensions up to $15 \mathrm{~km}$. These features correlate accurately with five of the six geothermal areas in the Imperial Valley having indicated reservoir temperatures exceeding $150^{\circ} \mathrm{C}$. The strongest features correlate with areas having the largest estimated heat reservoirs. The traveltime map shows an apparent connection between the Salton and Westmorland areas and between the Heber and East Mesa areas. The latter two appear to be right-laterally offset across the Imperial fault.

Using the new velocity structure for the Imperial Valley region to constrain a gravity model, we discover that a) gravitational compensation for the sediments is accomplished largely by the subbasement (lower crust), with a model density of $3.1 \mathrm{~g} / \mathrm{cc}, \mathrm{b})$ the relatively flat gravity profile across the Salton Trough requires that the upper surface of this subbasement largely mirror the contact between sediments and basement, and c) the negative gravity anomalies over the Peninsular Ranges and Chocolate Mountains require that the subbasement deepen and (or) pinch out in those directions.

The reader is referred to Fuis and others (in press) for petrologic and tectonic implications of the models developed here. 
ACKNOWLEDGMENTS

We estimate that data collection, analysis, and writing of this paper consumed over 10 man-years of effort since the beginning of 1979 . About half of this effort was expended by persons other than the authors of this paper. Thus, we wish to express our indebtedness to $S$. $K$. Gallanthine, L. R. Hoffman, Barry Keller, J. N. Roloff, and V. C. Sutton, who, together with $W$. J. Lutter, one of the authors, deployed the instruments; to W. M. Kohler and L. E. Leone, who digitized the data and kept the field computers and plotters running; to D. E. Taylor who permitted the shotpoints; to Bruce Echols and $S$. S. Wegener who managed the drilling and loading of shot holes; to R. D. Jones, Harry Tostado, and D. L. Styles, who drilled many of the shotholes; to P. T. German and Victor Lamanuzzi, who assisted with the surveying of instrument sites; to R. M. Kaderabek and Robert McClearn, who kept the instruments running; to V. Barba and Elsie Hirscher, who typed the manuscript; and to K. B. Berg, N. C. Crossley, Herbert Mills, and J. R. Van Schaack who provided administrative assistance. In addition, a number of persons facilitated this survey in various ways. Land owners who permitted us to drill and shoot on their properties include R. E. Casey and Hendell Finley (shotpoint 81/) and John Elmore (shotpoint 10). Permission to drill and shoot on government land was granted or expedited by Lieutenant Commander W. F. Ellis of the U.S. National Parachute Test Range (shotpoints 1 and 13), S. L. Johnson of the U.S. Bureau of Land Management (shotpoints 2, 3-, $5,6,7)$, and several persons at the U.S. Department of Interior Fish and Wildife Service (shotpoint 4 I). Clifford Brown, of the U.S. Department of Agriculture graciously allowed us to use the building at their Brawley facility for our field headquarters. Senior Chief C. W. Franklin at the U.S. National Parachute Test Facility kindly permitted us to store explosives at the facility. James Cantrell of the Southern Pacific Railroad Company held up trains for one of our shots. In addition, we wish to express our appreciation to the many people, public and private, of Imperial County who helped us in countless ways.

This paper was improved by many discussions with D. P. Hill and P. A. Spudich. V. Červený kindly provided the ray-tracing code used. $R$. L. Nowack provided an interactive version of the code. 
REFERENCES CITED

Baraday, R. J., 1974, Structure of the Panama Basin from marine gravity data: M. S. thesis, Oregon State University, Corvallis, 99 p.

Bateman, P. C., and Eaton, J. P., 1967, Sierra Nevada Batholith: Science, v. 158 , p. 1407-1417.

Berry, M. J., and West, G. F., 1966, An interpretation of the first arrival data of the Lake Superior experiment by the time-term method: Seismological Society of America Bulletin, v. 56, p. 141-171.

Biehler, Shawn, Kovach, R. L., and Allen, C. R., 1964, Geophysical framework of northern end of Gulf of California structural province, in van Andel, T. H., and Shor, G. G., Jr., eds., Marine geology of the Gulf of California: American Association of Petroleum Geologists, Memoir 3, p. 126-143.

Blank, H. R., Healy, J. H., Roller, John, Lamson, Ralph, Fisher, Fred, McClearn, Robert, and Allen, Steve, 1979, Seismic refraction profile, Kingdom of Saudi Arabia, field operations, instrumentation, and initial results: U.S. Geological Survey Saudi Arabian Mission, Project Report 259, 49 p.

Brook, C. A., Mariner, R. H., Mabey, D. R., Swanson, J. R., Guffanti, Marianne, and Muffler, L. J. P., 1978, Hydrothermal convection systems with reservoir temperatures $\geq 90^{\circ} \mathrm{C}$, in Muffler, L. J. P., ed., Assessment of geothermal resources of the U.S.--1978: U.S. Geological Survey Circular 790, p. 18-85.

Červený, Vlastilav, Molotkov, I. A., and Pšenčík, Ivan, 1977, Ray methods in seismology: Prague, Karlova University, $214 \mathrm{p}$.

Fuis, G.S., Mooney, W.D., Healy, J.H., McMechan, G.A., and Lutter, W.J., Crustal structure of the Imperial Valley region, in The Imperial Valley earthquake of October 15, 1979: U.S. Geological Survey Professional Paper (in press).

Hamilton, E. L., 1978, Sound velocity-density relations in sea-floor sediments and rocks: Journal of the Acoustical Society of America, v. 63 , no. 2 , p. 366-377.

Hamilton, R. M., 1970, Time-term analysis of explosion data from the vicinity of the Borrego Mountain, California, earthquake of 9 April, 1968: Seismological Society of America Bulletin, v. 60, p. 367-381.

Johnson, C. E., 1979, I. Cedar--an approach to the computer automation of short-period local networks II. Seismotectonics of the Imperial Valley of southern California: Ph.D. thesis, California Institute of Technology, Pasadena, 332 p.

Johnson, C. E., and Hutton, L. K., The 15 October 1979 earthquake: a study of aftershocks and prior seismicity, in The Imperial Valley earthquake of October 15, 1979: U.S. Geological Survey Professional Paper (in press).

Kovach, R. L., Allen, C. R., and Press, Frank, 1962, Geophysical investigations in the Colorado delta region: Journal of Geophysical Research, v. 67, p. 2845-2871.

Mooney, W. D., and McMechan, G. A., Synthetic seismogram modeling for the laterally varying structure in the central Imperial Valley, in The Imperial Valley earthquake of October 15, 1979: U.S. Geological Survey Professional Paper (in press). 
Oliver, H. W., Chapman, R. H., Biehler, Shawn, Robbins, S. L., Hanna, W. F., Griscom, Andrew, Beyer, L., and Silver, E. A., Preliminary gravity map of California and its continental margin: California Division of Mines and Geology, scale 1:750,000 (in press).

Plawman, T. L., 1978, Crustal structure of the continental borderland and the adjacent portion of Baja California between latitudes $30^{\circ} \mathrm{N}$ and $33^{\circ} \mathrm{N}$ : M. S. thesis, Oregon State University, Corvallis, $72 \mathrm{p}$.

Renner, J. L., White, D. E., and Williams, D. L., 1975, Hydrothermal convection systems, in White, D.E., and Williams, D. L., eds., Assessment of geothermal resources of the U.S.--1975: U.S. Geological Survey Circular 726, p. 5-57.

Warren, D. H., 1969, A seismic-refraction survey of crustal structure in central Arizona: Geological Society of America Bulletin, v. 80, p. 257-282.

Wesson, R. L., 1970, A time integration method for computation of the intensities of seismic rays: Seismological Society of America Bulletin, v. 60, p. 307-316.

Whitsett, R. M., 1975, Gravity measurements and their structural implications for the continental margin of southern Peru: $M$. $S$. thesis, Oregon State University, Corvallis, $82 \mathrm{p}$. 
$\underline{\underline{z}}$

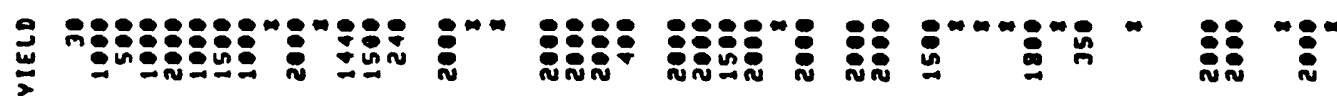

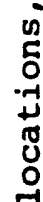

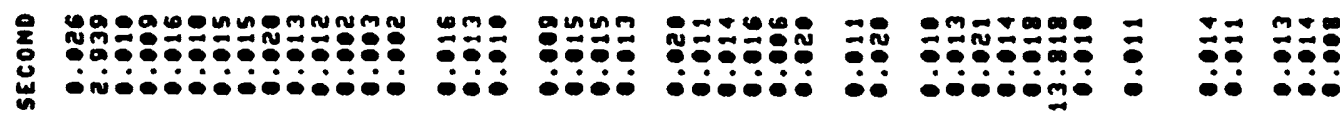

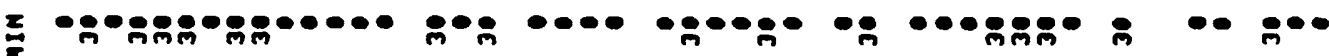

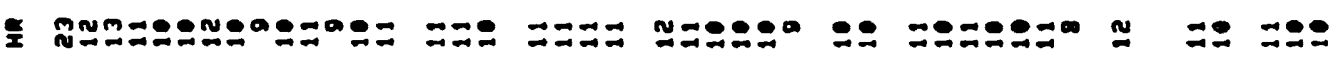

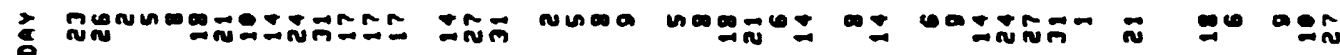

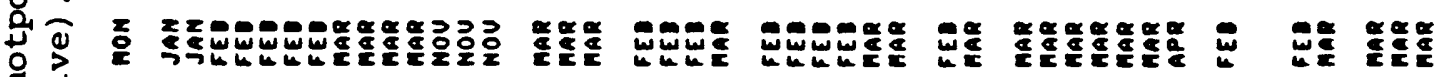
旨

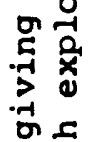

on $\frac{\text { c }}{6}$

i.

禹

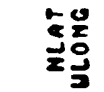

岁

I

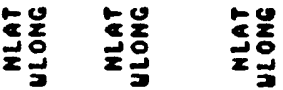

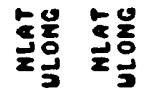

ஜ்

$\because$ : $: 9$

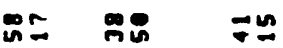

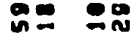

บี

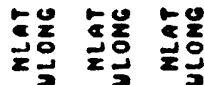

节虽 屵

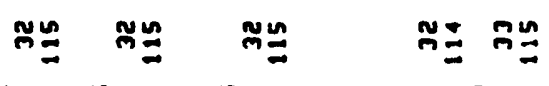

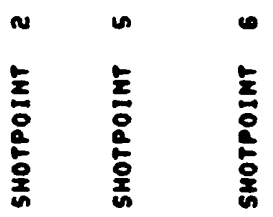

늘

טr.

iñ

宓 出 是

के

-

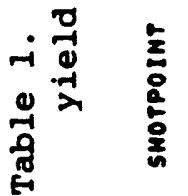

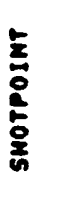

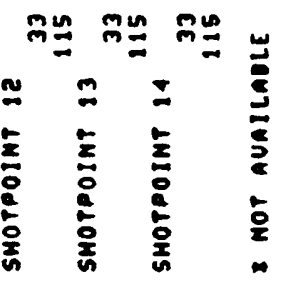




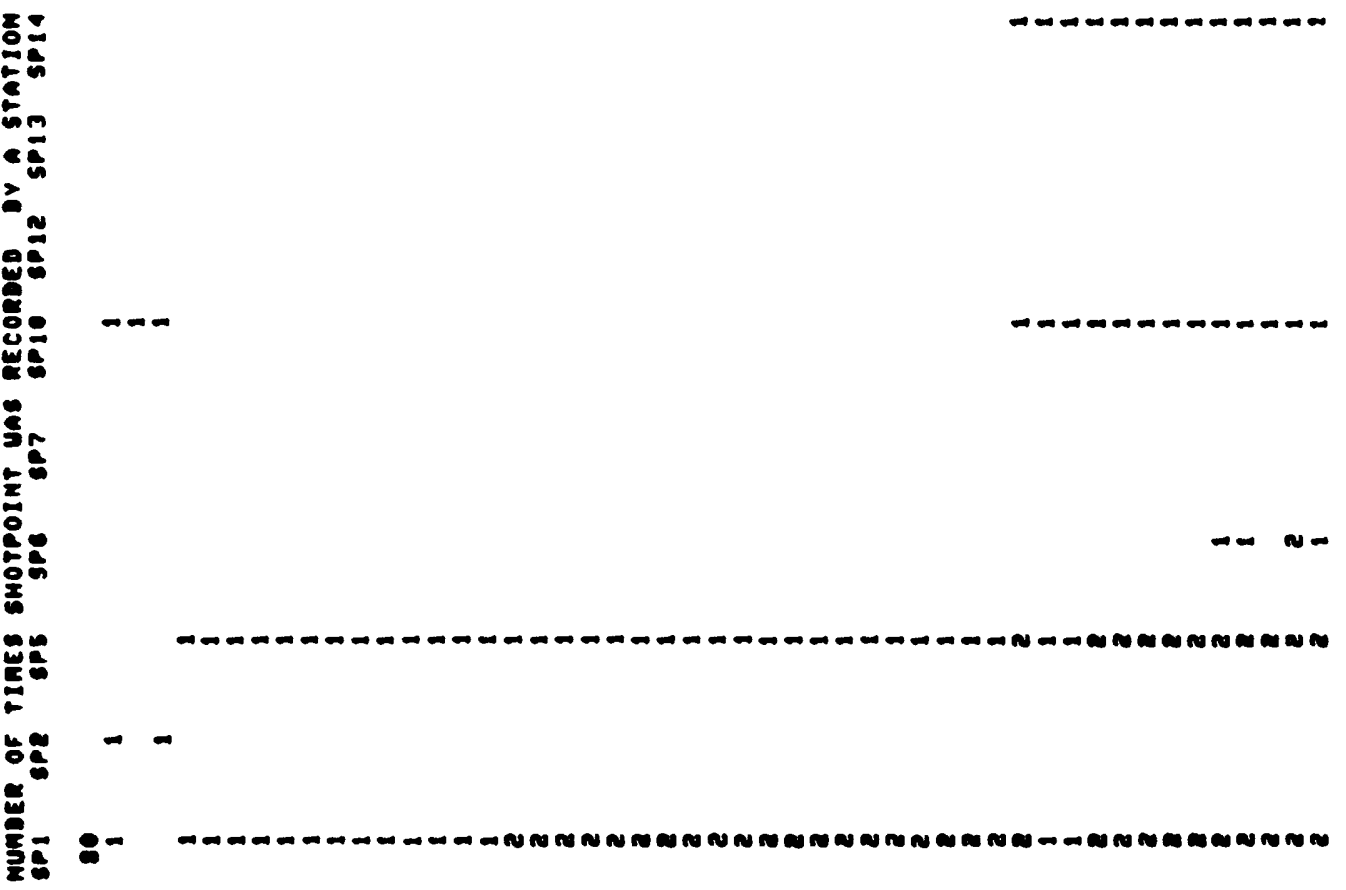

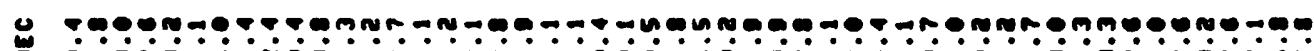

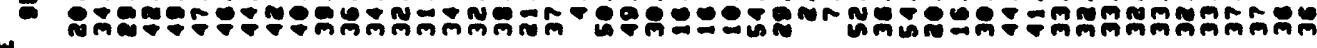
S:

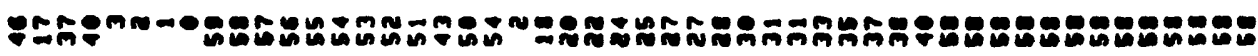

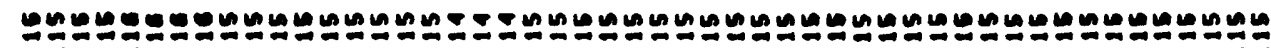

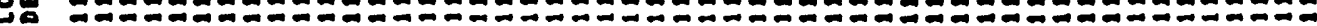

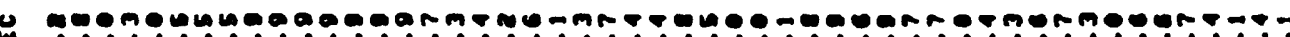

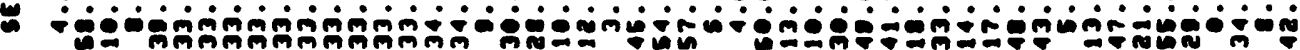

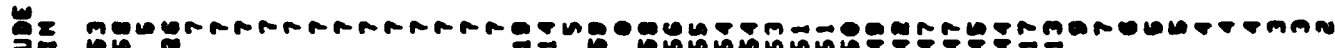
TE. แน

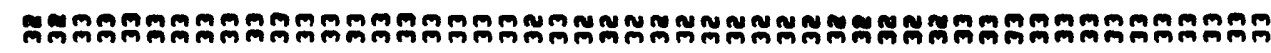

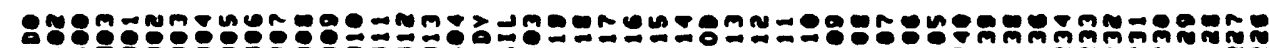

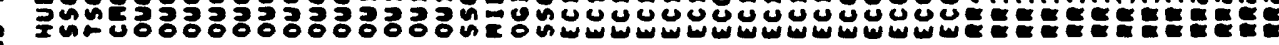
$\vec{w}$

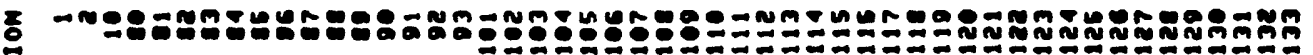




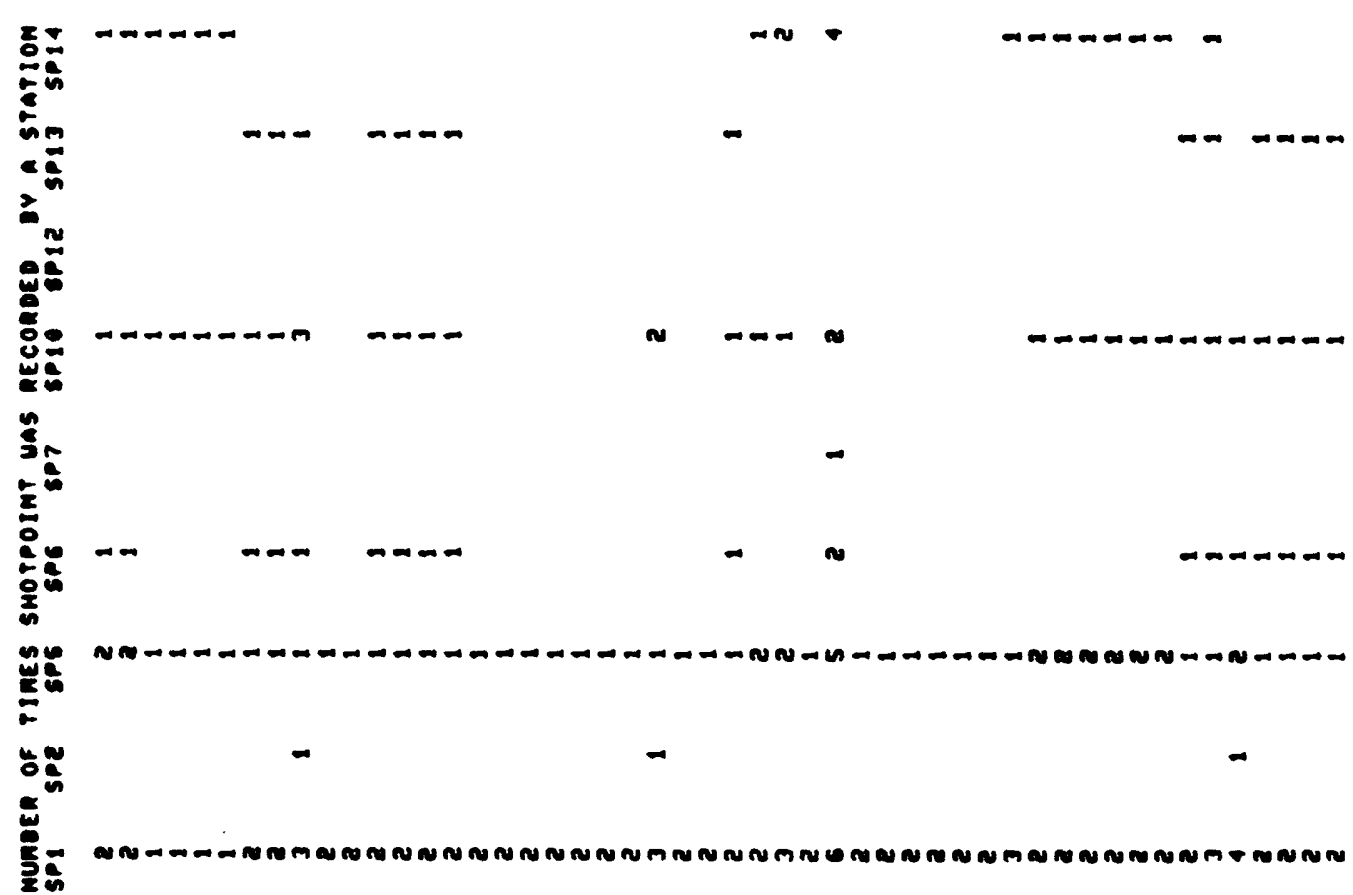

o

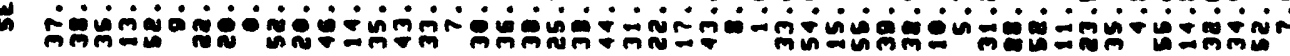
$\mathbf{8}$

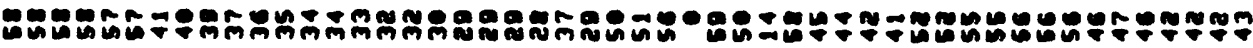

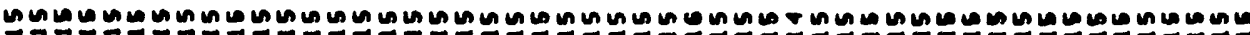

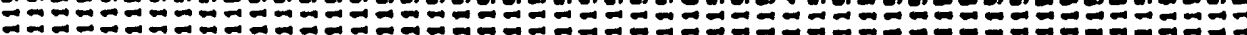

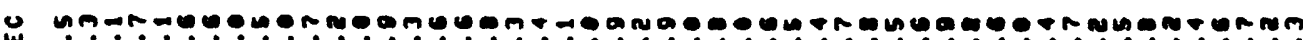

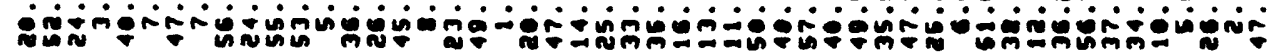

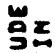

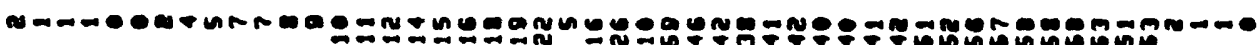
PE

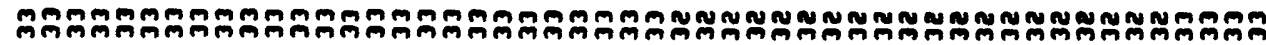

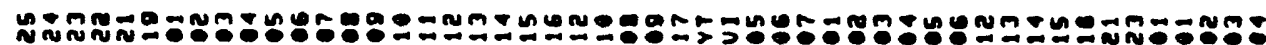

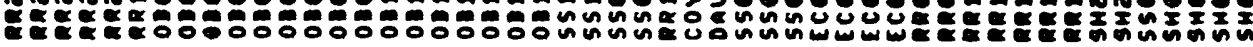




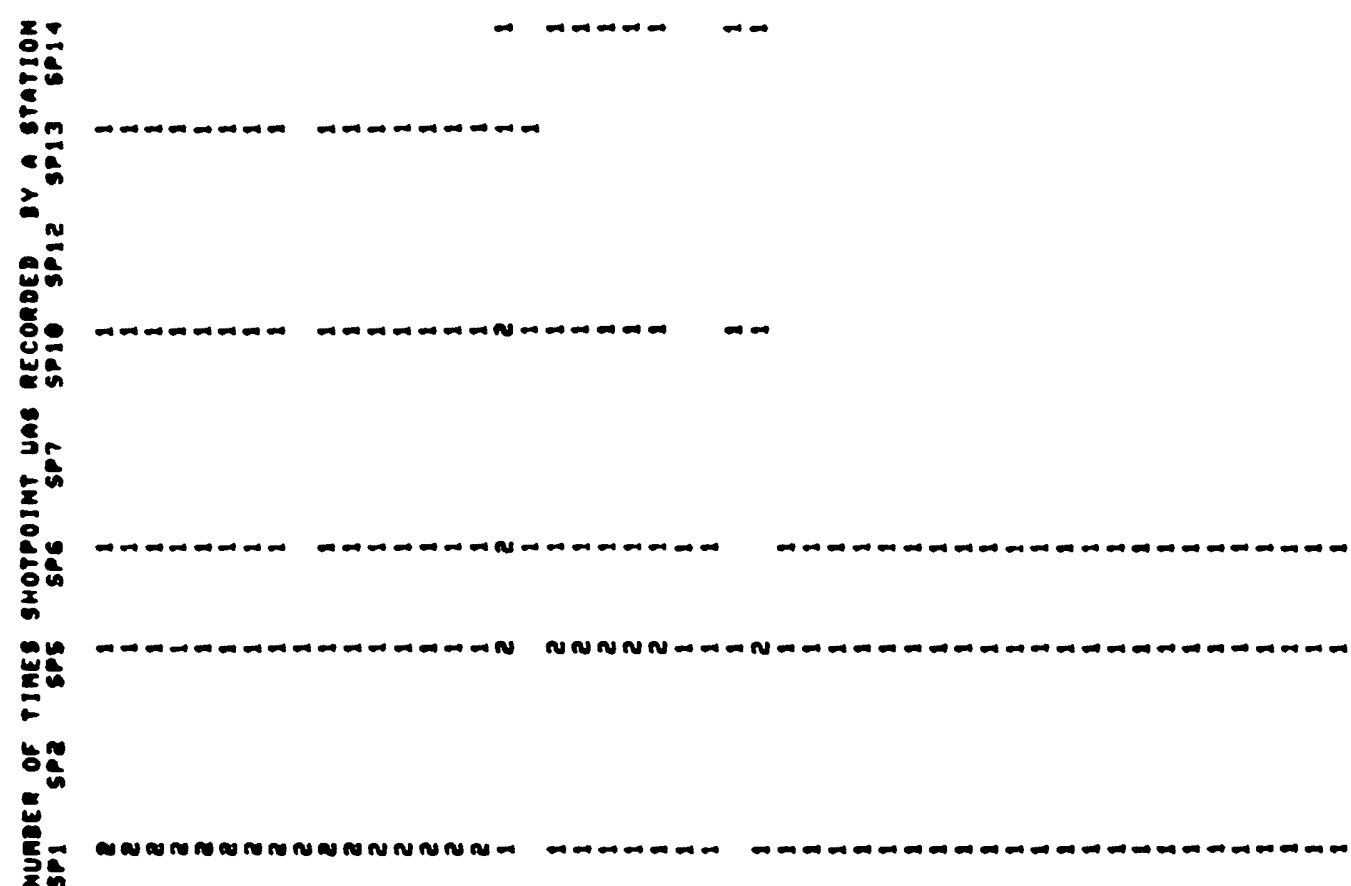

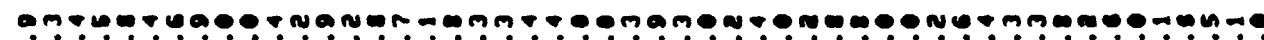

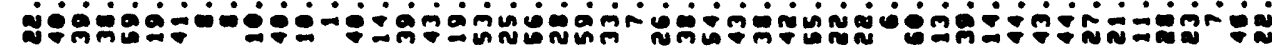
క్.

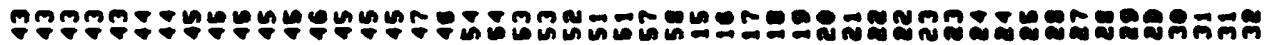

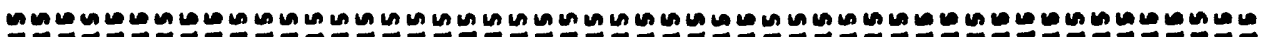

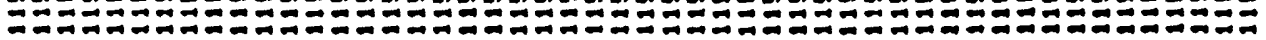

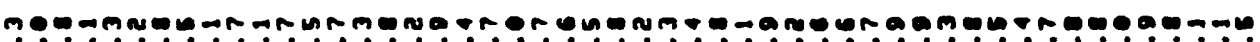

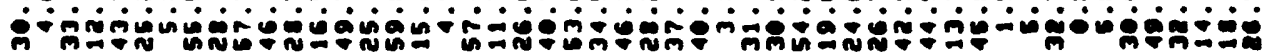

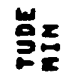

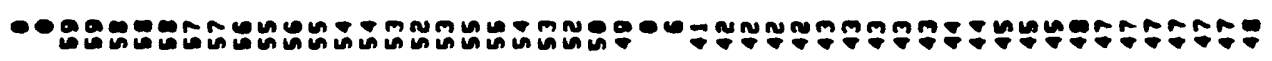
:

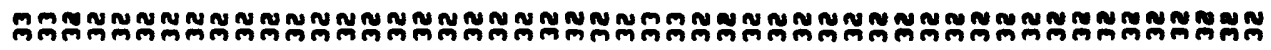

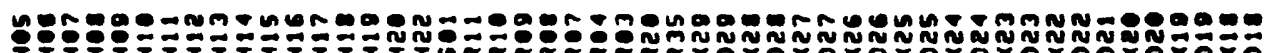

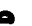

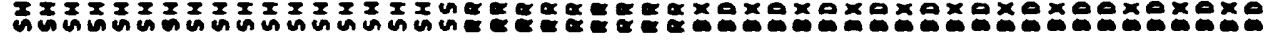

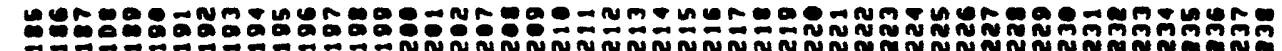
: 


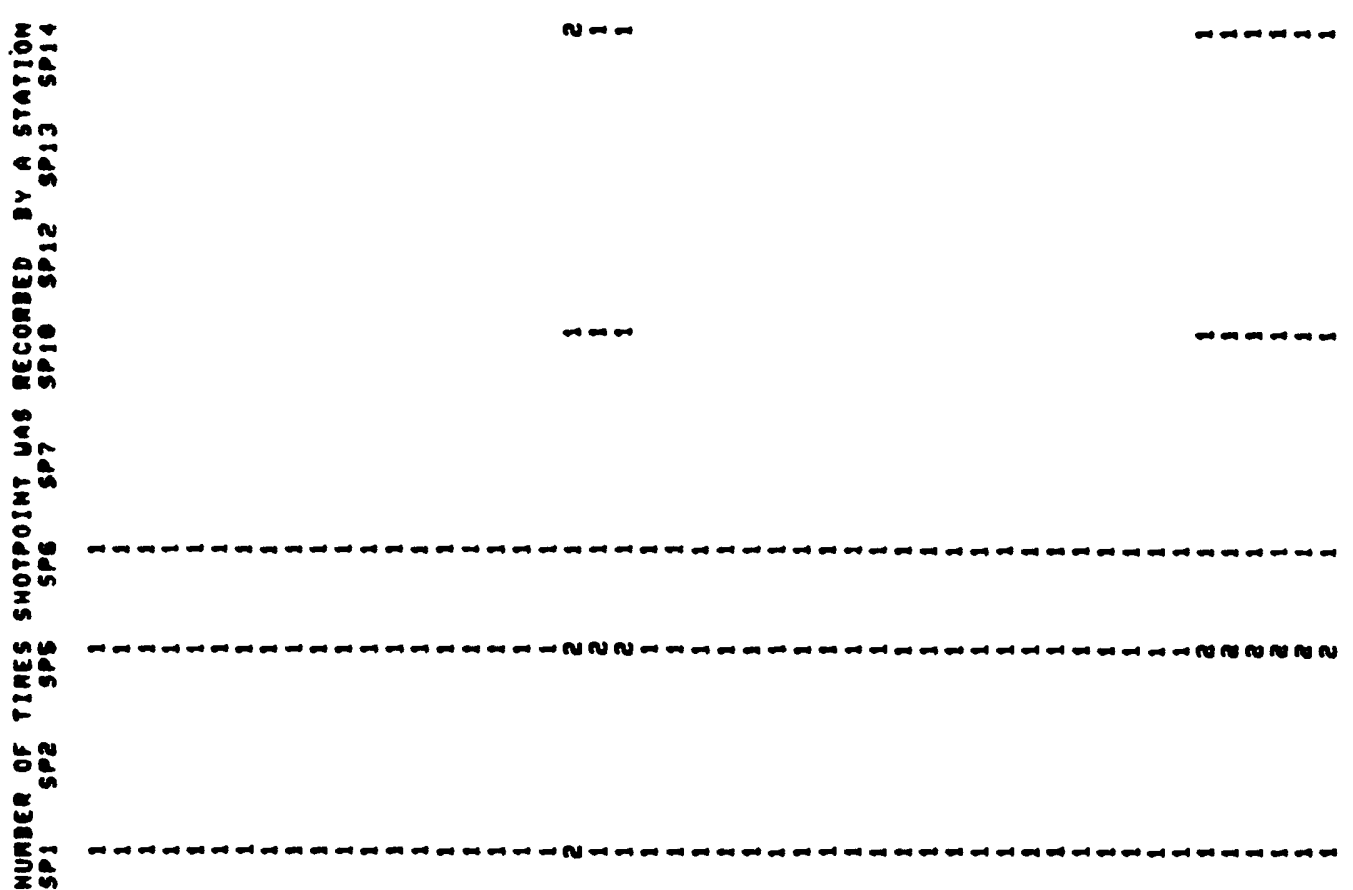

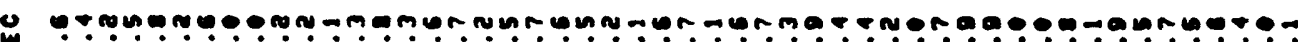

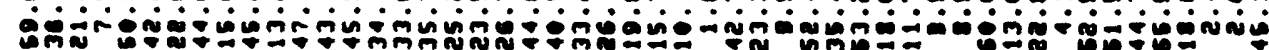

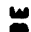

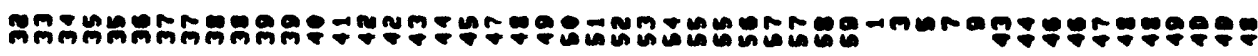

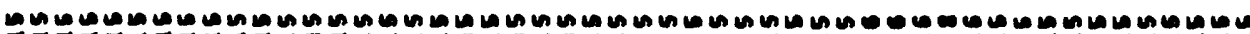

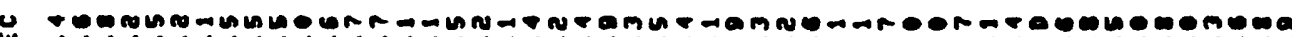

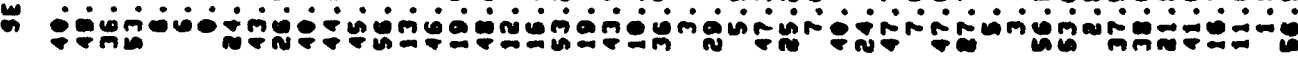
幽 $\sum^{2}$

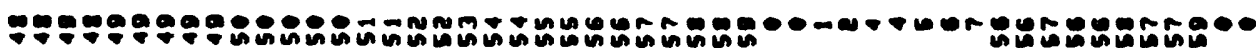

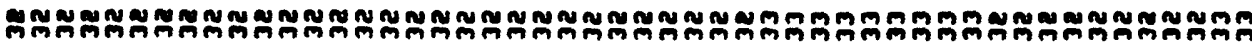

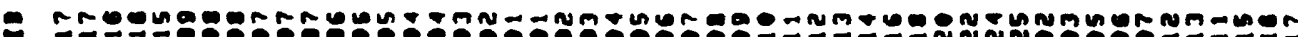

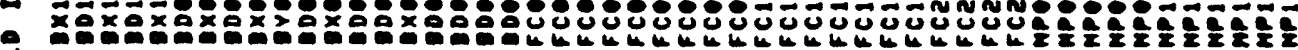

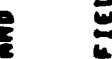

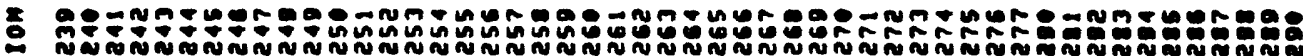
: 


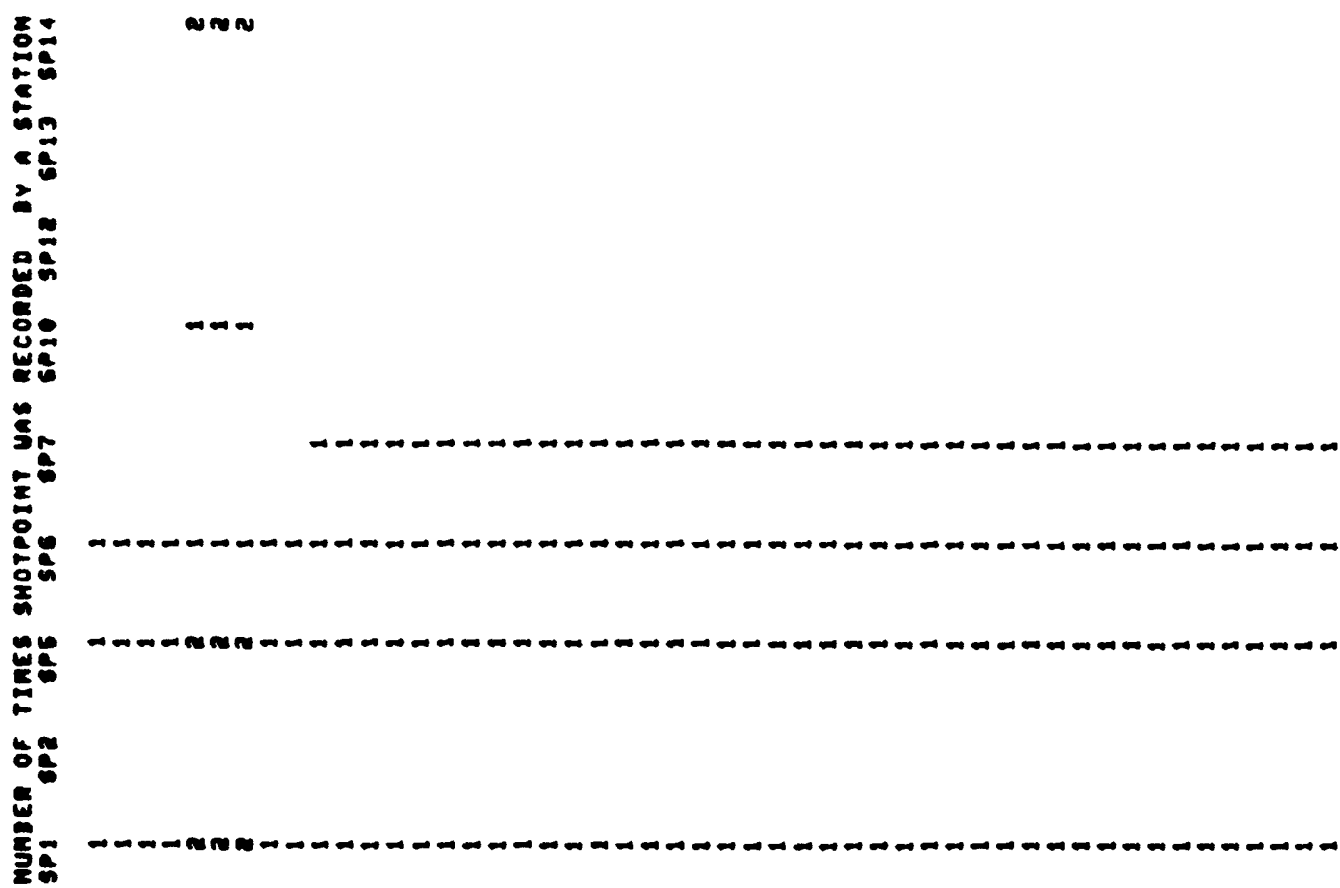

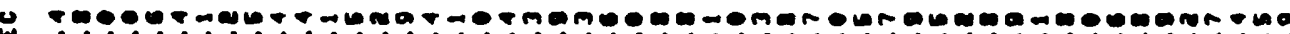
s. n்

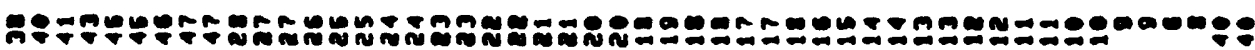

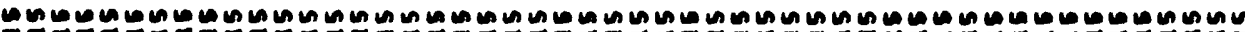

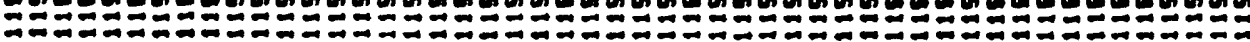

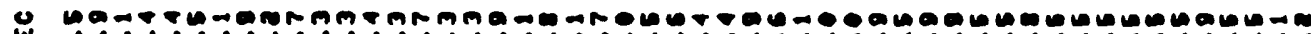

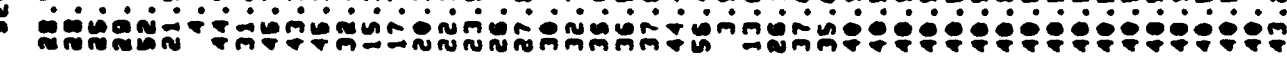
Mй́nー

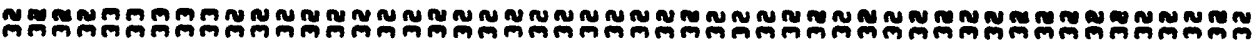

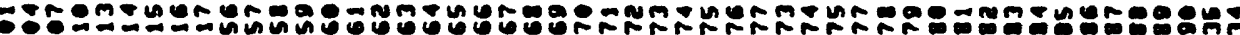

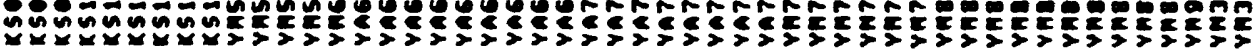

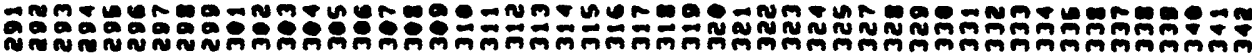


要

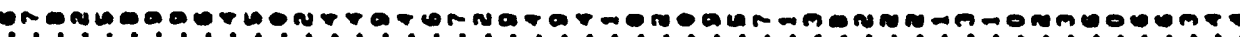

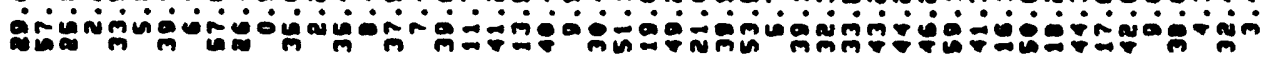

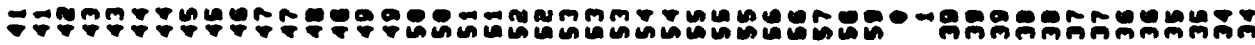

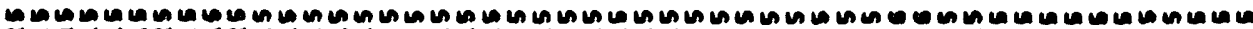

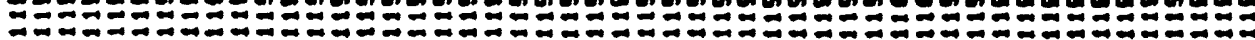
จำ

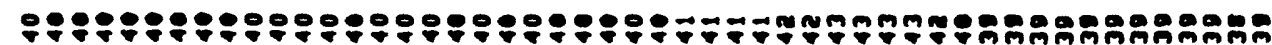

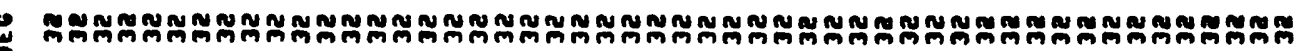

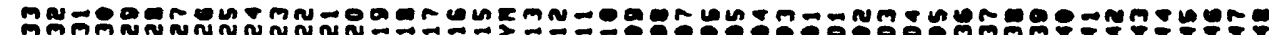

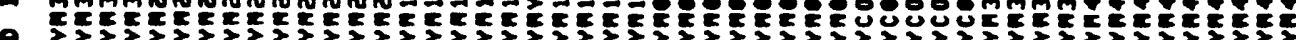
w.

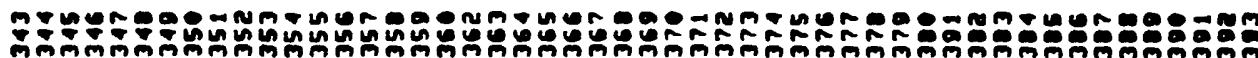




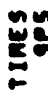

象

톨을

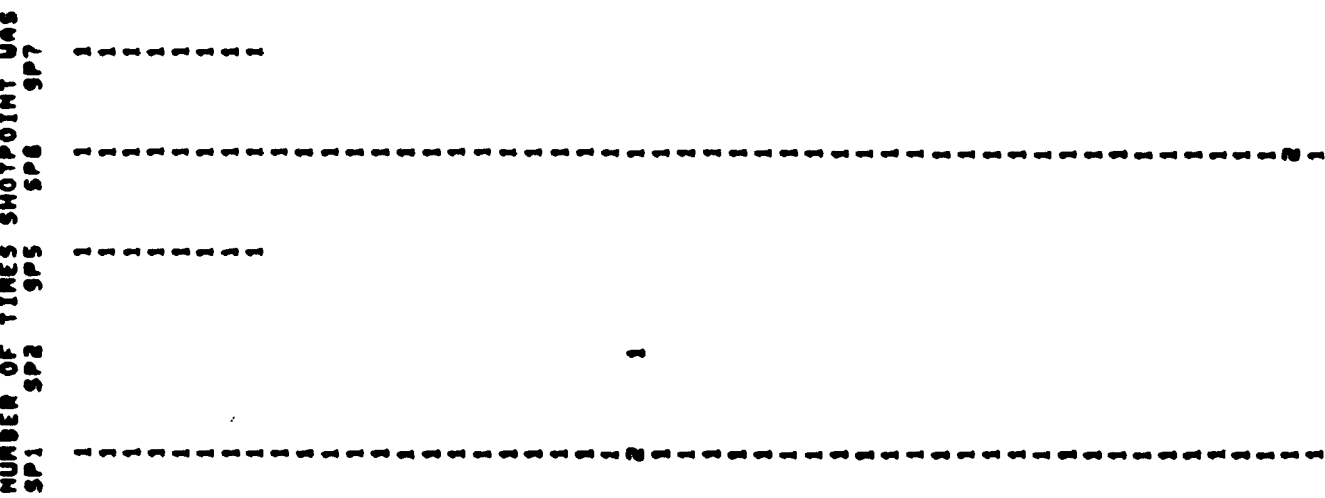

u Pmn

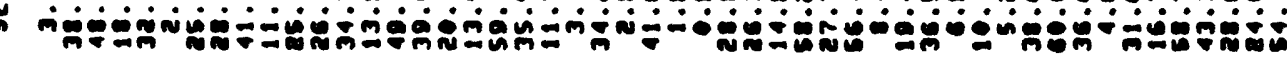
苛

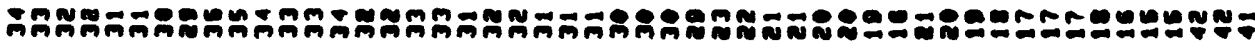

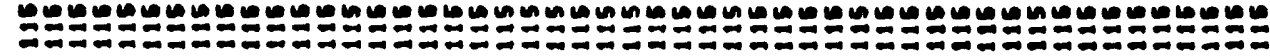

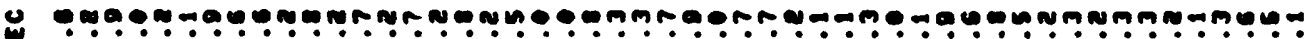

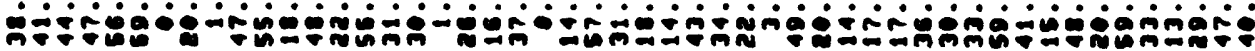

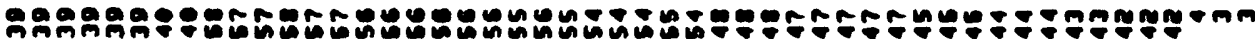
促

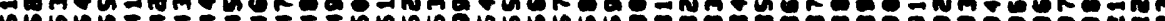

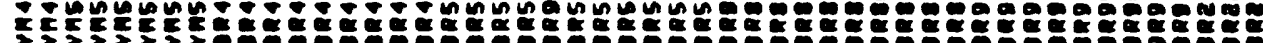

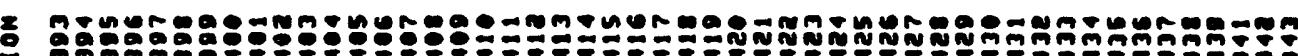
: 


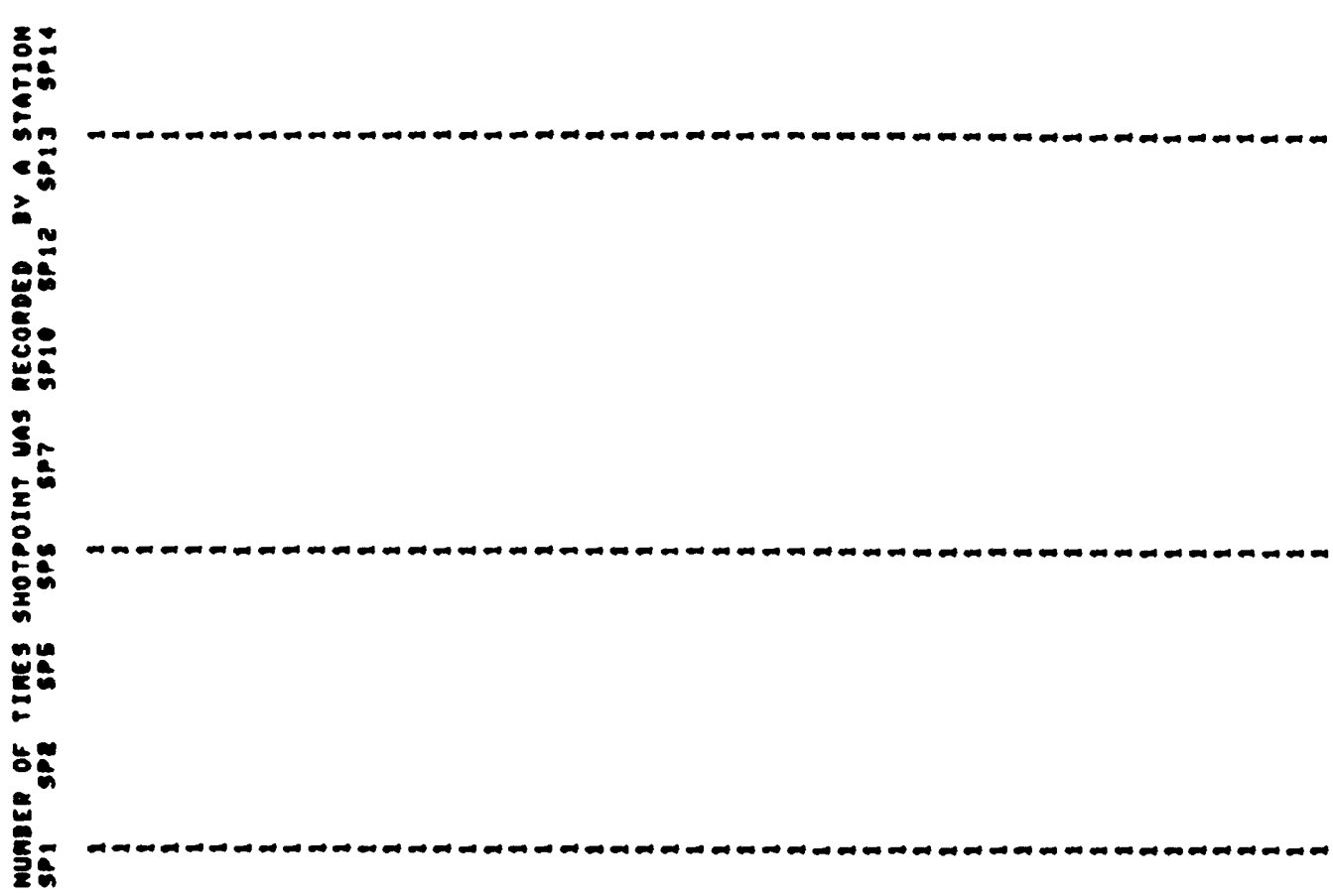

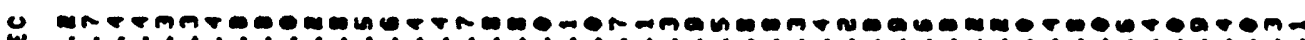

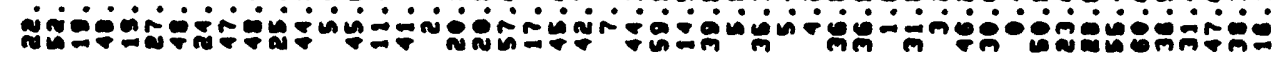
ڤั

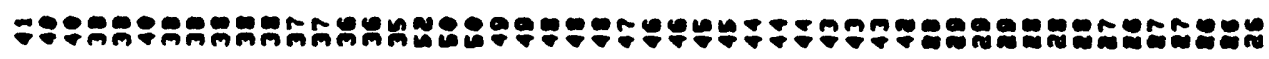

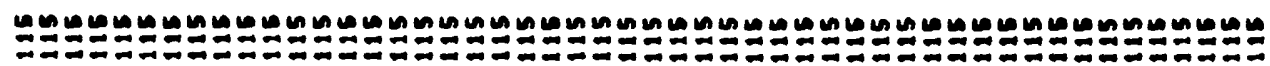

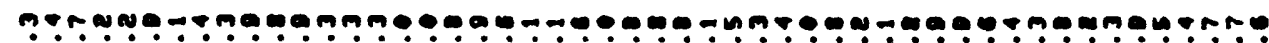

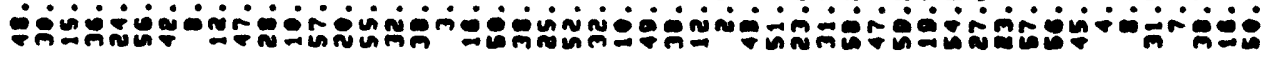

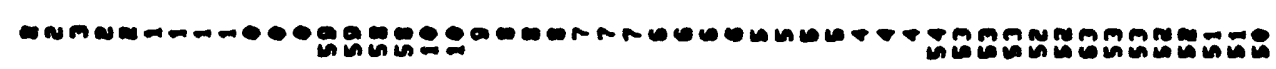

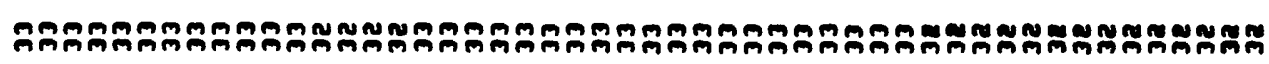

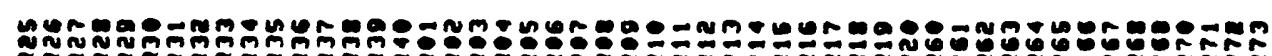

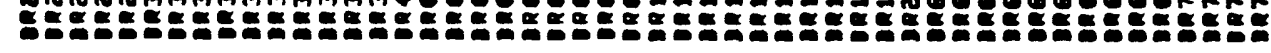
$\vec{w}$

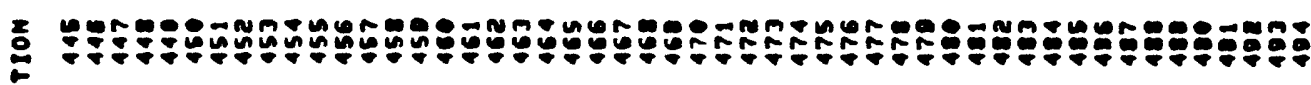
: 


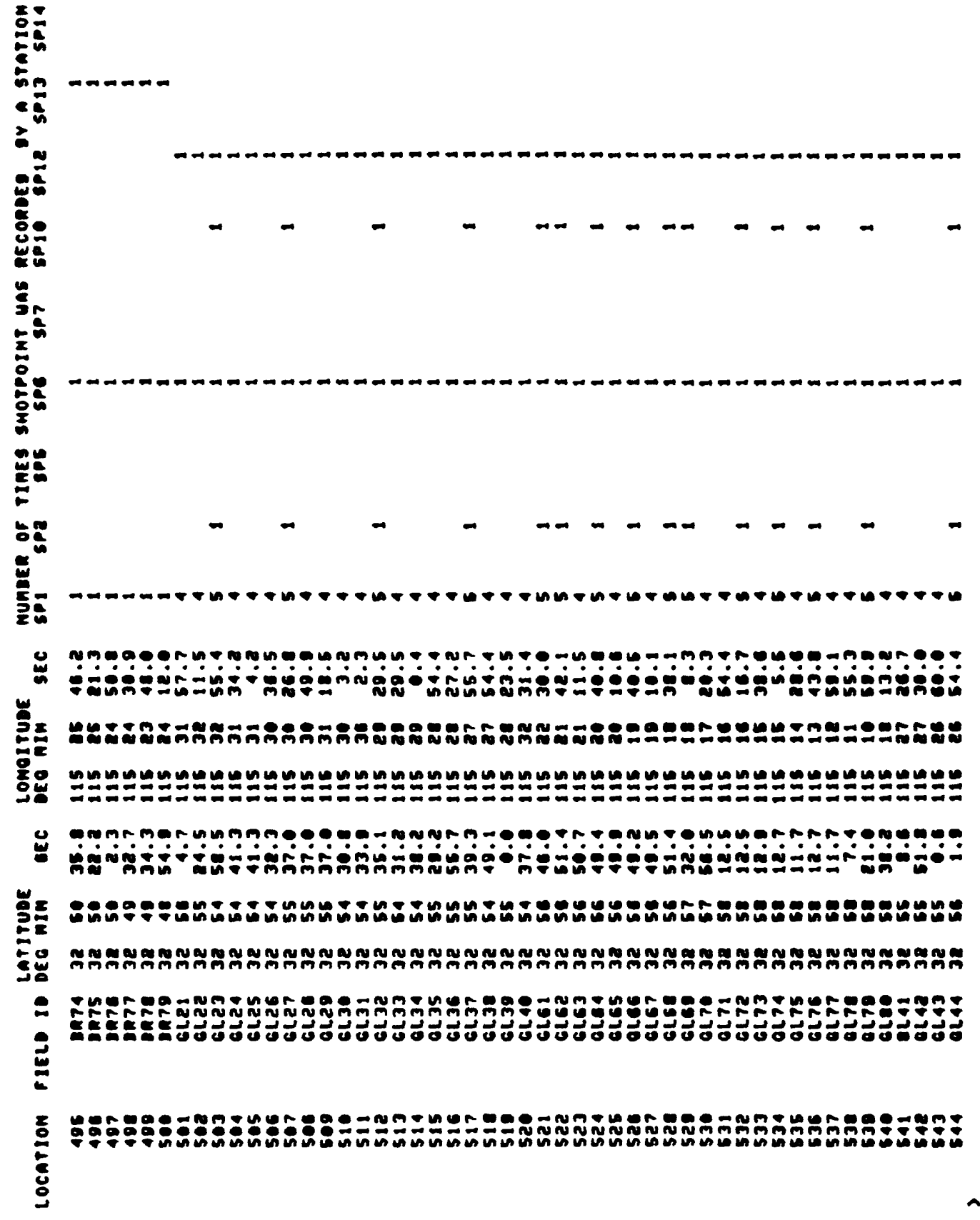


ด.

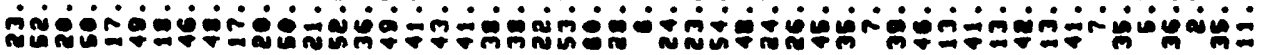

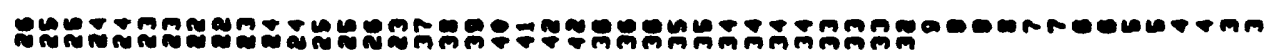

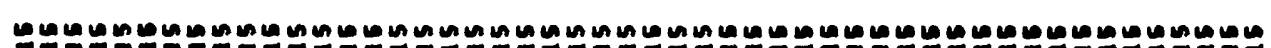

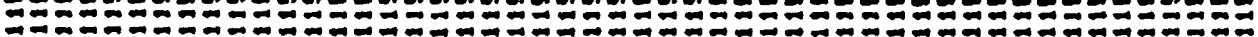

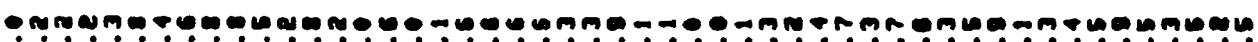

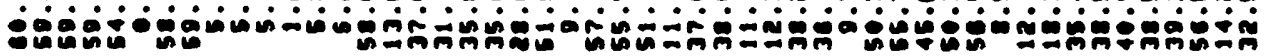

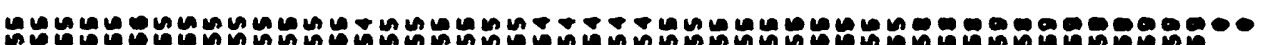

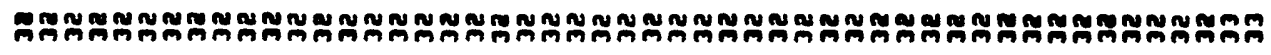

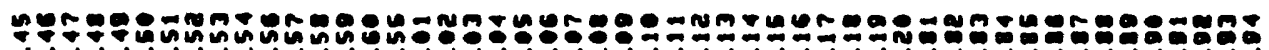

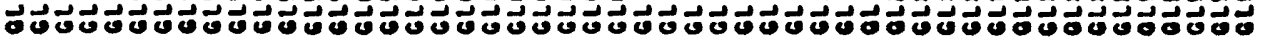

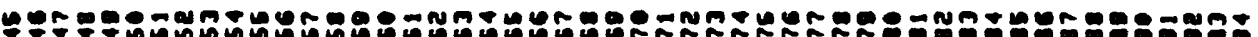
\& 


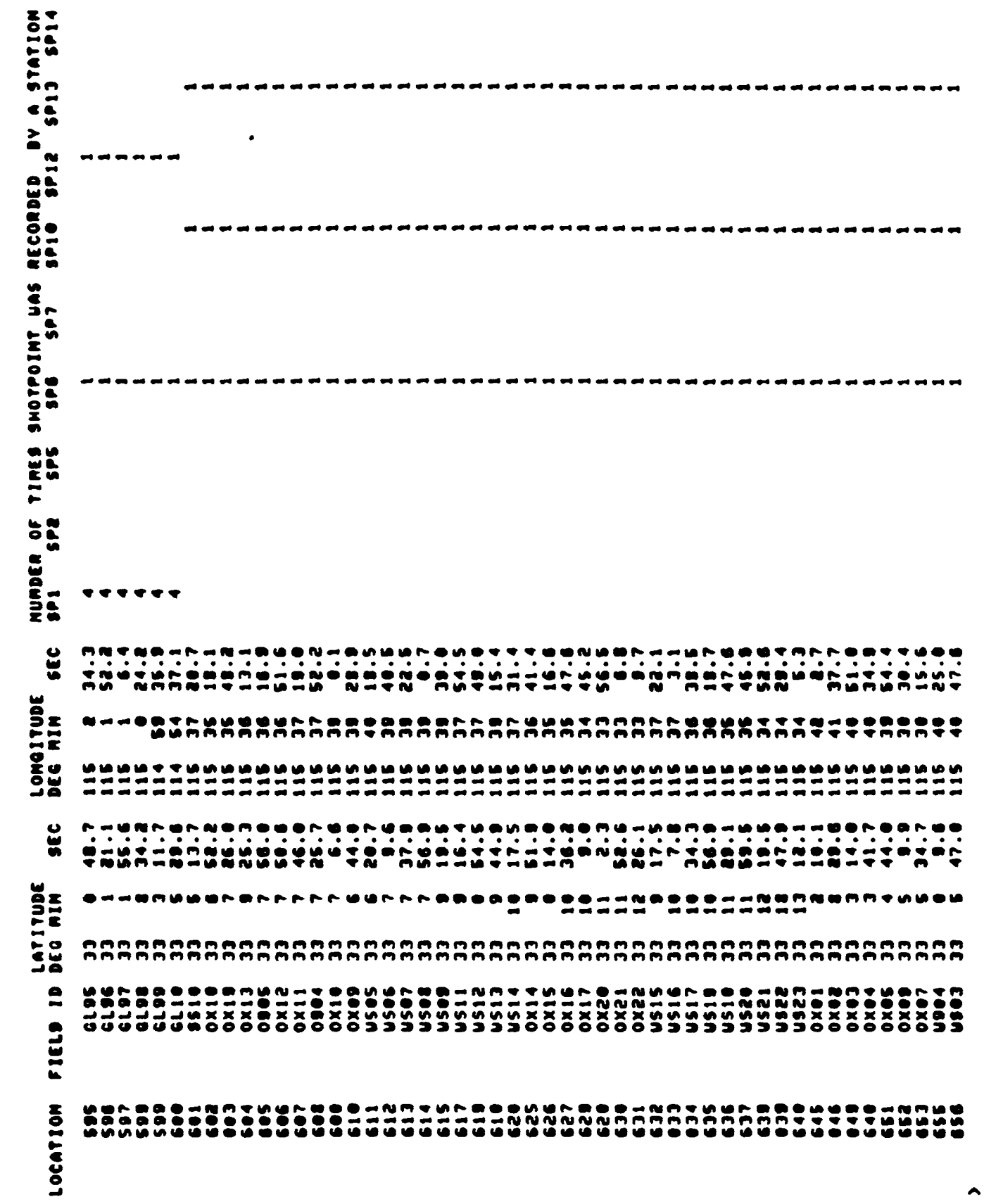




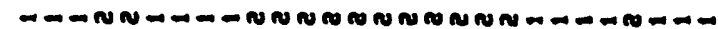

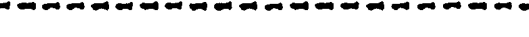

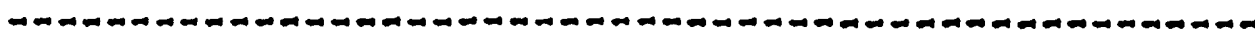

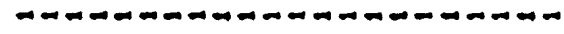

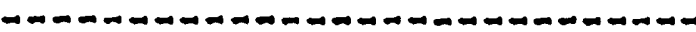

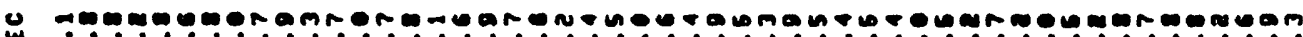

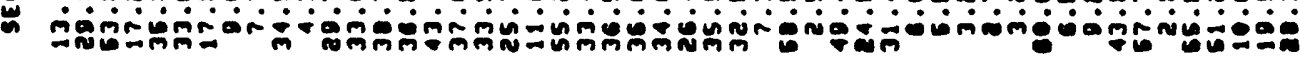
로을

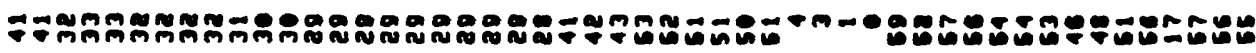

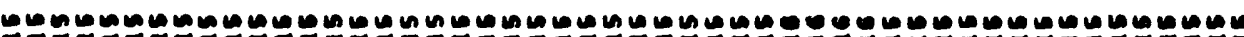

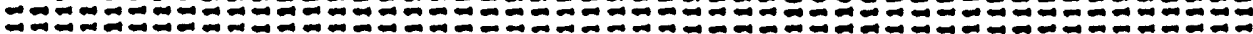

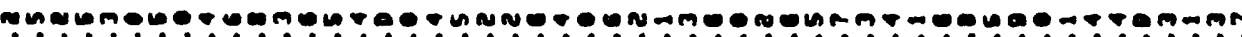

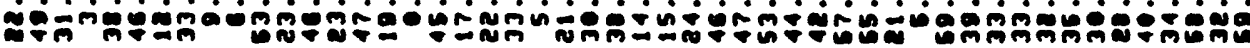

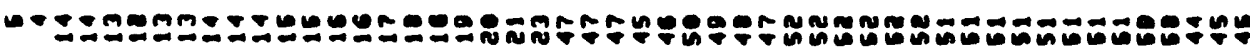

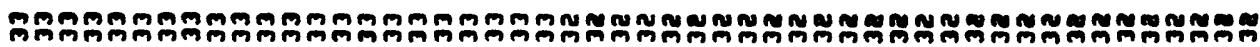

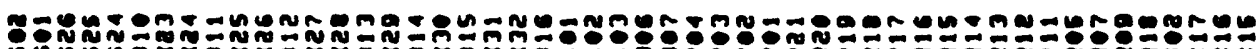

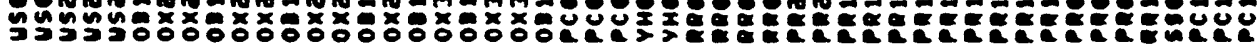

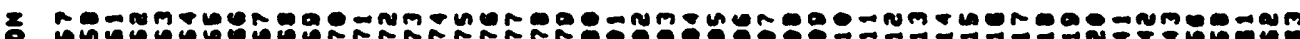

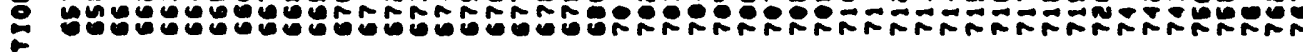




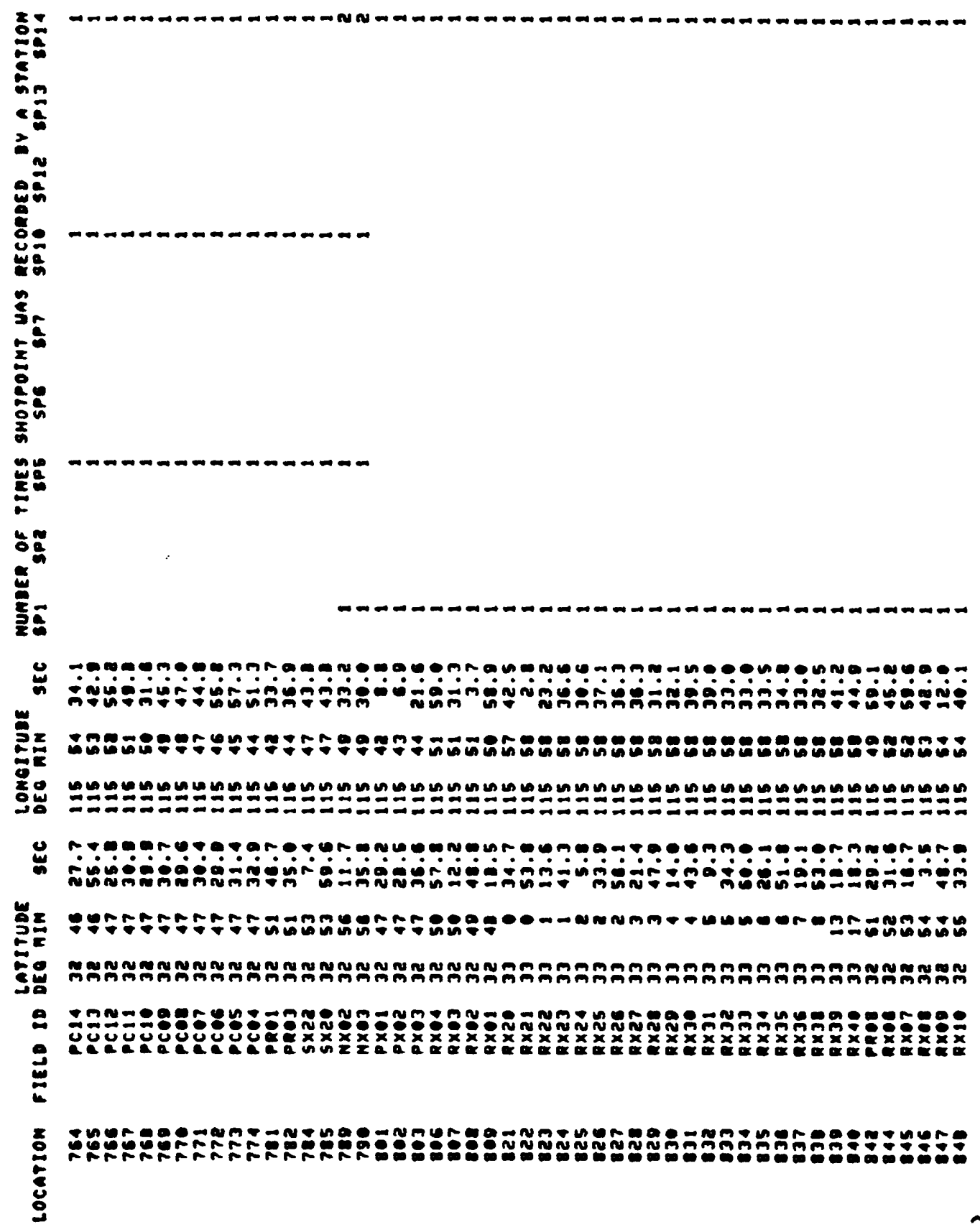




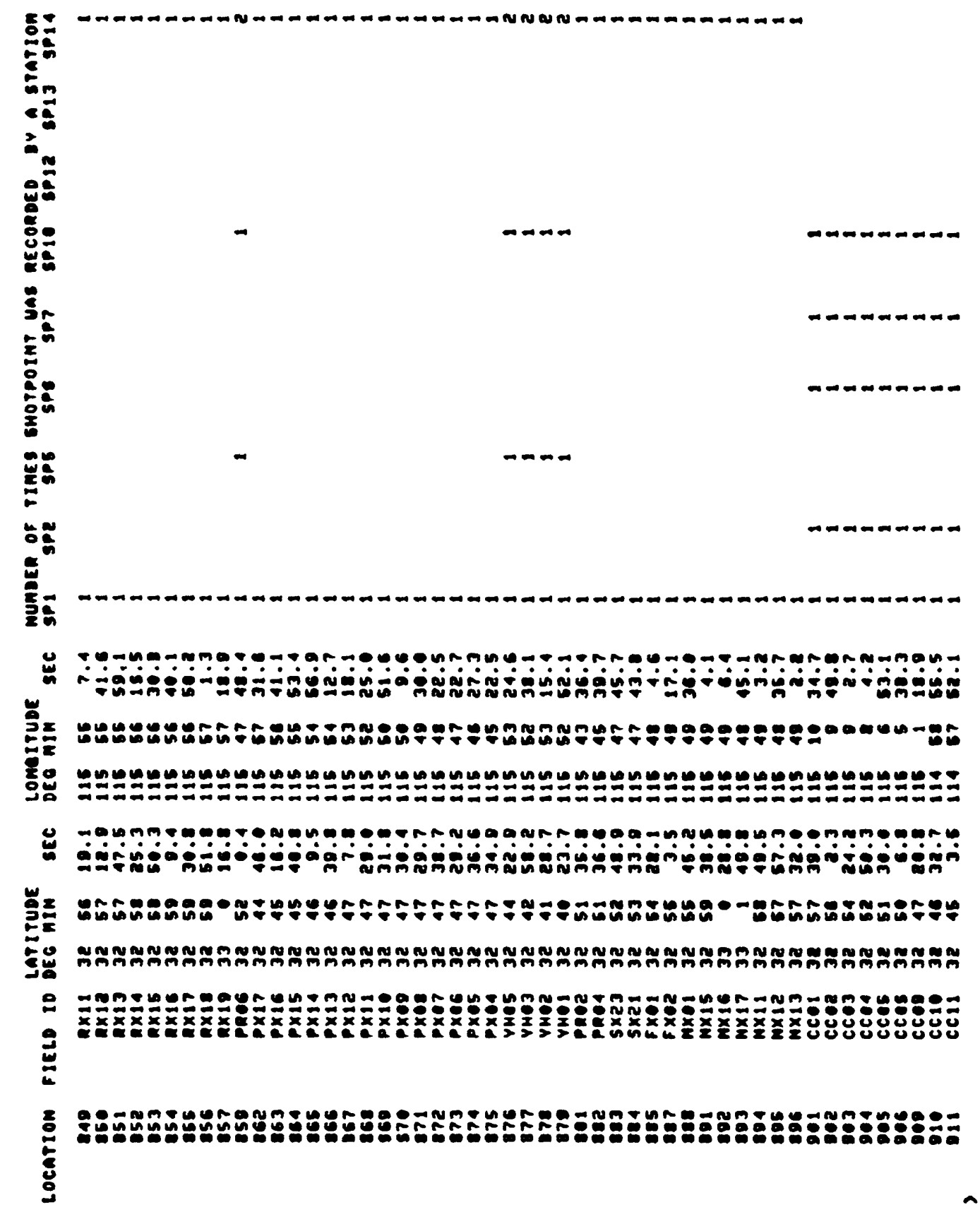


告

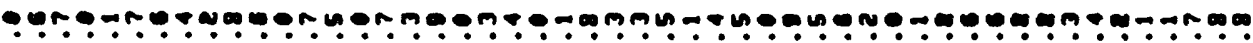
¿ 就

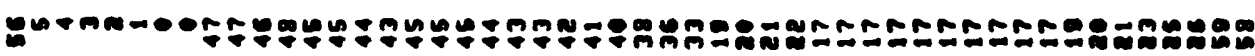

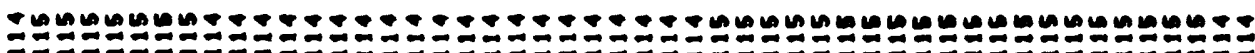

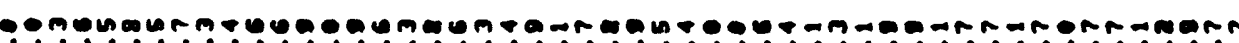

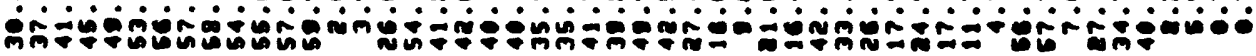

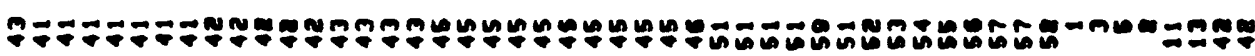

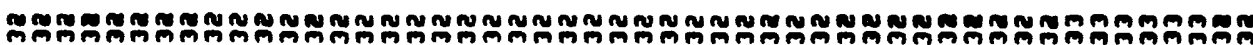

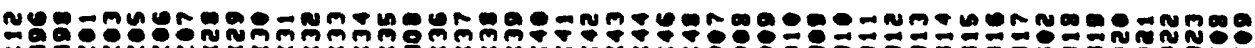

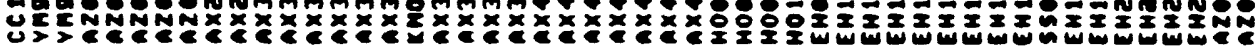

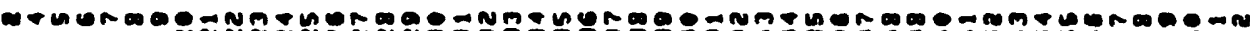

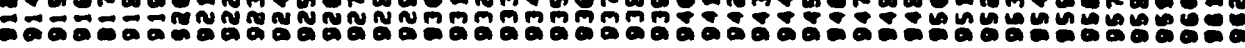




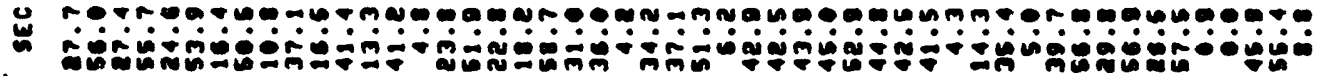

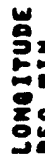

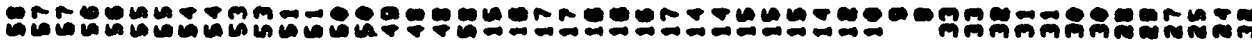

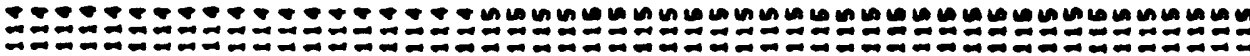

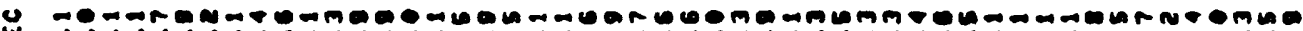

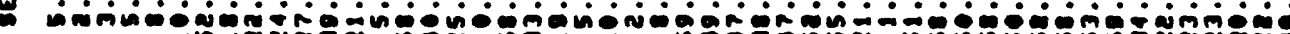

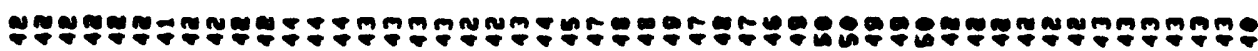

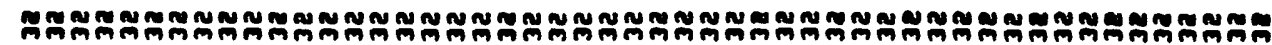

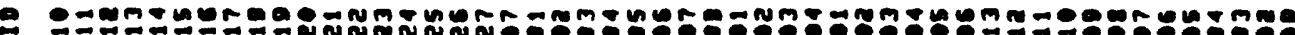

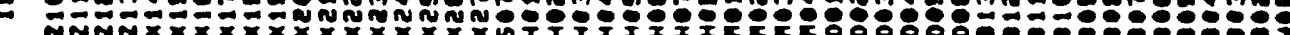

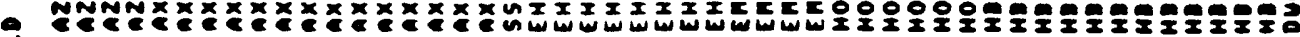

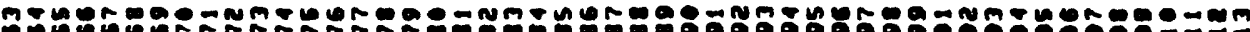

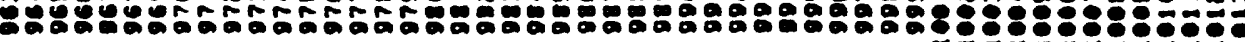




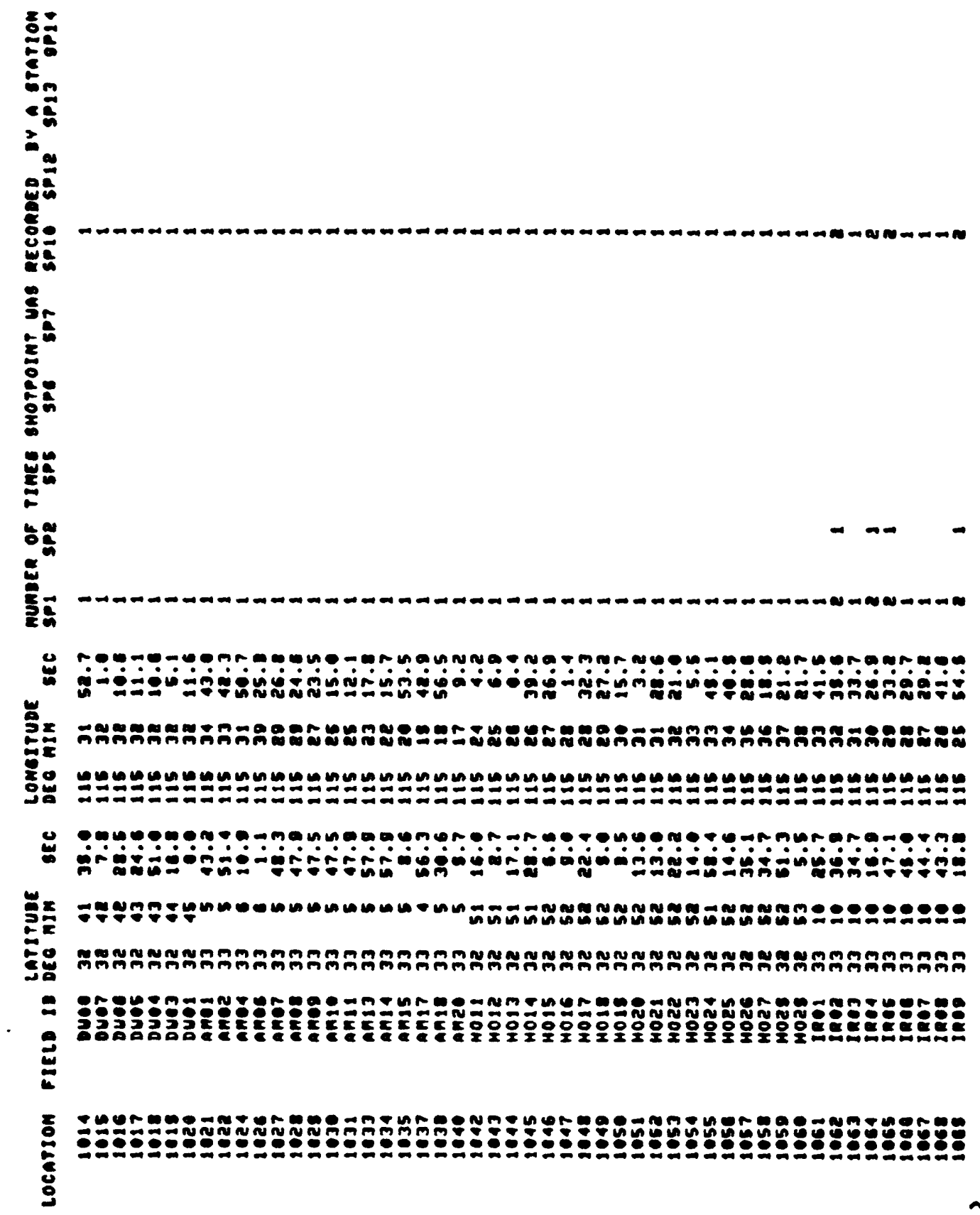




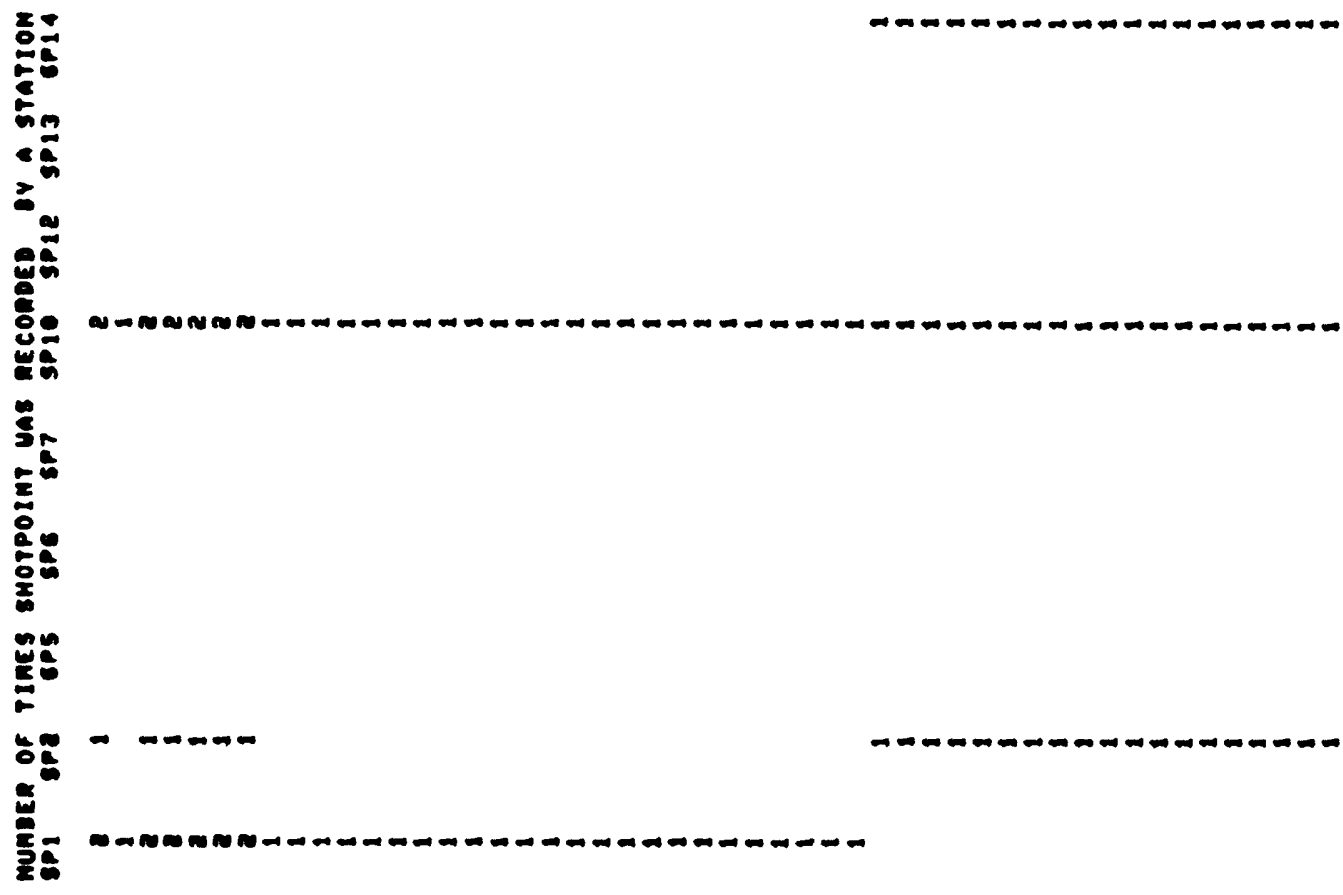

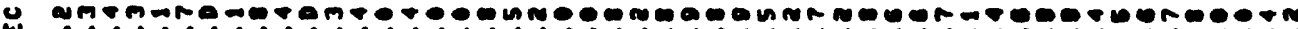

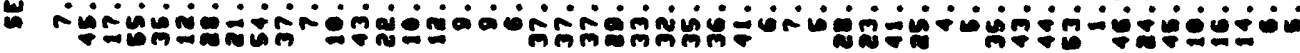
\%

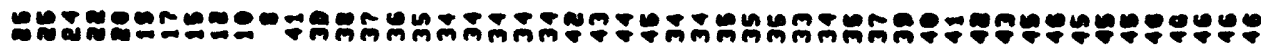

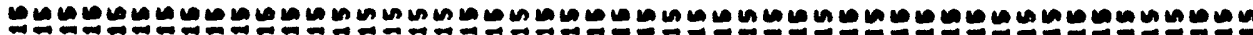

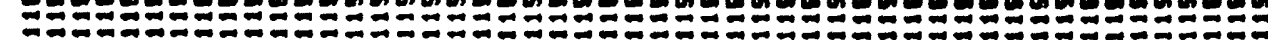

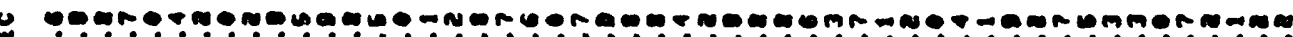

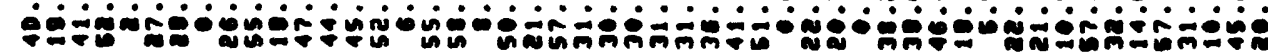

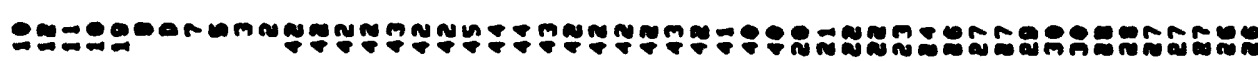
S:

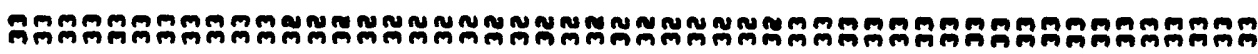

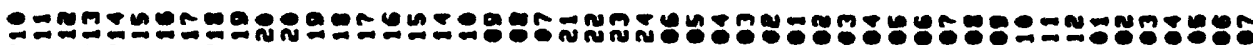

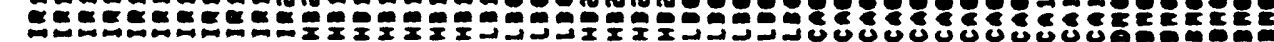

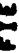

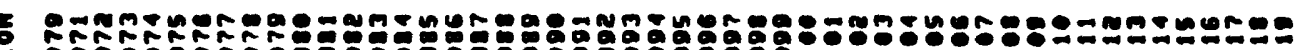

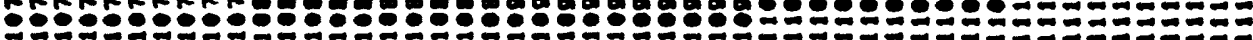




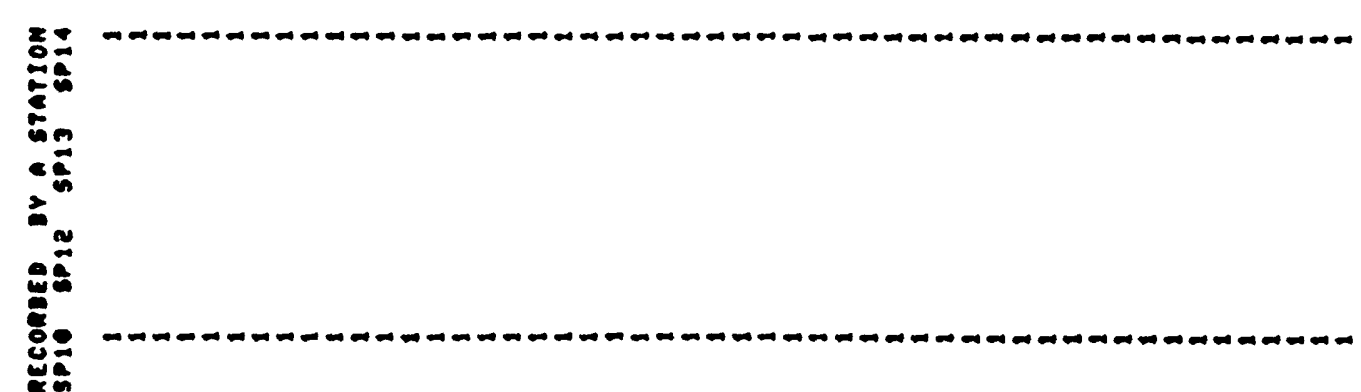

$\Sigma^{2}$

san

0

to

tex

$\approx$

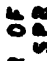

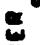

踣

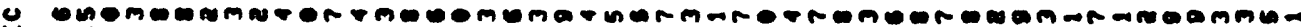

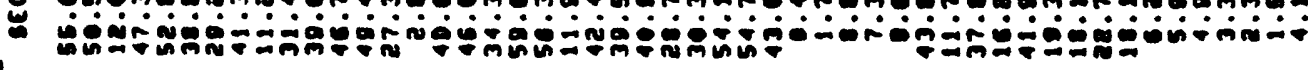

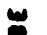

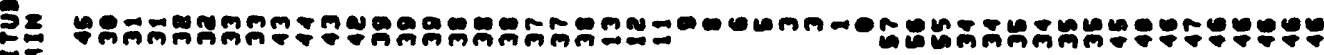
눙응

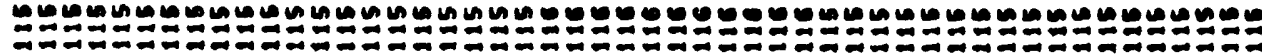

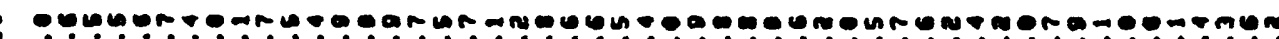
$5=$

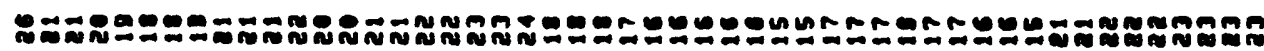

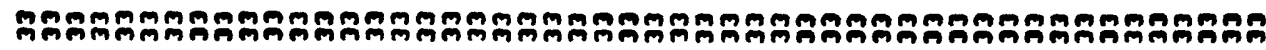

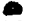

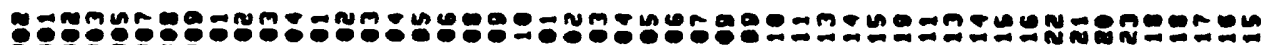
2 3 ㄴ.

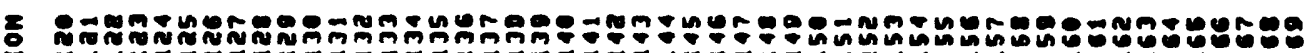

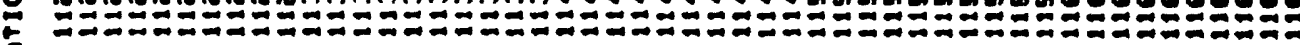




(

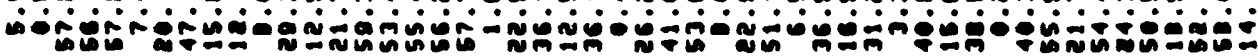
H.

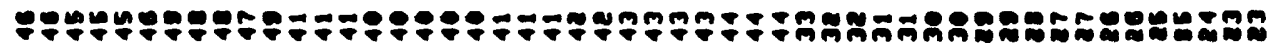

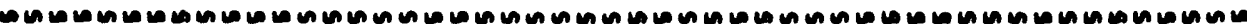

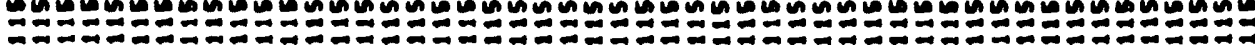

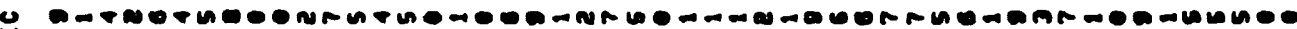

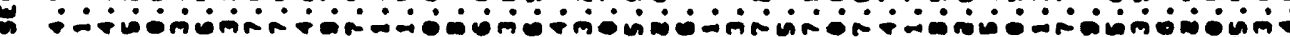

두울

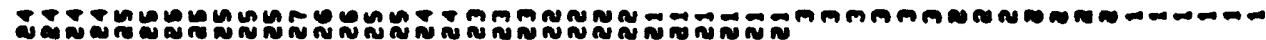

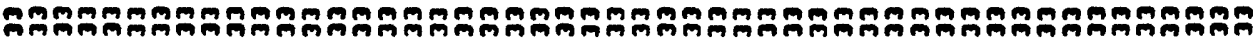

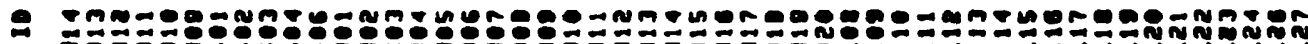

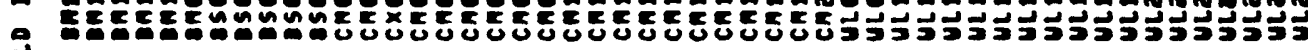

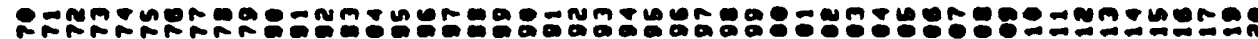

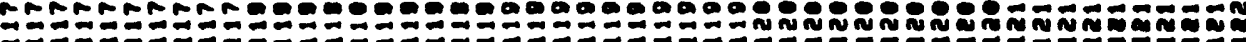




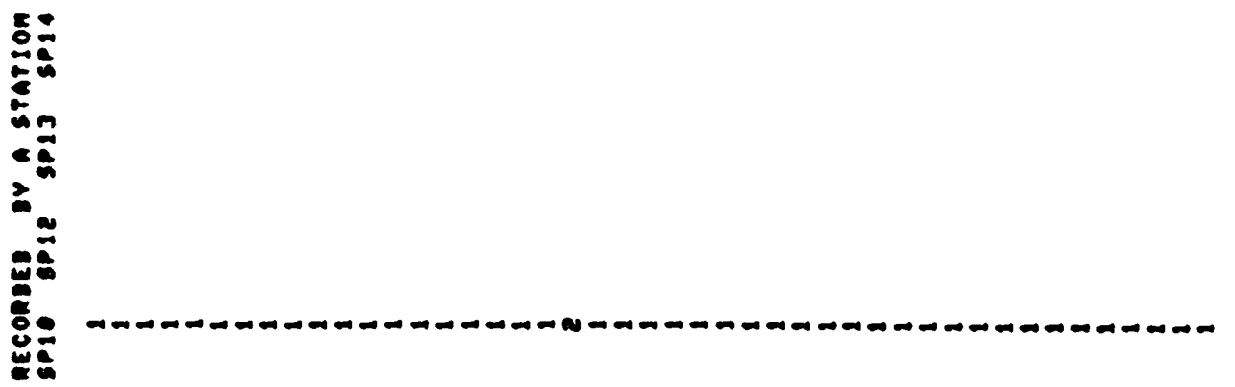

E.

훙

웅

웅웅

(1)

象象

6.

한

홀은

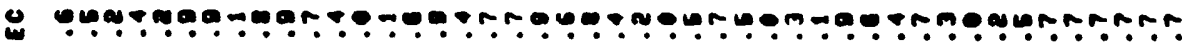<smiles>[CH]</smiles>

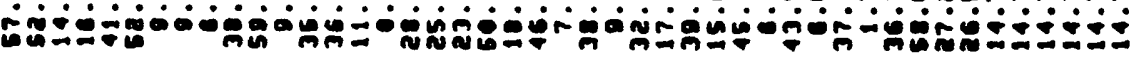

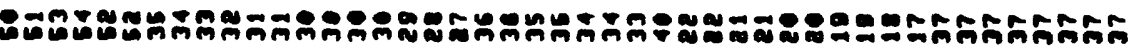

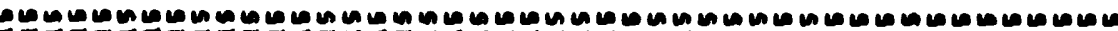

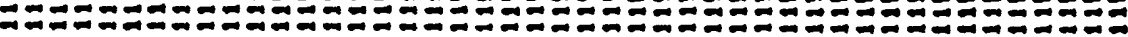

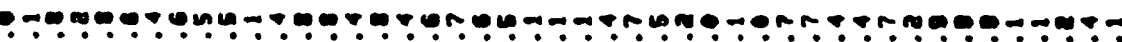

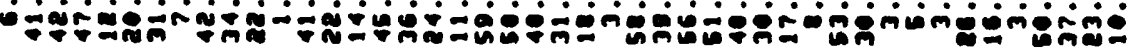

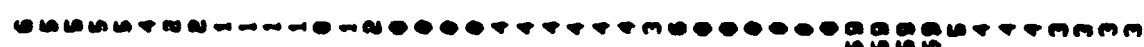

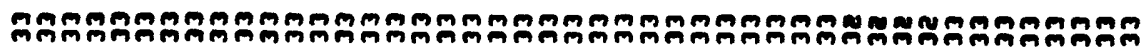

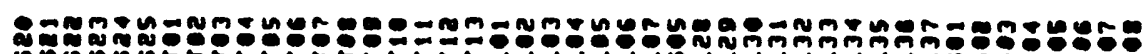

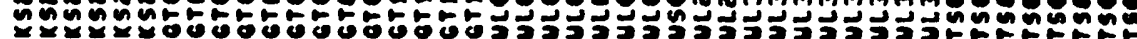

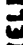
(2)

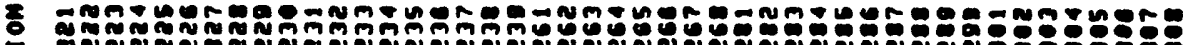
פNญ 
Table 3.--Velocity above and below model boundaries at locations of velocity-depth curves in

figure 8. Velocity-depth curves in figure 8 were constructed from values given here. Curve

numbers are same as in that figure; they indicate distance (in $\mathrm{km}$ ) southeast $6 r$ east of first-

named shotpoint (SP) in respective section of table. Approximate geographic location for curve

is given (in N. Lat. and W. Long.). Double slash between two velocities indicates discontinuity;

slash preceded by or followed by dash indicates top or bottom of model, respectively.

SPI to SPG

spd to $\mathbf{s p 2}$

\begin{tabular}{|c|c|c|c|c|}
\hline \multirow[t]{2}{*}{ pth to boundary (lon) } & \multicolumn{2}{|c|}{$\begin{array}{c}\text { Volocity bove/bolon } \\
\text { boundary }(\mathrm{b} / \mathrm{a} / \mathrm{)}\end{array}$} & \multirow[t]{2}{*}{$\begin{array}{l}\text { Inforrad } \\
\text { reo2er1e unit }\end{array}$} & \multirow[t]{2}{*}{ Depth to bour } \\
\hline & Curve $-132^{\circ} 53.4^{\prime}$ & $115^{\circ} 46.8^{\prime}$ & & \\
\hline $\begin{array}{l}0.0 \\
1.2 \\
1.4 \\
2.1 \\
12.5 \\
13.5 \\
20.0\end{array}$ & $\begin{array}{l}--11.9 \\
2.3 / 2.3 \\
2.35 / 15.2 \\
5.8 / 5.8 \\
6.6 / 17.0 \\
7.2 / 7.2 \\
8.01 \cdots\end{array}$ & & $\begin{array}{l}\text { eodimentary rocke } \\
\text { tranedtion sone } \\
\text { baubent } \\
\text { subbascont }\end{array}$ & $\begin{array}{l}0.0 \\
1.8 \\
1.55 \\
5.55 \\
12.4 \\
12.4 \\
20.0\end{array}$ \\
\hline
\end{tabular}

Curve $132^{\circ} 52.9^{\circ} \quad 215^{\circ} 45.7^{\circ}$

locity above/below

Inferred seologic unde

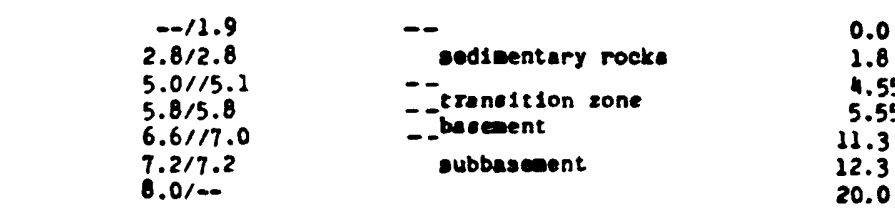

Curve $25 \quad 32^{\circ} 55.3^{\prime} 115^{\circ} 30.5^{\circ}$

Curve $1732^{\circ} 49.3^{\prime} \quad 115^{\circ} 37.1^{\prime}$

$-0 / 1.8$

$2.6 / 2.6$

$4.8 / 15.1$

$5.8 / 5.8$

$6.6 / 17.0$

$7.2 / 7.2$

8.0\%--

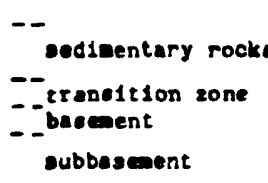

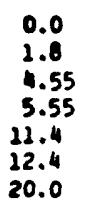

0.0

1.8
4.55

5.55

12.3

20.0

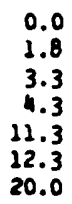

Curve $2.532^{\circ} 53.6^{\prime} \quad 115^{\circ} 44.7$ '

$-11.8$

$3.7 / 3.7$

$5.1 / 5.1$

$5.65 / 5.65$

5.95116 .6

7.217 .2

$7.76 \%$

-

cedientary roc

- eransition zone

- bevement

aubbasement

Curve 53 (SP6) $32^{\circ} 41.77^{\circ} \quad 215^{\circ} 15.1$ '

$-0 / 1.8$

$2.6 / 2.6$

$5.1 / 5.1$

5.615 .6

$6.6 / 17.0$

$7.2 / 7.2$

B. $r^{\prime} \cdot-$ oedientary rocka

- transition zone

- - transition

subbeceant

$$
\begin{aligned}
& --11.0 \\
& 3.0 / 3.0 \\
& 5.1 / 5.1 \\
& 5.65 / 5.65 \\
& 5.95 / 16.60 \\
& 7.2 / 7.2 \\
& 7.76 /=
\end{aligned}
$$

Curve $4332^{\circ} 57.1$ ' $115^{\circ} 19.1$ '

--11.8
$3.5 / 3.5$
5.015 .0
$5.65 / 5.65$
$5.951 / 6.6$
$7.2 / 7.2$
$7.76 / .-$

$--11.8$

5.015 .0

$5.65 / 5.65$

$7.2 / 7.2$

$7.76 \%$

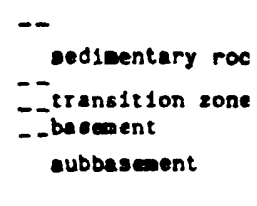
-- edientary roc - transition zone _basement oubbasement

SP10 to SP2

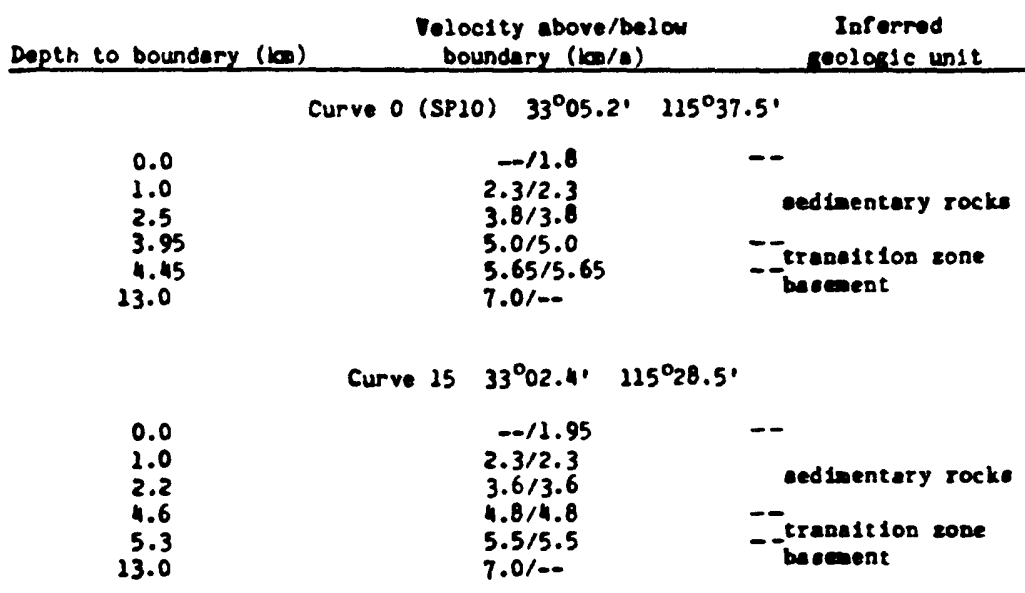

Curve 33 (3P2) 32059.0' 215097.6'

$\begin{array}{ll}0.0 & -11.90 \\ 0.6 & 2.1 / 2.1 \\ 2.8 & 3.8 / 3.8 \\ 3.1 & 5.0 / 5.0 \\ 1.1 & 5.65 / 5.65 \\ 13.0 & 7.0 /-2\end{array}$

eadsentary rocks 


\section{Figure Captions}

Figure 1. Index map showing shotpoints, recorder locations, and profiles analyzed. Profiles that are modeled are indicated by outline and stipple; profile segment $5 \mathrm{~N}-13 \mathrm{~S}$, indicated by outline only, is discussed in the text but not modeled. Mapped faults are indicated by solid lines, inferred faults by queried lines, and seismicity lineaments by dashed lines. Names for these structures are abbreviated A, Algodones fault; B, Brawley fault; BZ, Brawley seismic zone (as defined in Johnson, 1979); CC, Coyote Creek fault; E, Elsinore fault; EH, East Highline canal seismicity lineament; I, Imperial fault; SA, San Andreas fault; SdH, Sand Hills fault(?); SH, Superstition Hills fault; SM, Superstition Mountain fault. The shoreline of ancient Lake Cahuilla are indicated by a light dotted line. South of the Salton Sea this shoreline separates the Imperial Valley from East and West Mesas. The axis of the Salton Trough, as defined in this report, is a line that bisects the Salton Sea and projects southward. Note that this axis does not coincide with the topographic axis of the Imperial Valley. Sup. H., Superstition Hills; Sup. M., Superstition Mountains.

Figure 2. Record sections for lines $6 \mathrm{NW}$ (a) and 1SE and 1NW (b). Traveltime is reduced by $\Delta$ (distance in $\mathrm{km}$ ) $/ 6 \mathrm{~km} / \mathrm{s}$. The amplitude of each seismic trace is scaled by the maximum amplitude on that trace in the first $10 \mathrm{~s}$ of the record. The final model (c) for this profile is plotted below at the same distance scale; vertical exaggeration is 2.2x. Velocity boundaries in the model are indicated by heavy lines, dashed where uncertain, and velocity contours by light dashed lines with values given in $\mathrm{km} / \mathrm{s}$. Velocity contour interval is 0.5 $\mathrm{km} / \mathrm{s}$. Shotpoint locations are indicated as well as fault traces and seismicity lineaments crossed. Refer to caption of figure 1 for fault name abbreviations. Traveltime curves generated by the model are indicated on the record sections by smooth curves. For letter labels refer to the text. Refractions are indicated by solid lines and reflections by dashed lines.

Figure 3. Traveltime pick diagram for lines $6 \mathrm{NW}, 1 \mathrm{SE}$, and $1 \mathrm{NW}$, taken from figures $2 a$ and $2 b$. Picks for arrivals from shotpoint 6 are indicated with solid symbols and from shotpoint 1 with open symbols: circles for first arrivals from sediments and basement, squares for arrivals from subbasement, and triangles for "1st", "2nd", and "3rd" multiple refractions. Arrivals uncertain to more than $0.1 \mathrm{~s}$ are queried. Apparent velocities in $\mathrm{km} / \mathrm{s}$ are indicated for each line fitted to the data. Apparent velocities uncertain to more than 0.1 $\mathrm{km} / \mathrm{s}$ are given to only one decimal place.

Figure 4. Record sections for $2 W(a)$ and $1 E$ (b), and final model (c). For further explanation see caption for figure 2.

Figure 5. Record sections for 2NW (a) and 10SE (b) and final model (c). For further explanation see caption for figure 2. 
Figure 6. Record section for 1ESE (a) and final model (b). For further explanation see caption for figure 2.

Figure 7. Record sections for 135 (a) and $5 \mathrm{~N}$ (b). Solid lines are traveltime curves averaged for all arrivals. Dashed lines are traveltime curves for arrivals (heavy black dots) at the three stations that recorded both blasts. These record sections indicate a true basement velocity of 5.9 to $6.0 \mathrm{~km} / \mathrm{s}$ under West Mesa in contrast to the relatively low basement velocity of $5.65 \mathrm{~km} / \mathrm{s}$ in most places in the Imperial Valley.

Figure 8. Velocity-depth curves at various locations along the profiles analyzed. These are cross sections of the final models at the indicated distances from the shotpoints.

Figure 9. Ray diagrams. The final model for 6NW-1SE-1NW is shown with no vertical exaggeration. Ray termini are labeled to correspond with labeled arrivals on figure 2. Rays for first arrivals were plotted in angular increments of 0.01 radian, and rays for first multiple refractions were plotted in increments of 0.05 radian. Exceptions are in (a) the last ray represents an angular increment of 0.004 radian rather than 0.01 radian, in (b) the angular increment is 0.0002 radian for all rays rather than 0.01 radian, in (c) the last two rays represent angular increments of 0.01 and 0.02 radian, respectively, rather than 0.05 radian, and in ( $f$ ) the last ray represents an increment of 0.04 radian rather than 0.05 radian. These diagrams are used to determine traveltimes for first and multiple arrivals. In addition, seismic amplitude behavior can be inferred qualitatively from them. Seismic intensity observed at the surface is inversely correlated to the spacial separation of emerging rays.

Figure 10. Contour map of reduced traveltime for first arrivals from shotpoint 1. Reducing velocity is $6 \mathrm{~km} / \mathrm{s}$. The region of contours around shotpoint 1 (the black dot) with reduced traveltimes of less than $1.2 \mathrm{~s}$ is indicated with a light stipple pattern surrounded by a hashured contour. The faults shown are the same as in figure 1. Geothermal areas are abbreviated B, Brawley; Bd, Border; EM, East Mesa; H, Heber; S, Salton Sea; and W, Westmorland. This map is roughly similar to a sedimentary isopach map, where greater reduced traveltime correlates with greater sediment thickness.

Figure 11. (a) Gravity profile oriented east-northeast across California from La Jolla to the Chocolate Mountains; taken from a gravity map of California by Oliver and others (1979) along a straight line from La Jolla through Glamis. Control on boundaries in model (b) is provided by seismic refraction (see text). Numbers are density in g/cc. The $3.1 \mathrm{~g} / \mathrm{cc}$ "subbasement" beneath the Imperial Valley, a feature lacking in previous gravity models for the Imperial Valley region, is the material which provides most of the compensation for the valley sediments. 


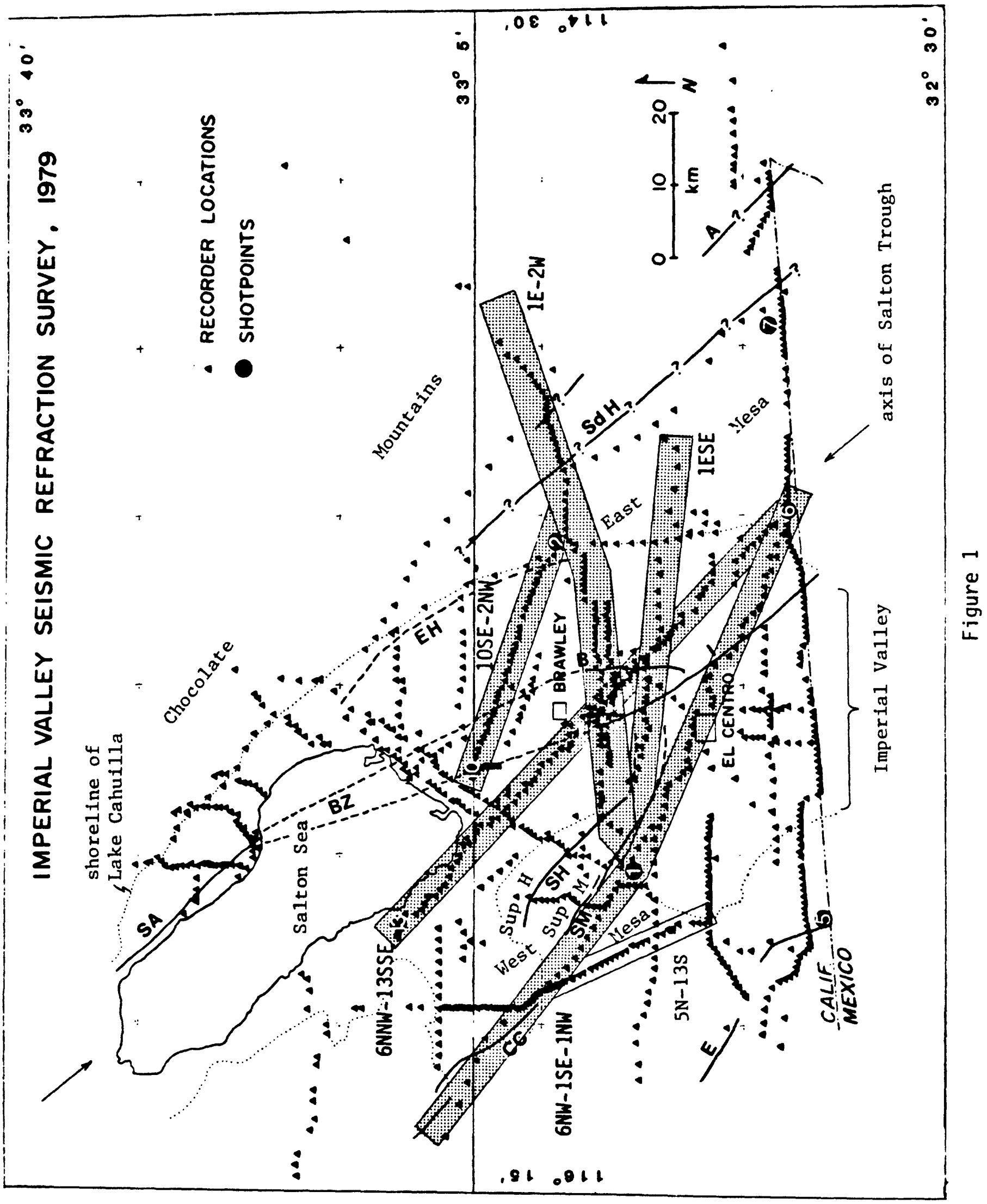



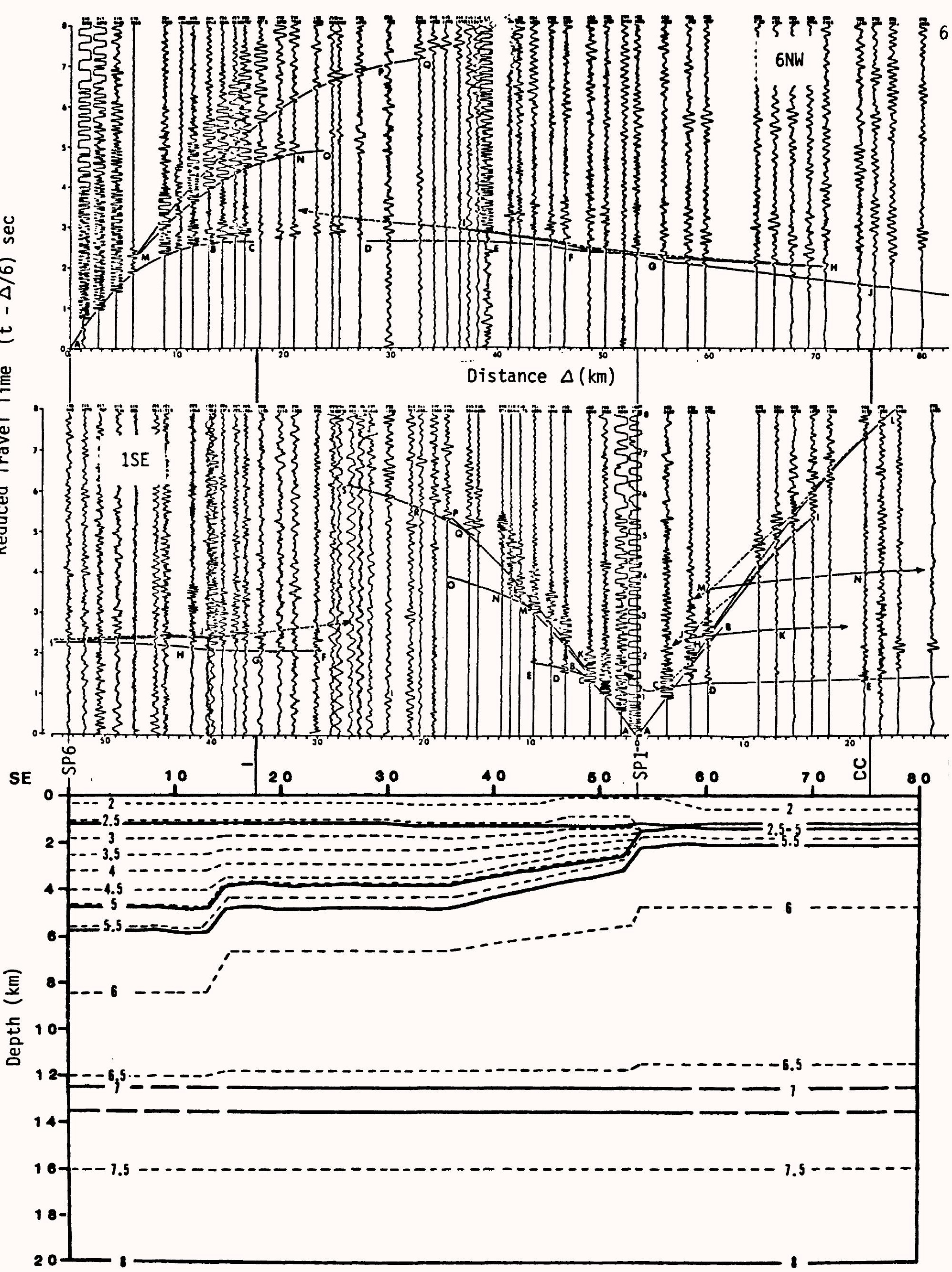

Figure 2 



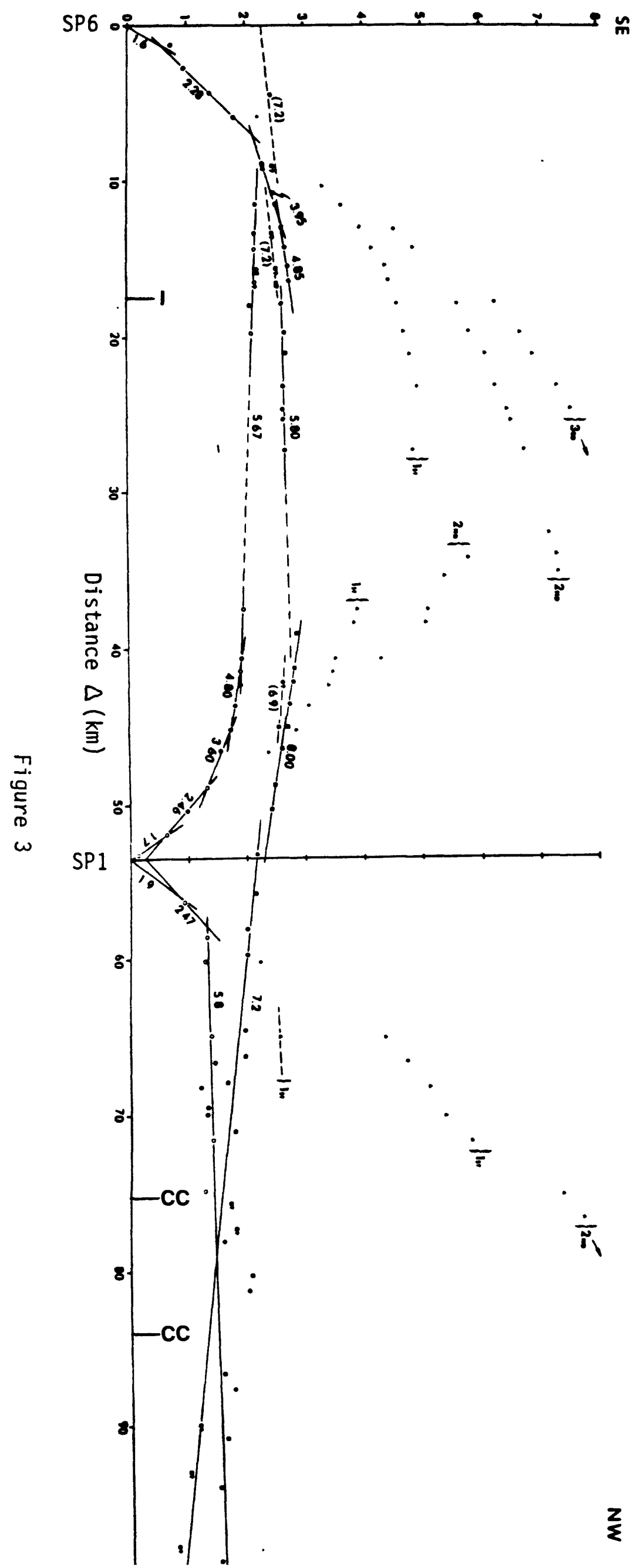

65 


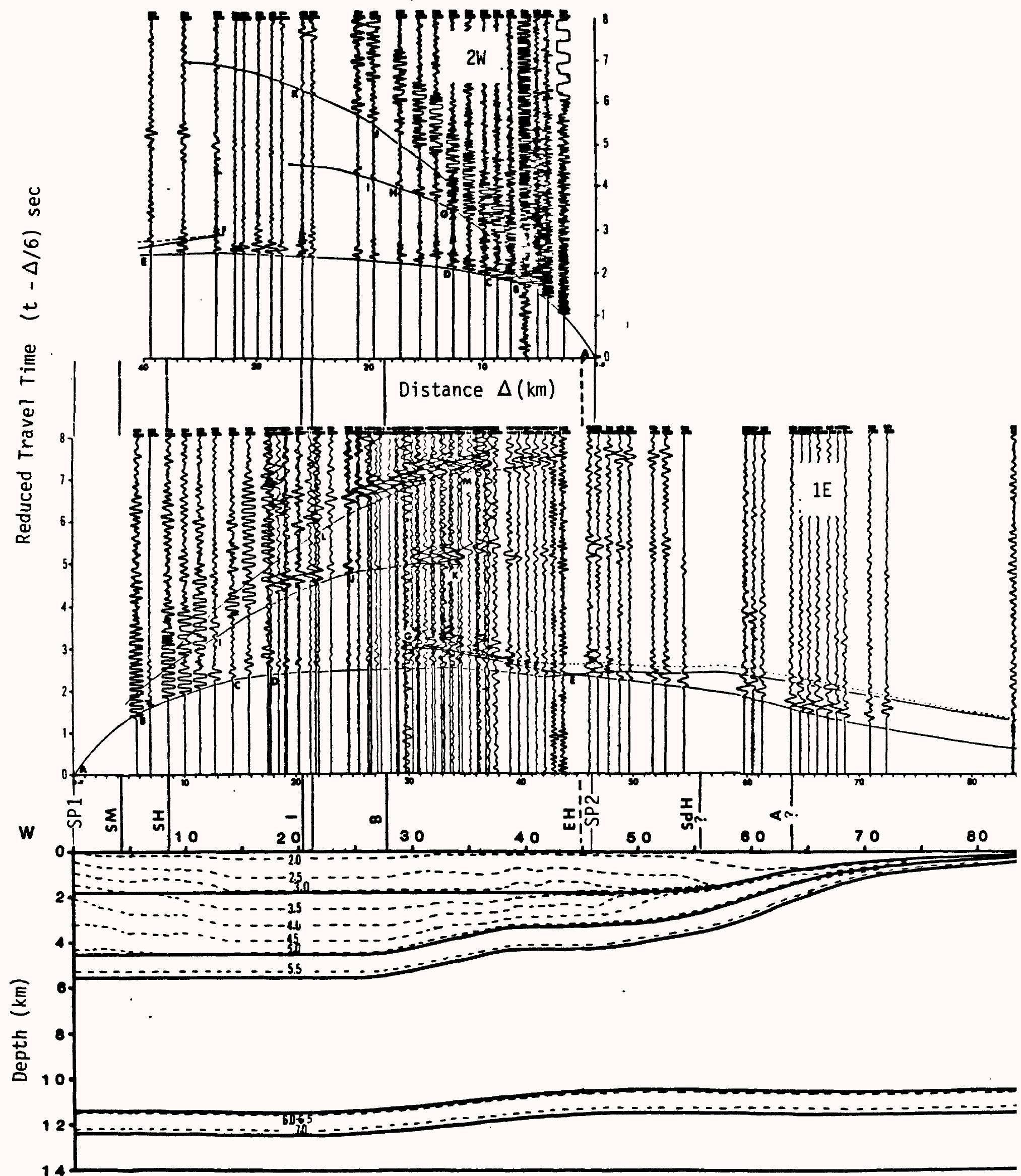

Figure 4 


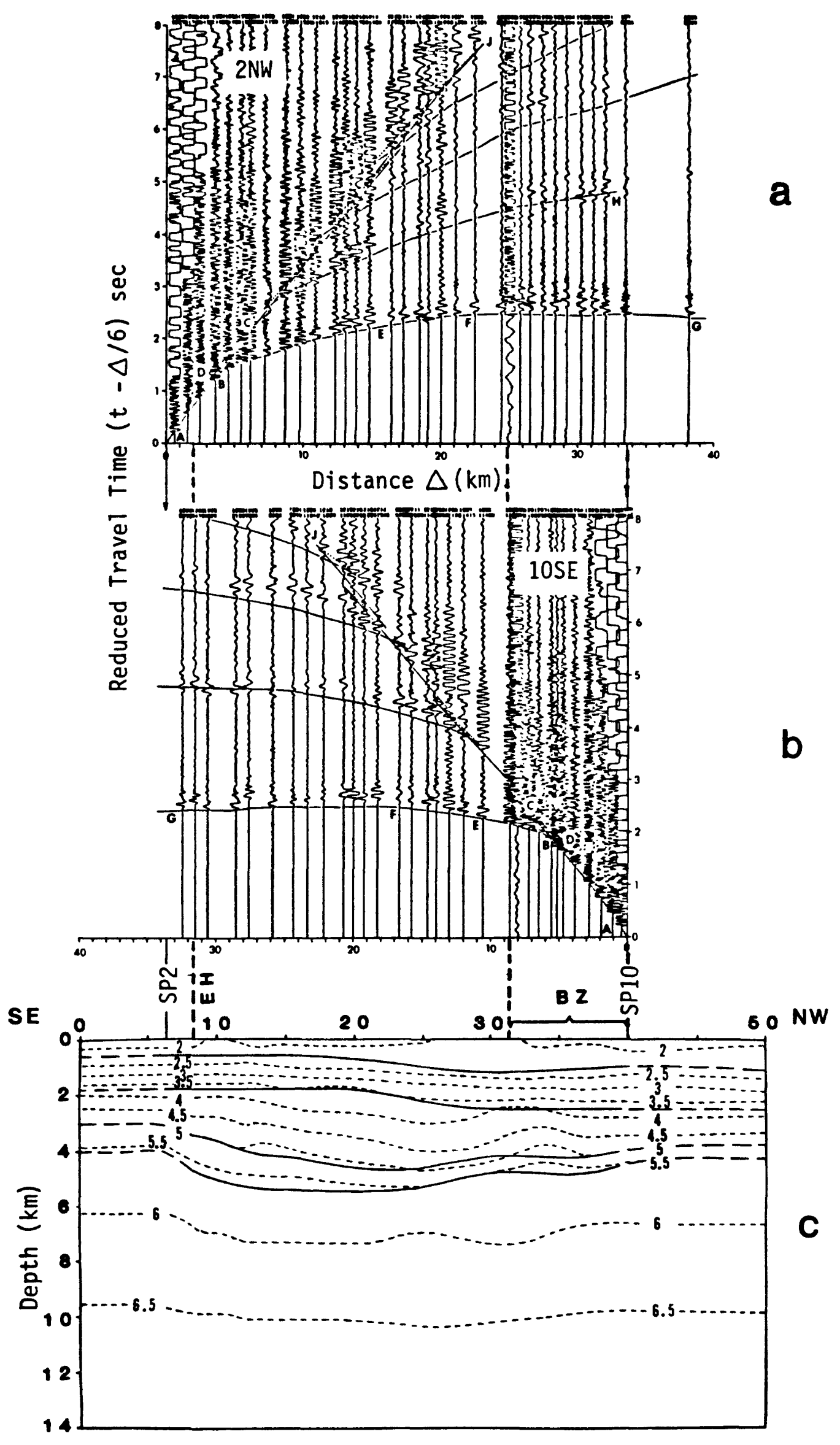

Figure 5 


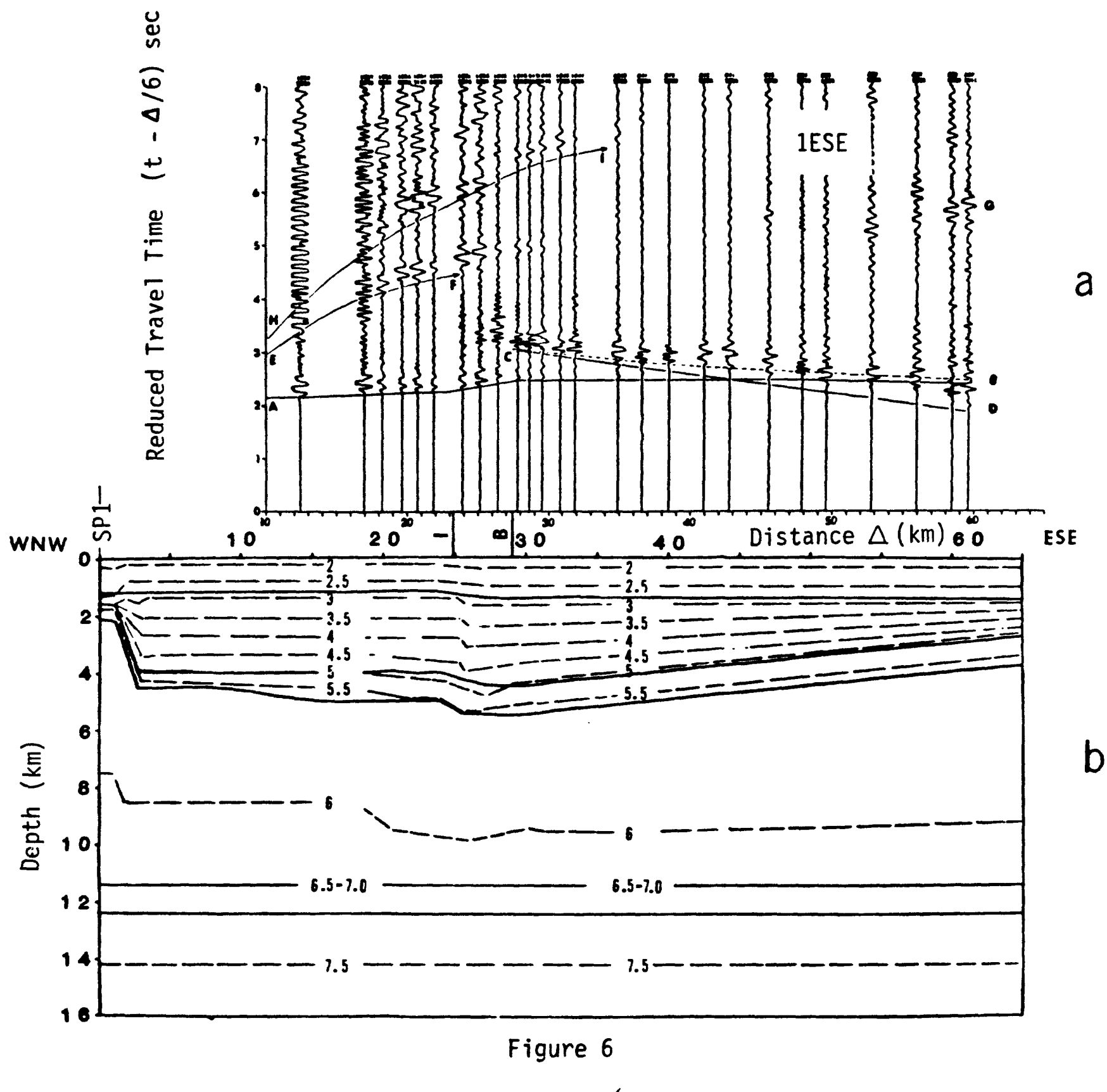




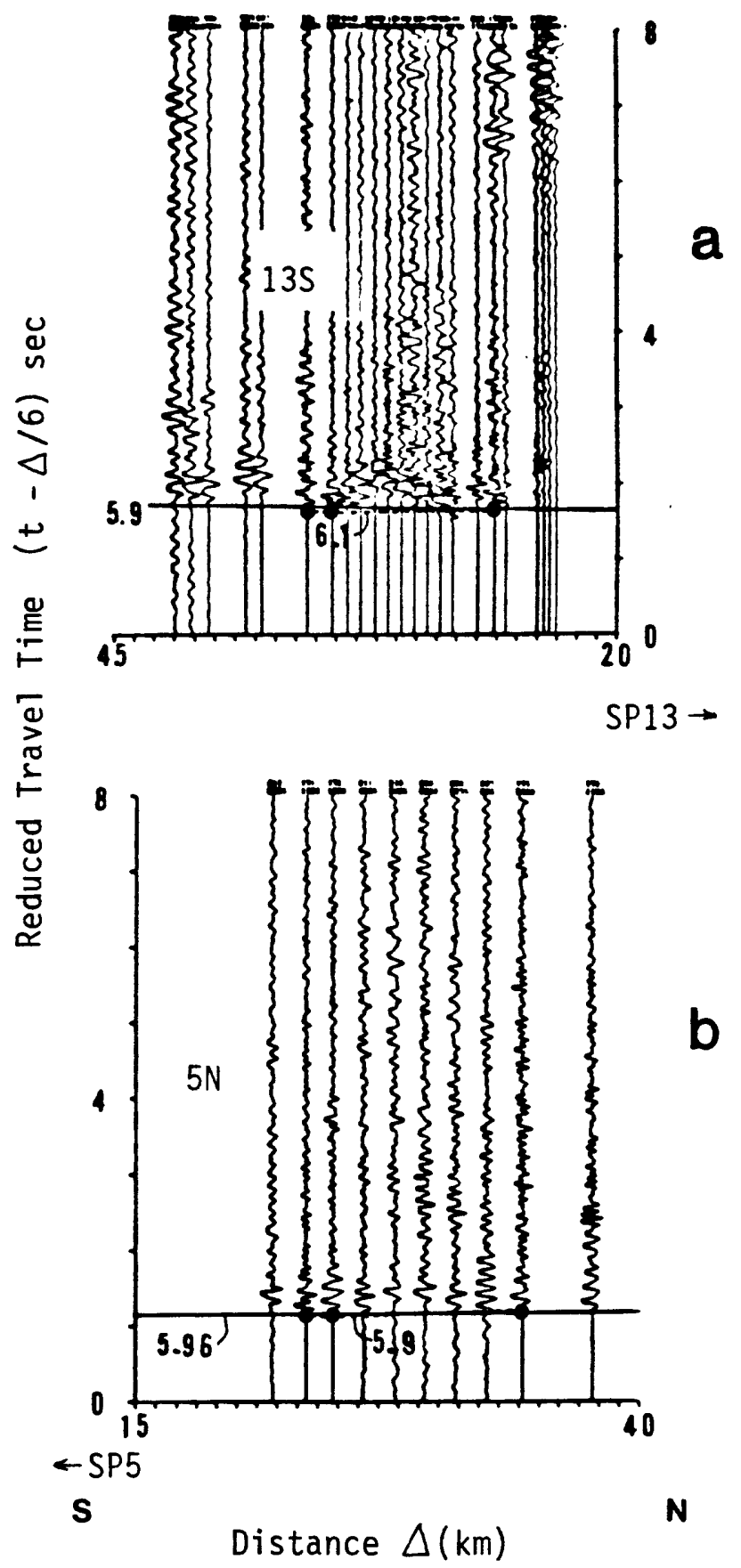

Figure 7 


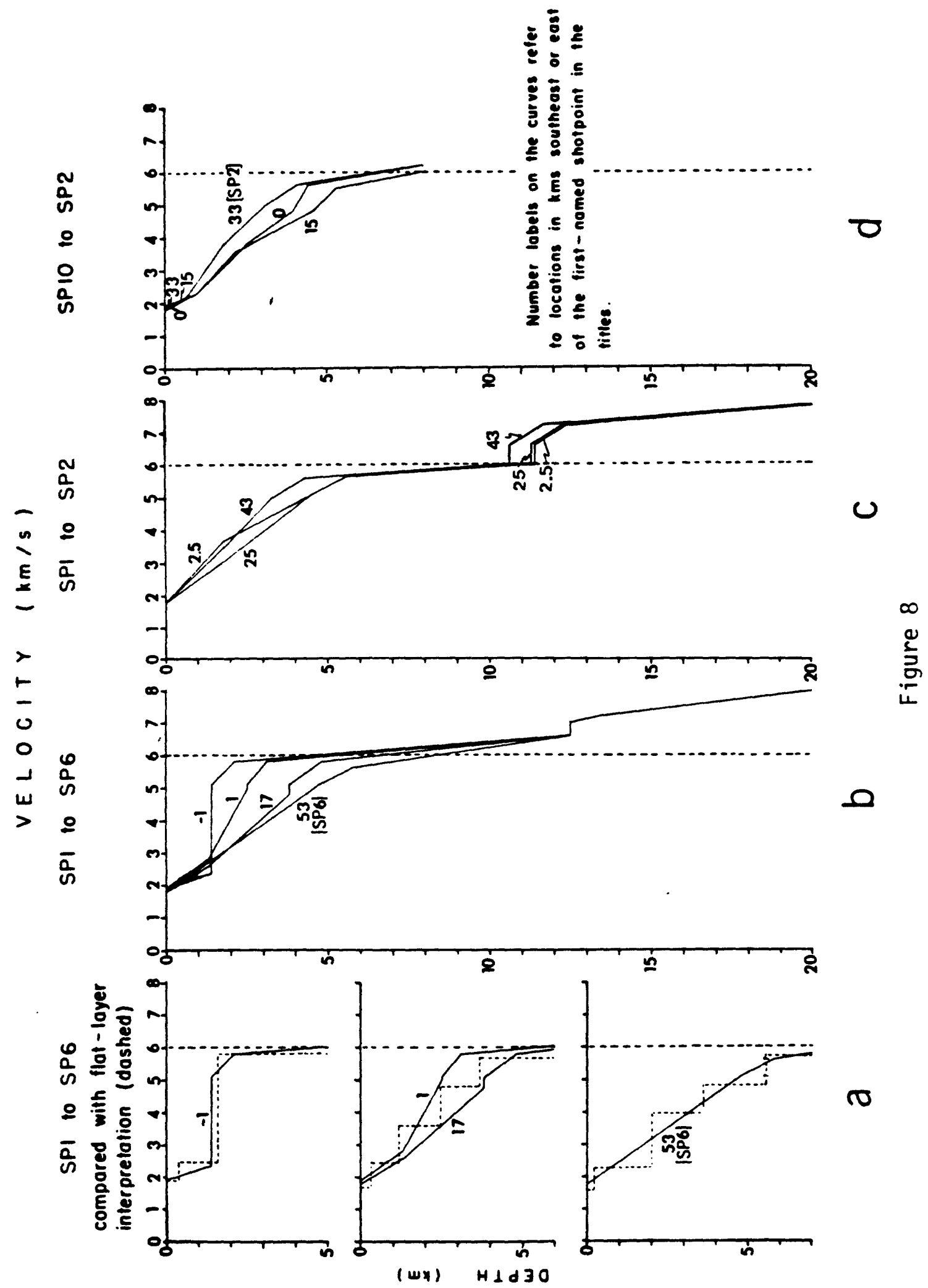




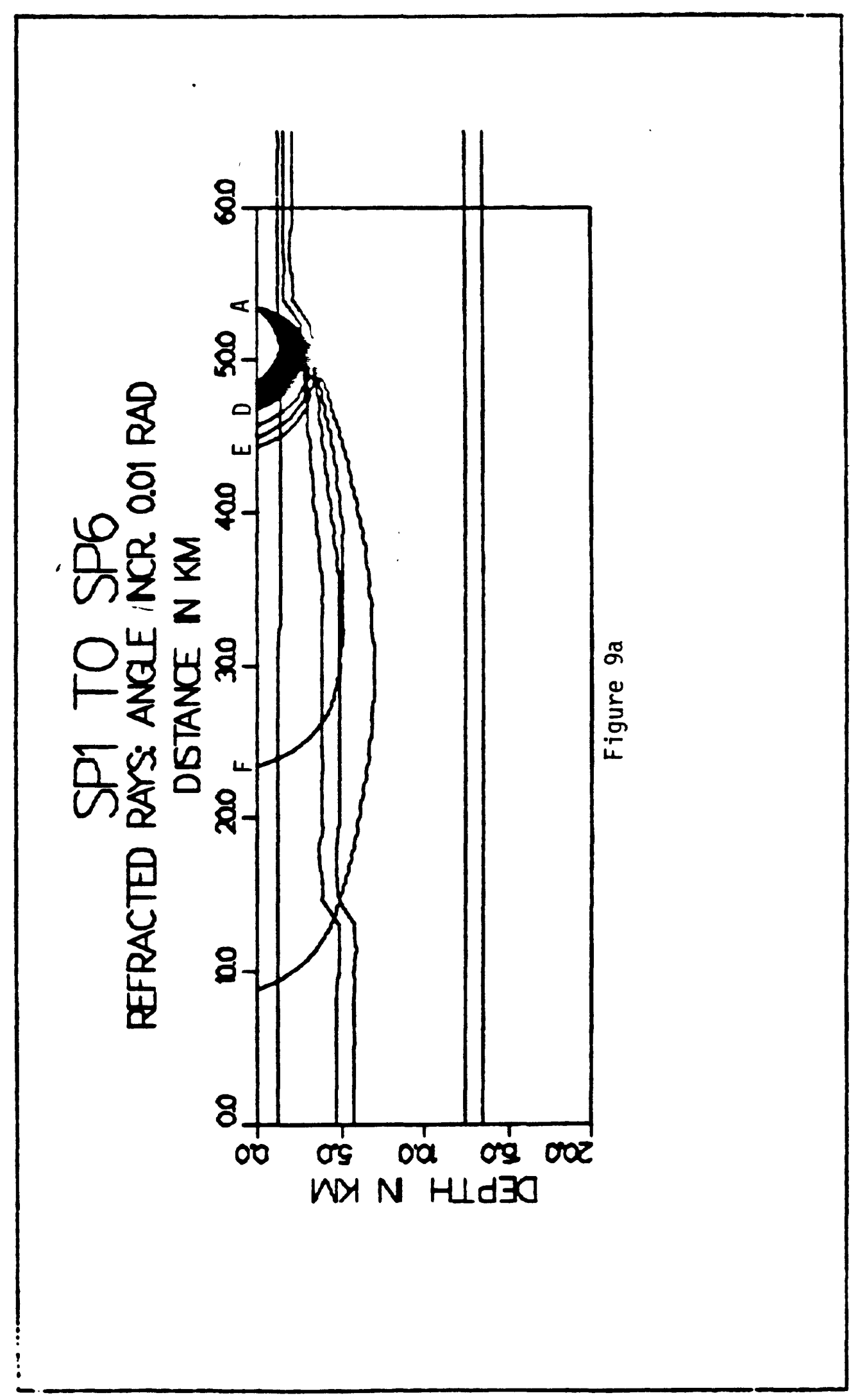




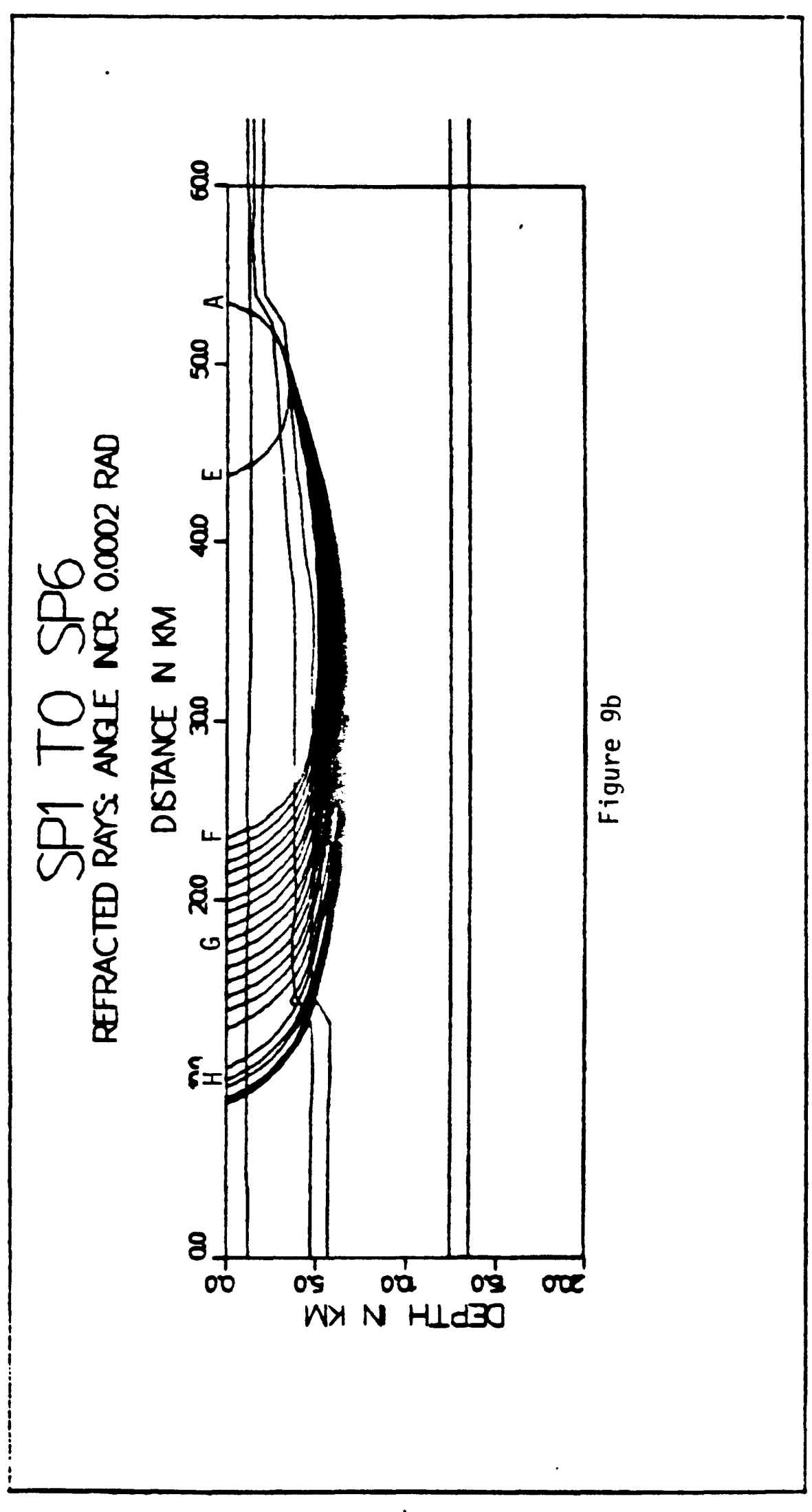




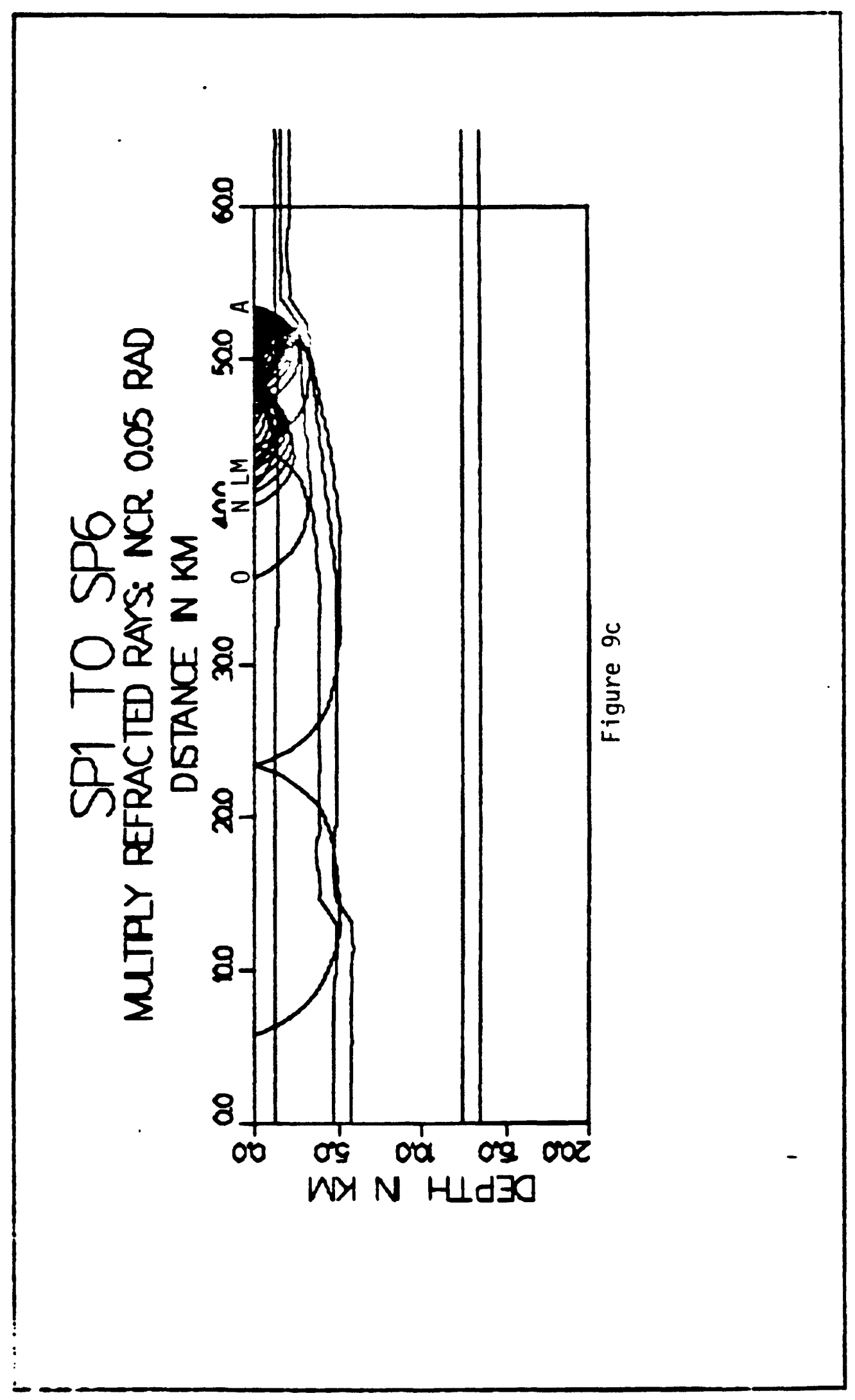




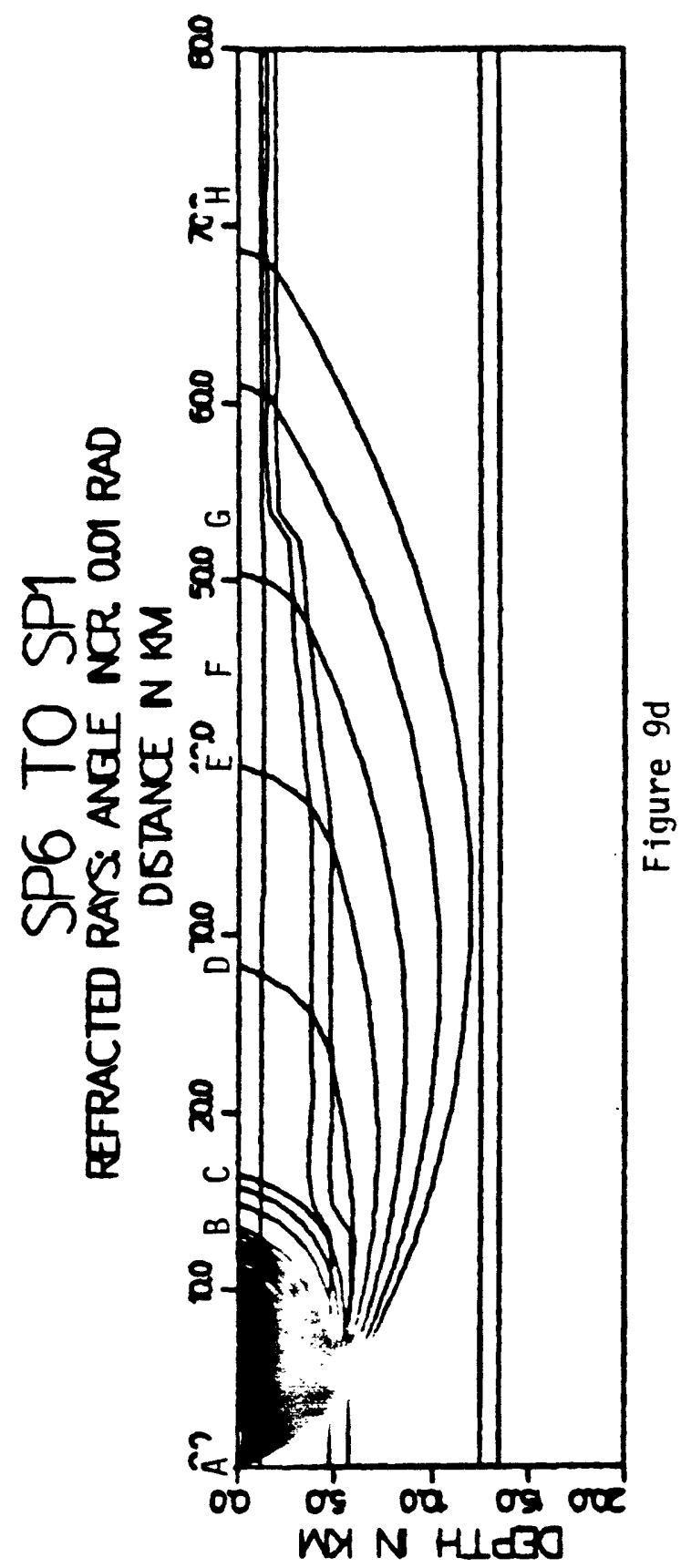




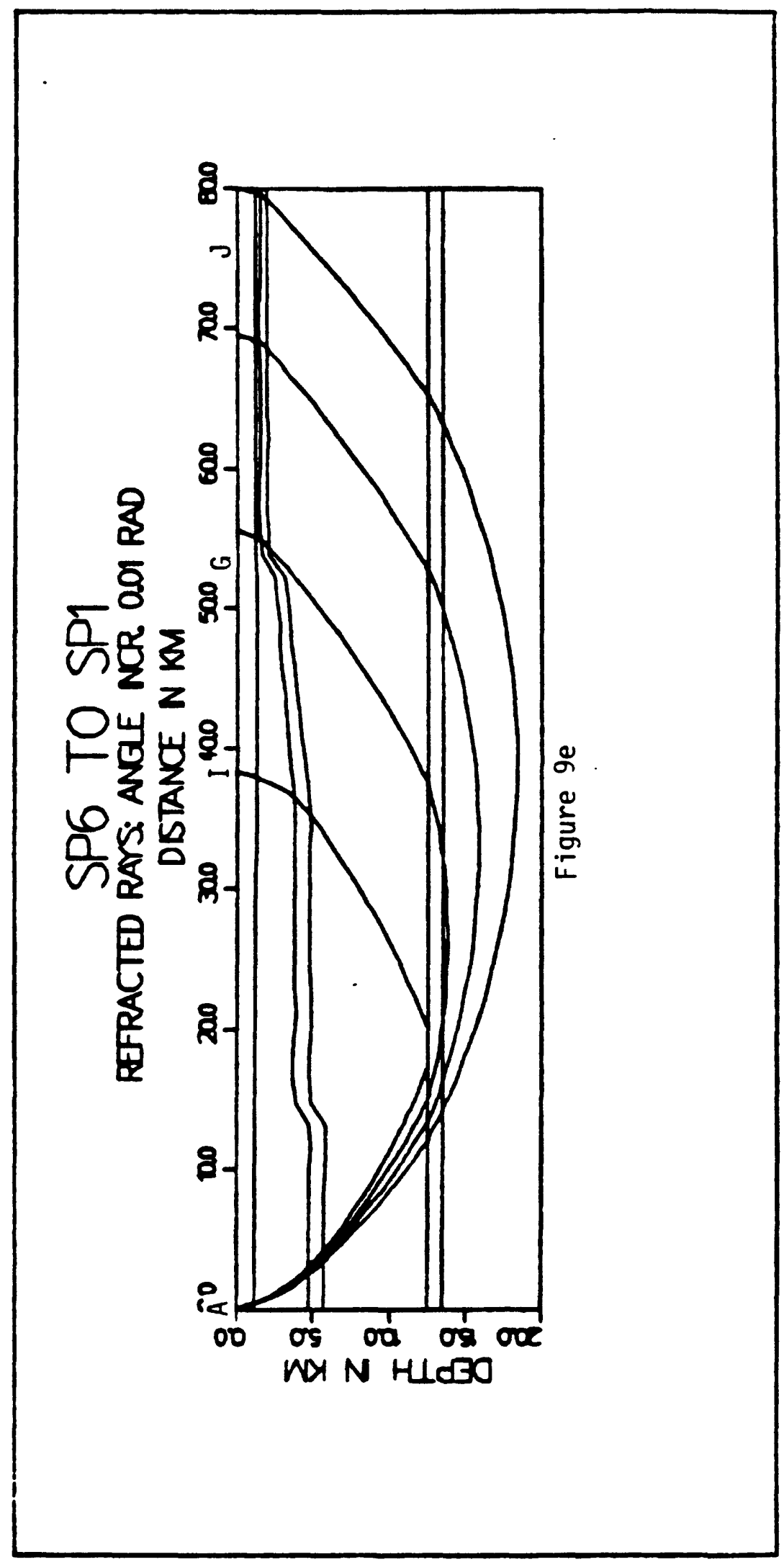




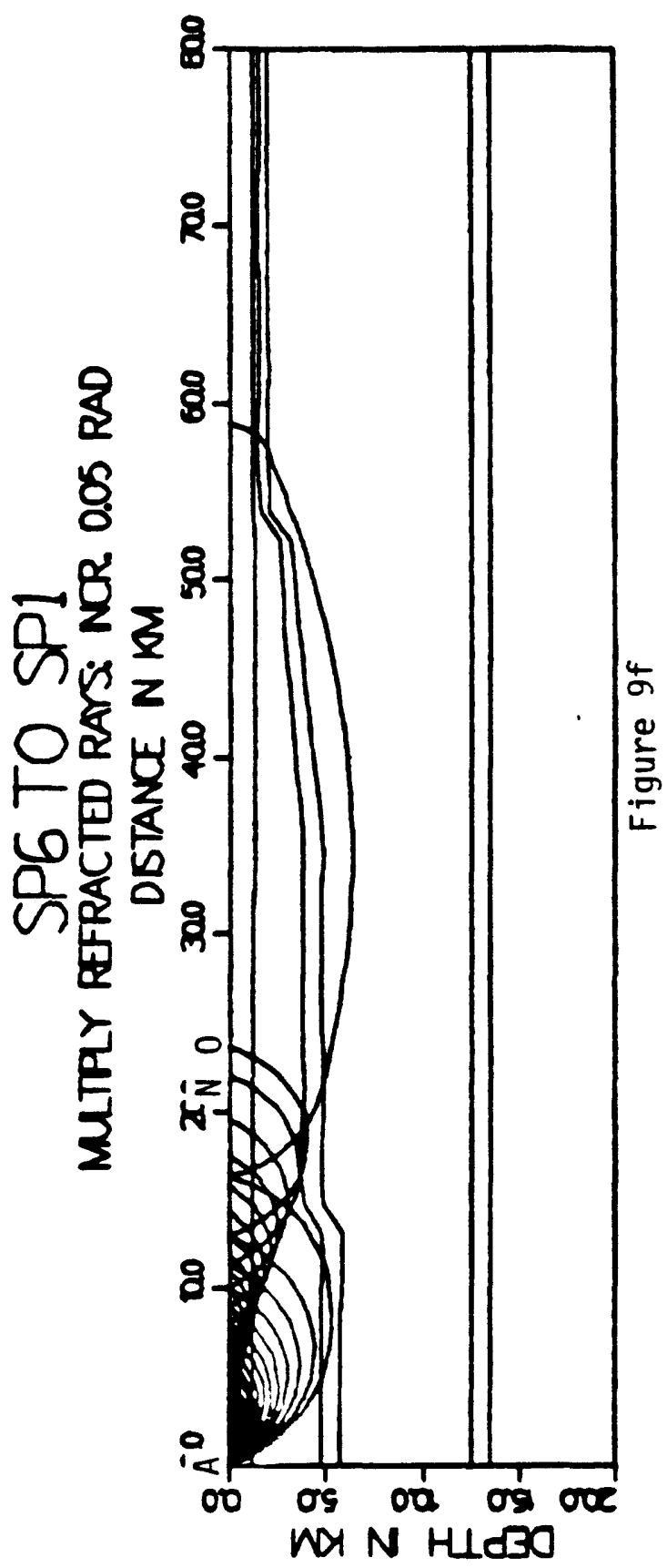




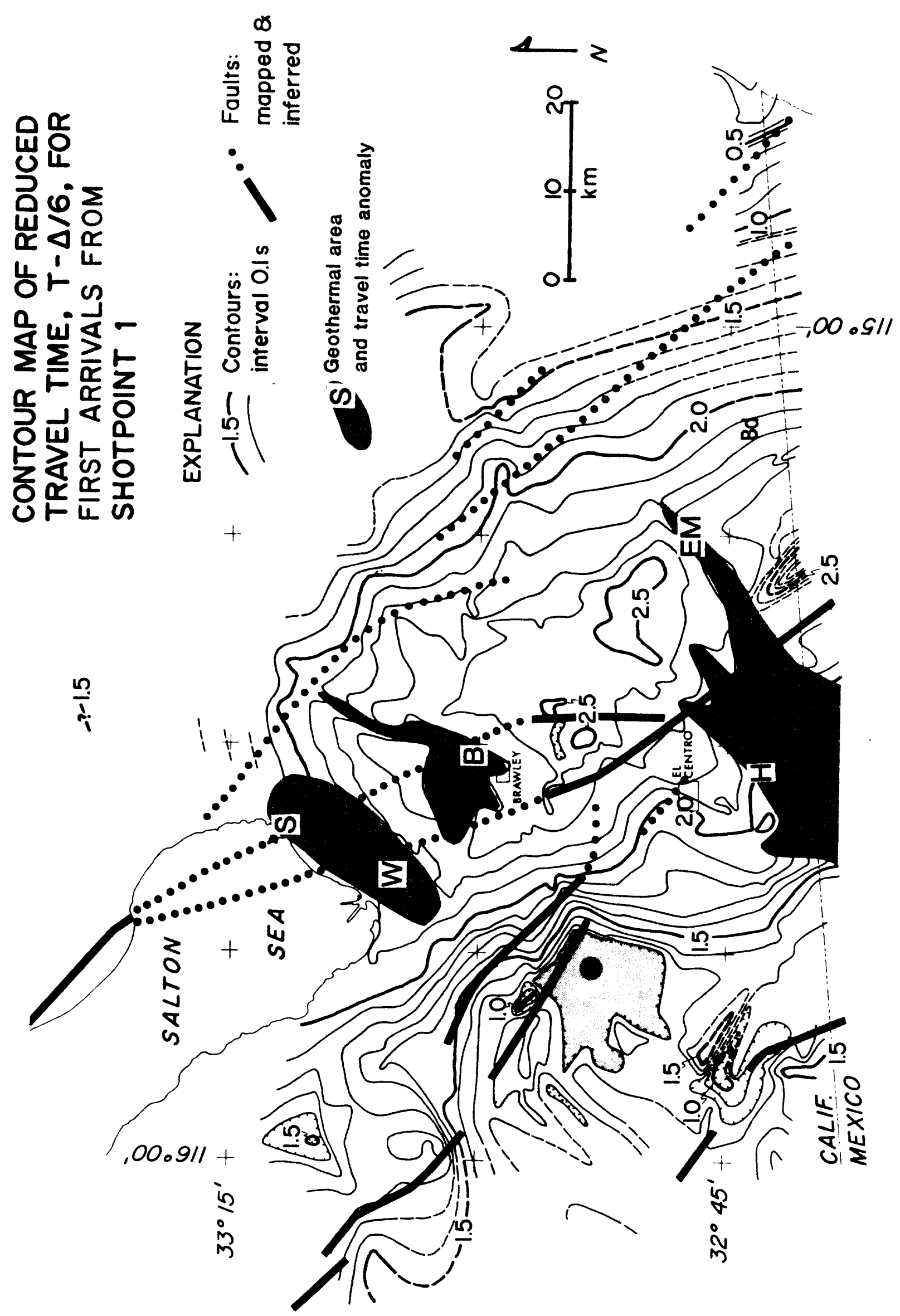

0
0
0
5
5
0
$\frac{1}{4}$ 

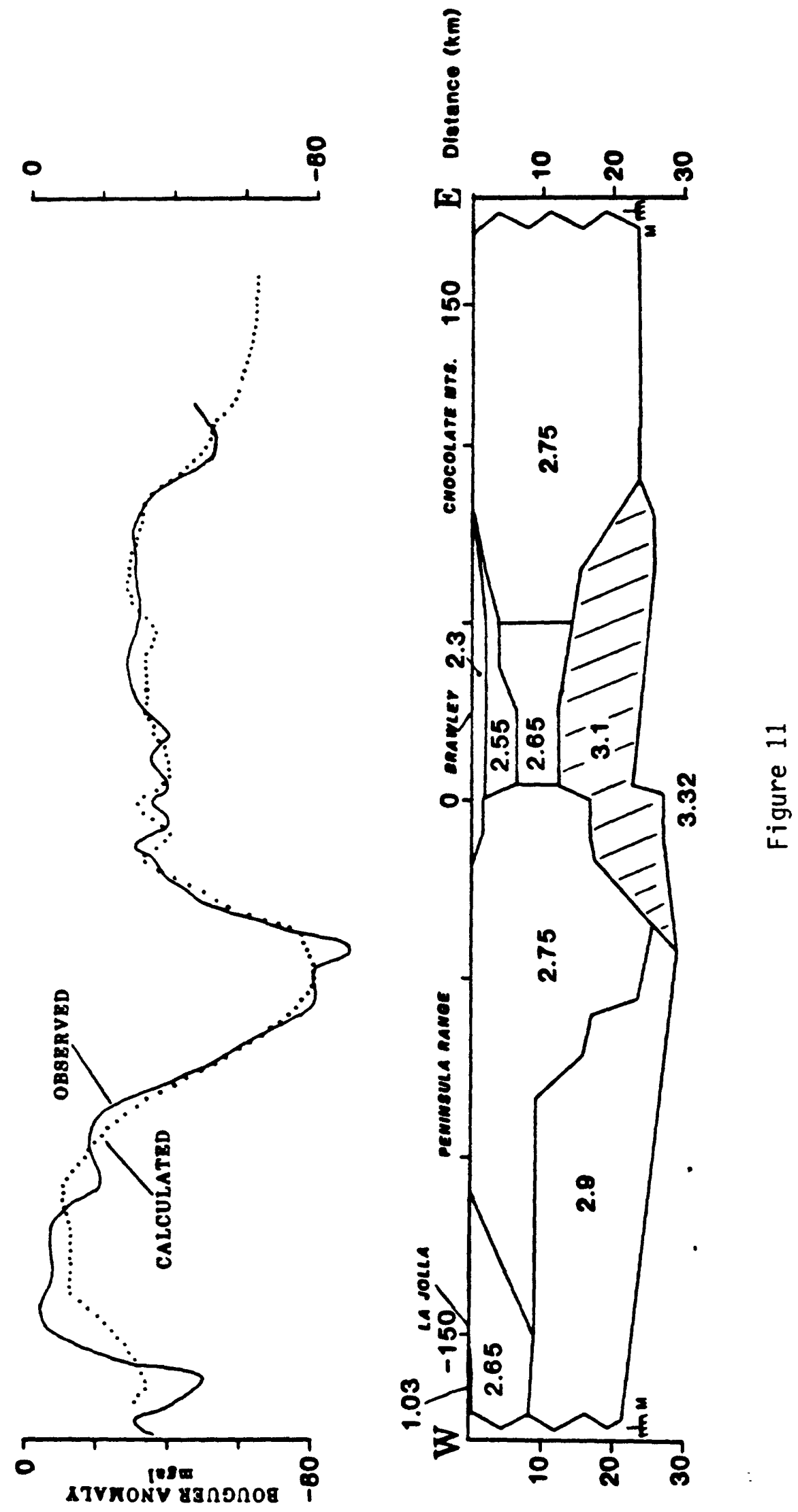

(wy) 41000 